University of San Diego

Digital USD

2015-11

\title{
Socially Responsible and Small: A Quantitative Study of Corporate Social Responsibility in Small and Medium Organizations in the United States
}

\author{
Abigail Sorenson Berk \\ University of San Diego
}

Follow this and additional works at: https://digital.sandiego.edu/dissertations

Part of the Business Administration, Management, and Operations Commons, and the Business Law, Public Responsibility, and Ethics Commons

\section{Digital USD Citation}

Sorenson Berk, Abigail, "Socially Responsible and Small: A Quantitative Study of Corporate Social Responsibility in Small and Medium Organizations in the United States" (2015). Dissertations. 29. https://digital.sandiego.edu/dissertations/29 


\title{
SOCIALLY RESPONSIBLE AND SMALL: \\ A QUANTITATIVE STUDY OF CORPORATE SOCIAL RESPONSIBILITY IN SMALL AND MEDIUM ORGANIZATIONS IN THE UNITED STATES
}

\author{
by \\ ABIGAIL SORENSON BERK \\ A dissertation submitted in partial fulfillment \\ of the requirements for the degree of \\ Doctor of Philosophy
}

November 13, 2015

Dissertation Committee

Fred Galloway, Ed.D.

Robert Donmoyer, Ph.D.

Patricia Marquez, Ph.D. Mark Peters, Ph.D.

University of San Diego 



\section{(C) Copyright by Abigail Sorenson Berk}

All Rights Reserved 2015 


\begin{abstract}
Corporate social responsibility (CSR) has become a global imperative supported by governments, industry, and citizens alike. In 2000, the United Nations launched the Global Compact to encourage businesses to adopt socially responsible policies. In tandem, businesses became increasingly attentive to their social practices with the vast majority of executives declaring CSR important to their organization's success. Despite this increase in attention - which occurred among businesses of all sizes - the academic literature on CSR has focused almost exclusively on large, public companies. Ironically, the majority of businesses in the United States are small, private businesses suggesting the existing CSR field has overlooked a significant segment of business.

To address this knowledge problem, this study analyzed pre-existing survey data from 3,005 small and medium enterprises (SME) located in the United States. This research first addressed the various types and levels of CSR by using factor analytic techniques to identify 22 organizational activities that corresponded to five areas of internal CSR and two areas of external CSR. Correlation coefficients and regression analysis were then used to determine the extent to which variation in these CSR activities could be explained by the 22 organizational characteristics identified in the data.

The study results indicated that more than $99 \%$ of SMEs participated in some form of CSR, although participation rates varied from a low of 5\% to a high of $92 \%$ for specific CSR activities. Organization size, as measured by number of employees, proved to be the most significant variable with a positive relationship to CSR activity. In addition, leadership characteristics such as longer tenure, a higher percentage of women executives, and more frequent executive-employee meetings were also found to have a
\end{abstract}


positive relationship with CSR activity. Other characteristics including industry type and geographic region showed both positive and negative relationships with CSR.

Overall, organization characteristics, including size, explained only $17 \%$ of the variation in CSR activity suggesting SMEs of all sizes can and do participate in CSR. It is hoped this study will provide practical data to further encourage SMEs in the United States to pursue CSR for the mutual benefit of business and society. 


\section{ACKNOWLEDGEMENTS}

While the familiar proverb states, "it takes a village to raise a child," it took more than a village to help me complete this dissertation. I am indebted to the many people in my personal and academic villages that have helped me through this process.

First, I must acknowledge the boundless patience and support of my committee chair, Dr. Fred Galloway. I came to your office as a doctoral student but appreciated your holistic view that respected the many roles in my life. Your belief and encouragement were invaluable throughout the doctoral program.

I also benefitted from the wisdom and guidance of my committee members. Dr. Donmoyer provided an insightful perspective and a much-appreciated voice of reassurance. Dr. Marquez kindly shared her time and expertise even when her responsibilities to the school escalated. Dr. Peters provided valuable feedback and encouragement throughout this voyage. Thank you all.

I would also like to acknowledge the kindness and humility of Dr. David Herrera. I am forever grateful that you shared your love of teaching with me. Your personal strength and insight are inspiring.

Many of my fellow students at the University of San Diego provided guidance and encouragement through the years. I have been genuinely touched by the supportive and nurturing environment. I am proud to be your colleagues.

Through the seven years of my doctoral program my family and friends have patiently supported my studies. Kimmy Nice's limitless patience and love for children allowed me the peace of mind to study knowing my children were loved and cared for. Thank you for being there for us. 
To my three children, Chloe, Dylan, and Logan, I am so proud of the people you are becoming. You provided the inspiration for me to finish this work. I look forward to returning the support and encouragement you gave me as you continue on your personal academic journeys.

Finally, I must acknowledge the incredible support of my husband, Bill, who has encouraged me throughout this extended journey. I am so thankful for your love, patience, and support. This accomplishment is ours to share. 
TABLE OF CONTENTS

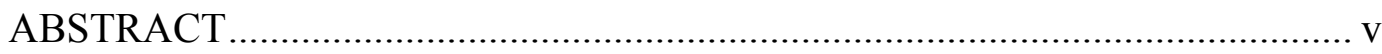

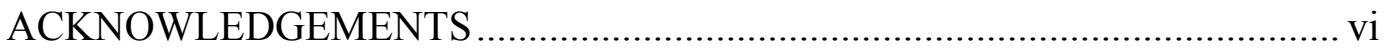

TABLE OF CONTENTS ................................................................................... viii

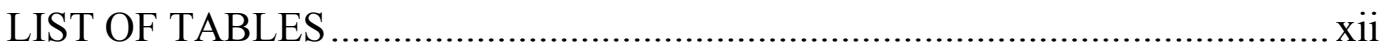

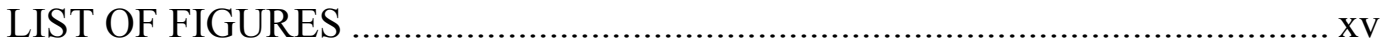

CHAPTER ONE: INTRODUCTION AND BACKGROUND ............................ 1

Defining Corporate Social Responsibility ................................................ 1

Prevalence of Corporate Social Responsibility ......................................... 2

Small and Medium Organizations ............................................................ 2

Corporate Social Responsibility in Small and Medium Organizations ............. 3

Problem Statement ..................................................................................... 4

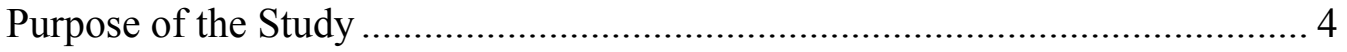

CHAPTER TWO: LITERATURE REVIEW ................................................ 6

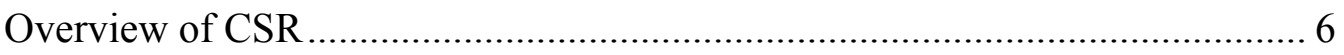

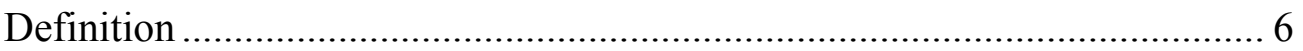

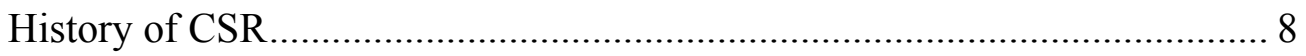

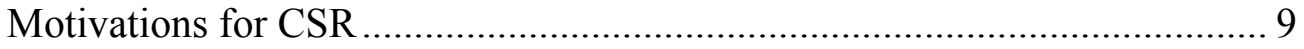

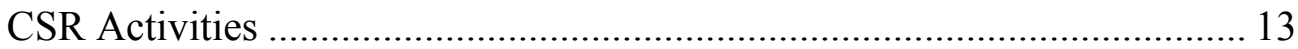

Small and Medium Business..................................................................... 15

How SMEs Differ from Large Organizations......................................... 15 


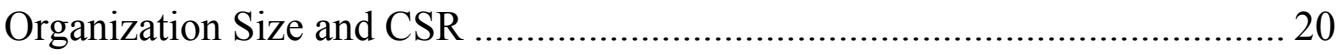

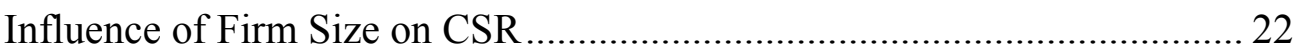

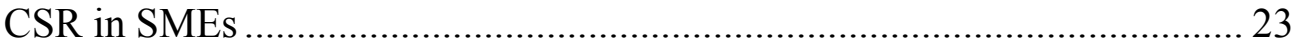

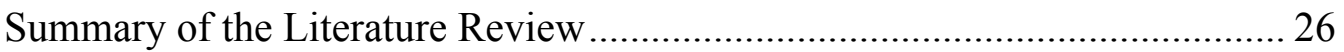

CHAPTER THREE: METHODOLOGY …………………………............ 28

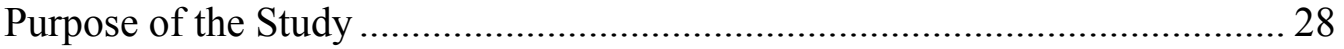

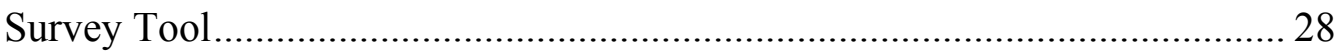

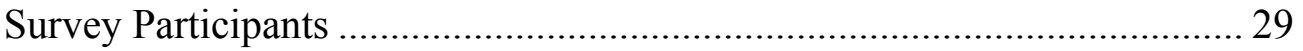

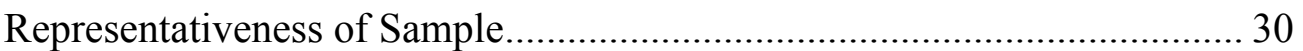

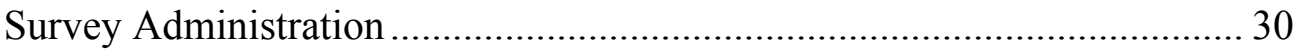

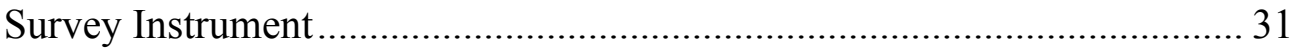

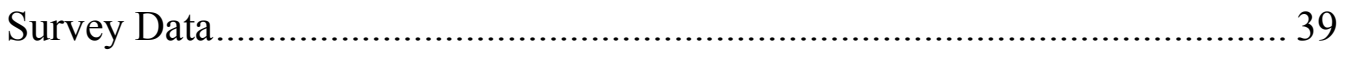

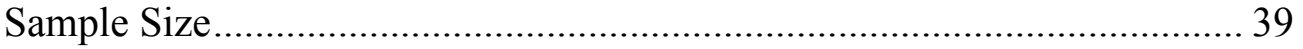

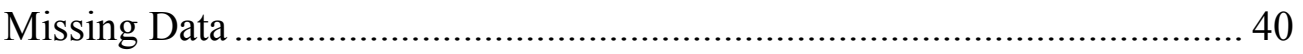

CHAPTER FOUR: RESEARCH FINDINGS ..................................................... 41

Descriptive Statistics on Survey Participants .................................................... 41

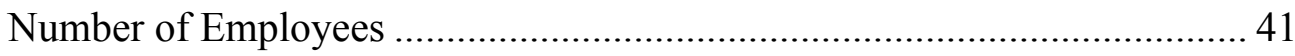

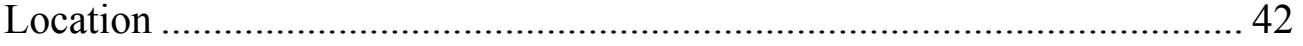

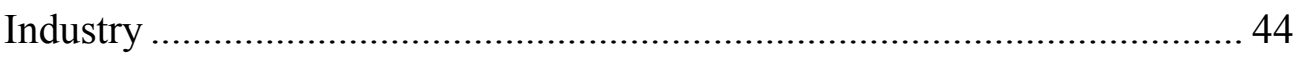

Additional Organization Characteristics ......................................................... 47

Relationship Between Size And Organization Characteristics ....................... 48

Organization Characteristic Variables ........................................................... 50 


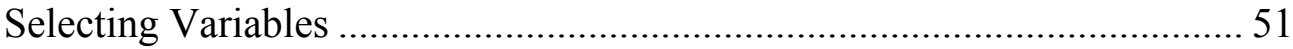

Research Question One: CSR Activities....................................................... 52

Summary: An Answer to the First Research Question ................................... 62

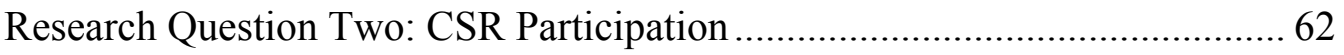

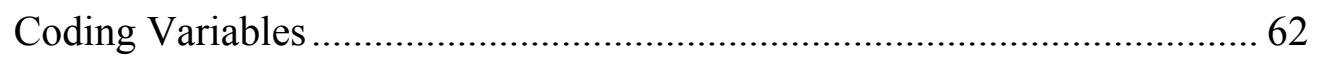

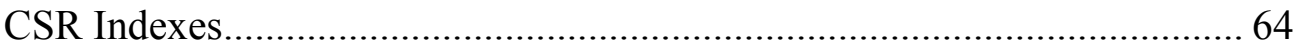

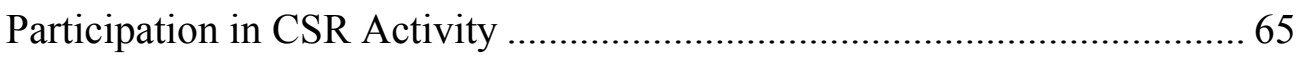

Summary: An Answer to Research Question Two ………………………... 78

Research Question Three: CSR Activity and Organization Characteristics..... 78

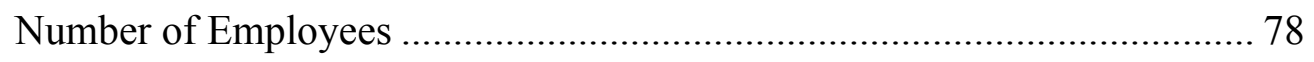

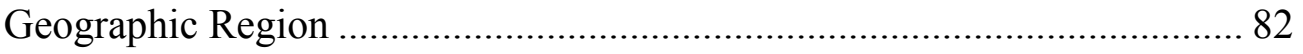

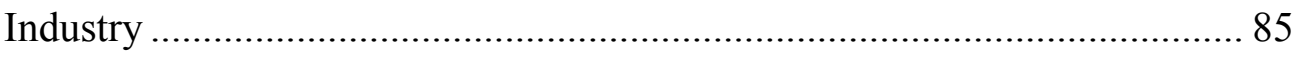

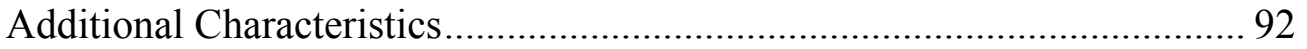

Organization Characteristic Relation to CSR …………………………….... 94

Models Predicting CSR Activity ................................................................ 103

Comparing CSR Index Values.................................................................. 123

Alternate Organization Characteristic Selection........................................... 126

Summary: An Answer to Research Question Three .................................... 127

Summary of Research Findings .................................................................... 127

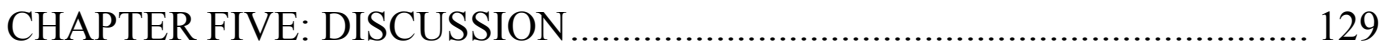

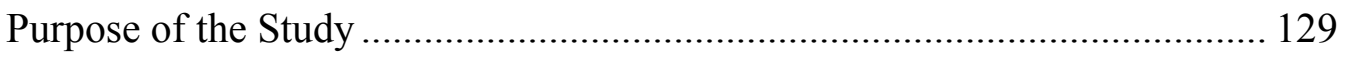

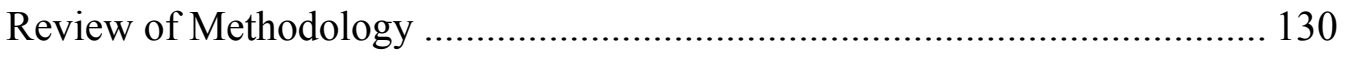

Summary of Findings ................................................................................ 131 


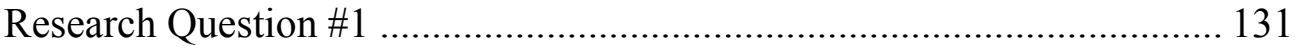

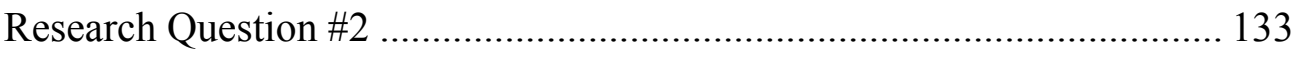

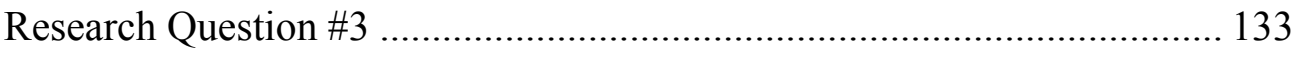

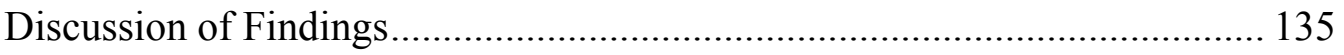

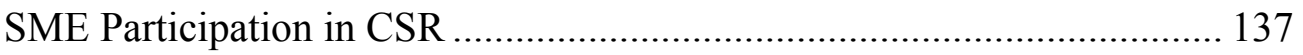

Role of Organization Size on CSR Activity ............................................. 138

Role of other organization characteristics............................................. 139

Characteristics with no Significance to CSR Activity ................................ 144

Limitations and Delimitations.................................................................... 145

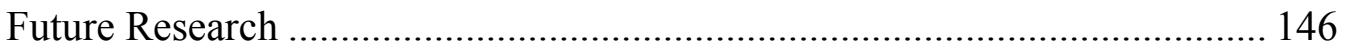

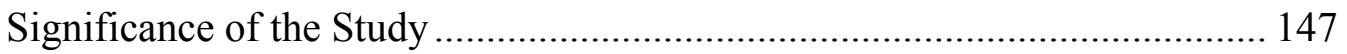

Implications for Business Associations …………………………............. 148

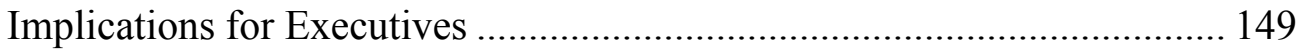

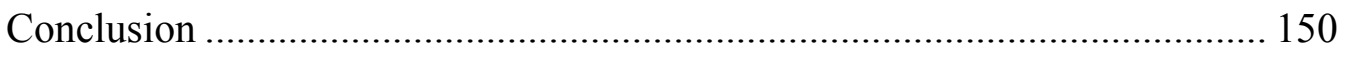

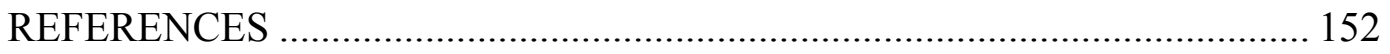

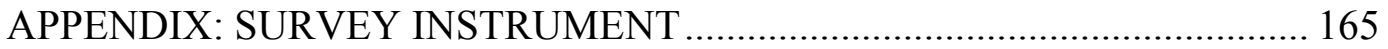




\section{LIST OF TABLES}

Table 1. Cultural Comparisons of Corporate and Small Business.................................... 17

Table 2. Survey Questions Identified as Organization Characteristics............................. 34

Table 3. Survey Questions Identified as Indicators of CSR ………............................... 37

Table 4. Geographic Distribution of Respondents....................................................... 43

Table 5. Industry Distribution of Respondents ............................................................. 45

Table 6. Distribution of Respondents by Industry Categories .......................................... 46

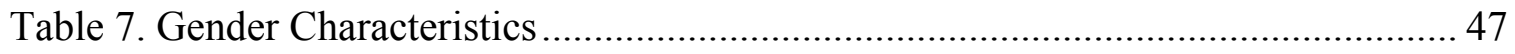

Table 8. Descriptive Statistics for Additional Organization Characteristics .................... 48

Table 9. Significant Correlations for Number of Employees and Organization............... 50

Table 10. CSR Activities Excluded After First Factor Analysis on All CSR Variables .. 54

Table 11. Final Factor Analysis Results for CSR Activity Variables................................ 56

Table 12. Reliability of Variables in CSR Constructs ....................................................... 59

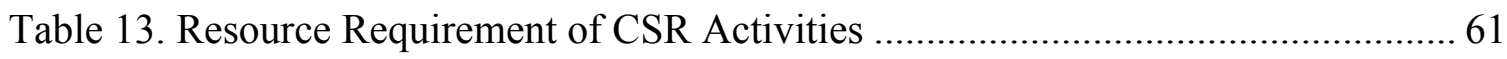

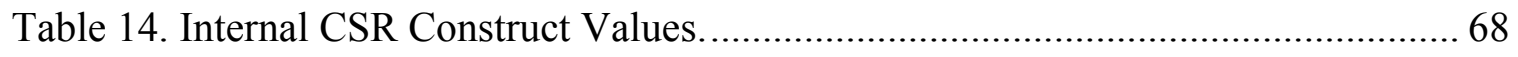

Table 15. Participation by Internal CSR Activity ………................................................. 70

Table 16.External CSR Construct Values................................................................... 72

Table 17. Participation by External CSR Activity ........................................................ 73

Table 18. Summary of CSR Index Values.................................................................... 75

Table 19. Participation by CSR Resource Intensity....................................................... 77

Table 20. Summary of CSR Activity by Geographic Region.......................................... 83

Table 21. Summary of CSR Activity for Most Represented States.................................. 83

Table 22. CSR Index Values by Population Density ……................................................ 84 
Table 23. External CSR Construct Values by Population Density ................................... 85

Table 24. Summary of CSR Activity by BLS Industry Category..................................... 86

Table 25. Difference in Means of CSR Activity by BLS Industry Category .................... 88

Table 26. Summary of CSR Activity by BLS Category with Industry Detail.................. 90

Table 27. Significance of Difference in Means by Industry ............................................ 91

Table 28. Summary of CSR Activity by Gender of Top Executive ................................ 92

Table 29. Summary of CSR Activity for Additional Organization Characteristics ......... 93

Table 30. Significant Correlations Between Geographic Locations and CSR ................. 96

Table 31. Significant Correlations Between BLS Industry and CSR Indexes................... 97

Table 32. Significant Correlations for Additional Organization Characteristics............ 100

Table 33. Individual Regression Results for Organization Characteristics .................... 102

Table 34. Stepwise Regression Results for Total CSR ................................................ 104

Table 35. Industry Detail for Stepwise Regression Results for Total CSR ..................... 106

Table 36. Stepwise Regression Results for Internal CSR ............................................. 108

Table 37. Stepwise Regression Results for Internal CSR: Diversity ............................ 110

Table 38. Stepwise Regression Results for Internal CSR: Personal Develop ….............. 111

Table 39. Stepwise Regression Results for Internal CSR: Health and Well .................. 112

Table 40. Stepwise Regression Results for Internal CSR: Family Support ………….. 113

Table 41. Stepwise Regression Results for Internal CSR: Flexible Work ..................... 115

Table 42. Summary of Significant Variables for Internal CSR Constructs ..................... 117

Table 43. Stepwise Regression Results for External CSR............................................ 119

Table 44. Stepwise Regression Results for External CSR: Community ........................ 121

Table 45. Stepwise Regression Results for External CSR: Sustainability …….............. 122 
Table 46. Summary of Significant Variables for External CSR Constructs .................. 123

Table 47. Organization Characteristics in CSR Regression Models ............................ 124

Table 48. Standardized Coefficients for Top Five Organization Characteristics ........... 125 


\section{LIST OF FIGURES}

Figure 1. Distribution of participants by number of employees. ................................ 42

Figure 2. Scree plot of eigenvalues for factor analysis on CSR variables...................... 53

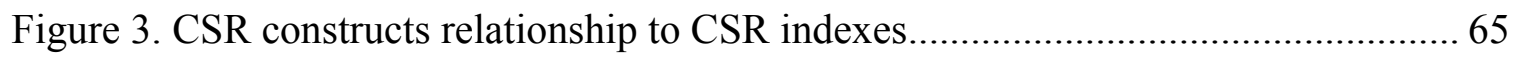

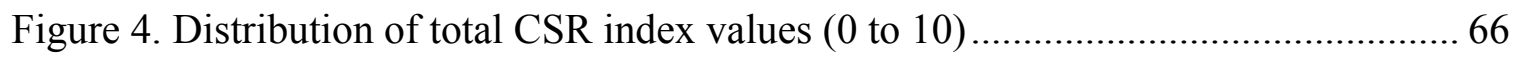

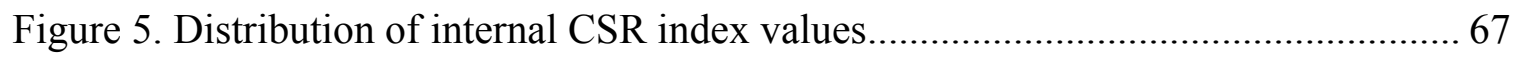

Figure 6. Distribution of external CSR index values ............................................. 71

Figure 7. Word cloud for examples of community service initiatives.......................... 74

Figure 8. Word cloud for examples of sustainability initiatives ................................ 75

Figure 9. Scatter plot for number of employees and total CSR .................................. 79

Figure 10. Scatter plot of internal CSR and number of employees. …......................... 80

Figure 11. Scatter plot for external CSR and number of employees. ........................... 81 


\section{CHAPTER ONE: INTRODUCTION AND BACKGROUND}

Despite significant developments in recent history, the global economy still suffers from glaring inequities in human well-being. While many governments and nongovernment organizations focus on promoting social progress, there is also a role for business to address social problems. Esteemed strategist Michael Porter (2013) claimed "only business can create the resources" to tackle social issues. In recent decades, businesses started formalizing their involvement in social issues by embracing the concept of Corporate Social Responsibility (CSR). Since that time, the concept of CSR has been endorsed by organizations such as the United Nations, the World Bank, the European Commission, the International Labor Organization, and the majority of businesses in the S\&P 500 and Fortune 500 (Governance and Accountability Institute, 2011).

\section{Defining Corporate Social Responsibility}

While the definition of CSR has evolved over time and has yet to be agreed on, a frequently cited definition that will be used in this study is "actions that appear to further some social good beyond the interests of the firm and that which is required by law" (McWilliams \& Siegel, 2006). While this definition is intentionally broad, much of the CSR literature centers around four main areas of activity: the environment, the workplace, the marketplace, and communities (Apospori, 2012). Notably, this definition recognizes a scope and breadth of CSR that extends well beyond its origins in corporate philanthropy. In addition, the current research demonstrates the motivations for engaging 
in CSR extend beyond an ethical desire to "do good" and into strategic and financial implications for improved business performance (McWilliams \& Siegel, 2006).

\section{Prevalence of Corporate Social Responsibility}

Many businesses have heeded the call to incorporate social responsibility. The latest UN Global Compact-Accenture CEO (2013) study found 93\% of CEOs declared CSR as important or very important to their organization's future success. Similarly, another study found $98 \%$ of the Fortune 500 reference CSR issues on their websites (Smith \& Alexander, 2013). This attention from businesses has led to a vibrant body of academic and popular research on corporate social responsibility. Indeed there are numerous respected publications that discuss the definition, motivations, measurement, results, effectiveness, and implementation of CSR. However, the academic literature todate has focused primarily on CSR in the domain of large, public companies (Jenkins, 2004; Lee, 2008). Even the inclusion of the word "corporate," by definition, indicates an emphasis on large companies. This focus has overlooked how small and medium business organizations (SME) engage in CSR.

\section{Small and Medium Organizations}

The private sector of the United States economy encompasses over 7,600,000 establishments - 99.7\% are small businesses (United States Census Bureau, 2008). The federal agency of Small Business Administration (SBA) currently defines "a small business as an independent business having fewer than 500 employees" (SBA, 2014) and makes no distinction for a medium business. However, this definition of a small business is not universal. The European Commission categorizes business size as micro (less than 10 employees), small (between 11 and 50 employees) and medium (51 to 250 
employees). Studies in Singapore (Lee, Mak and Pang, 2012) and Colombia (Pastrana and Sriramesh, 2014) used a maximum of 200 employees to be considered an SME. An extensive study of CSR in Latin America categorized small firms as 1-49 employees and medium firms as 50-250 employees (Vives, 2005). Given this study is focused on businesses in the United States, it will use the SBA standard of 500 or fewer employees when referring to a SME. However, future comparisons between countries will need to consider the different criteria for SMEs.

The SBA (2014) reports that small businesses represent $49 \%$ of private sector employment and nearly 60,000,000 employees (United States Census Bureau, 2008). In addition, SMEs in the United States created 63\% of the net new jobs between 1993 and mid-2013 (Small Business Administration, 2014). Census data also shows that the average size of business has been declining since 2001 as new businesses are starting smaller and staying smaller (Choi \& Spletzer, 2012) suggesting small businesses will be increasingly important. Clearly, SMEs are a significant contributor to the United States economy, suggesting SMEs could also be a significant contributor to CSR activities for social betterment.

\section{Corporate Social Responsibility in Small and Medium Organizations}

The existing CSR research has not yet adequately addressed the specific needs of SMEs. Studies consistently show that SMEs are not merely miniaturized versions of large companies (Baumann-Pauly \& Spence, 2013; Fitjar, 2011; Spence, 1999; Welsh \& White, 1981). More specifically, some key areas of difference include ownership structure (Jenkins, 2004), the role of the owner-manager (Murillo \& Lozano, 2006), 
financing options, and the various financial and non-financial motivations for operating a SME (Hurst \& Pugsley, 2011; Spence \& Rutherfoord, 2001).

Following Jenkins (2004) initial critique of CSR theory, a few scholars began studying CSR applied to SMEs. A 2006 European Academy of Business conference prompted an issue of the Journal of Business Ethics dedicated to "SMEs and CSR: identifying the knowledge gap." Despite this attention, the topic has yet to be fully embraced, even by CSR scholars. Consequently, the work on CSR in SMEs is mostly published within the realm of business ethics. By comparison, the most prominent research on CSR in large organizations is featured in the most selective management journals such as the Academy of Management, Strategic Management Journal, or the Harvard Business Review. While there has been some recent progress in expanding the understanding of CSR for SMEs, the current body of literature is still incomplete.

\section{Problem Statement}

Considering the societal benefits of CSR and the significant role of SMEs in the economy, the paucity of research on CSR in SMEs is disconcerting. The current body of literature is clearly insufficient to address the questions and needs of the SME community in regards to CSR activities. This knowledge gap makes it difficult to advocate for, implement, and assess CSR in SMEs at a time when pressing societal issues warrant the attention of everyone.

\section{Purpose of the Study}

The purpose of this study was to begin filling the current gap in CSR and SME knowledge by researching the CSR activities of SMEs in the United States, the level of participation in these CSR activities, and the organization characteristics that influence 
participation in CSR activities. This information could inform CSR advocates seeking to promote CSR to the SME population as well as organizations wishing to adopt SME relevant CSR activities. The following three research questions guided this study:

1. What are the CSR activities of SMEs in the United States?

2. To what extent, if any, do SMEs in the United States participate in these CSR activities?

3. What organization characteristics contribute to varying levels of CSR activity in SMEs? 


\section{CHAPTER TWO: LITERATURE REVIEW}

This review of the relevant literature highlights key research in the areas of CSR, SMEs, and the intersection of CSR and SMEs. This discussion of the CSR research will focus on (a) the debate around defining CSR, (b) a brief history of CSR, (c) the motivations for participating in CSR, and (d) the type of activities that constitute CSR. This section will also demonstrate the CSR literature's predominant focus on large companies.

The literature on small and medium business enterprises, SMEs, demonstrates the prevalence and significance of this sector as well as the characteristics that make this business segment different from large companies. The discussion of CSR in SMEs provides an overview of this burgeoning area of research including the preponderance of qualitative studies on SMEs outside the United States.

\section{Overview of CSR}

Corporate social responsibility has become an increasingly popular topic in academic and popular literature. However, discussions of the topic do not always employ a consistent understanding or definition of CSR. This section provides an overview of the recent literature on CSR to ensure a common understanding of the related terms and their application to research.

\section{Definition}

In recent decades the academic literature has presented multiple definitions and interpretations of CSR. In a 2006 paper, Dahlsrud identified 37 definitions from 27 authors over a period of 23 years while acknowledging the actual number of definitions in circulation is likely much higher. Despite the plethora of definitions, several leading 
researchers present a decisive definition of CSR in their work. In 2010, Archie Carroll, a prolific author on CSR since the 1970s, and Kareem Shabana identified an "appropriate definition to use" when they wrote "The social responsibility of business encompasses the economic, legal, ethical and discretionary expectations that society has of organizations at a given point in time" (p. 89). An oft-cited McWilliams and Siegel (2001) paper acknowledged the confusion surrounding CSR but definitively defined CSR as "actions that appear to further some social good beyond the interests of the firm and that which is required by law" (p. 117). In their widely cited 2007 paper, Aguilera, Rupp, Williams, and Ganapathi defined CSR as “the firm's considerations of, and response to, issues beyond the narrow economic, technical, and legal requirements of the firm to accomplish social (and environmental) benefits along with the traditional economic gains with the firm seeks.” (p. 837).

While there is no definitive agreement on the definition of CSR, this study selected McWilliams and Siegel's 2001 definition, i.e., "actions that appear to further some social good beyond the interests of the firm and that which is required by law" ( $\mathrm{p}$. 117). This definition was intentionally chosen for its brevity and relative simplicity, important characteristics when researching business practitioners.

Comparable terms. The definition debate is heightened by the presence of other terms used in ways that appear synonymous with CSR. Margolis, Eifenbein, and Walsh (2007) discussed corporate social performance (CSP) as it relates to corporate financial performance (CFP). Aguilera et al. (2007) analyzed reactive social change and proactive social change, while Porter and Kramer (2006) discussed responsive CSR and strategic CSR. Carroll and Shabana (2010) addressed the overlapping concepts of corporate 
citizenship, business ethics, stakeholder management and sustainability. Elkington (1998) introduced the "triple bottom line" standard of reporting while Kinder, Lydenberg, Domini and Company provide the KLD Index for social performance. The term corporate social opportunity (CSO) (Jenkins, 2009) references the commercial viability of CSR activities. This abundance of apparently related and often interchangeable terms only adds to the complexity of defining CSR.

Practitioner preferred terms. Despite the academic debate on CSR definitions, businesses do not always choose to use the CSR term. An analysis of CSR references on corporate websites found the preferred terms used by more than $80 \%$ of the Fortune 500 when discussing CSR were "community” and "environment" (Smith \& Alexander, 2013). Around $60 \%$ of the Fortune 500 also used the terms "health and wellness," "sustainability," "diversity," and "ethics" when referencing their CSR activities. Ironically, only $36 \%$ of the Fortune 500 used the term "corporate responsibility" on their website (Smith \& Alexander, 2013). Vives (2006) found that SMEs in Latin America that were engaged in CSR were not aware of the concept of CSR so did not use this term even when discussing their CSR activities. Jenkins (2006) also found that SMEs did not use the term CSR, instead referencing the components of CSR such as environmental management, work-life balance, and community involvement. In Jenkins's 2006 study, the SMEs were selected as "exemplars of CSR" but the majority of participants were uncomfortable using the CSR term in reference to SMEs.

\section{History of CSR}

While business has been an integral part of society throughout history, Bowen (1953) formally introduced the concept of CSR in his seminal book Social Responsibility 
of the Businessman. In the 1950's, CSR focused on three principles - the manager as a public trustee, the balancing of competing claims to corporate resources, and corporate philanthropy - without any reference to benefiting the business. Instead, Bowen presented CSR as a means to promoting a "better American society" (1953). While Bowen's writing was embraced by some, his approach also had vocal critics. Most notably, Nobel-prize laureate, Milton Friedman invoked agency theory to deride CSR as "an unfair and costly burden on shareholders" while reminding businesses that "there is one and only one social responsibility of business -- to use its resources and engage in activities designed to increase its profits" (1970). While there are few contemporary proponents of agency theory that critique CSR, Friedman's influence is evidenced by continued widespread references to his work in the CSR literature.

Despite the prominent Friedman critique, the field of CSR has evolved to become "almost universally sanctioned and promoted by all constituents in society from governments and corporations to non-governmental organizations and individual consumers" (Lee, 2008, p. 53.) While a few critics persist (van Oosterhout \& Hougens, 2006), CSR has proven to be a legitimate and enduring practice influencing businesses today.

\section{Motivations for CSR}

In 2012 nearly all of the Fortune 500 businesses promoted their CSR activities on their website (Smith \& Alexander, 2013) suggesting there are compelling reasons for these corporations to both engage in and promote their socially responsible activities. The literature presents a myriad of motives for engaging in CSR including economic benefit, stakeholder management, and ethical duty. While there is ongoing discussion 
about the relative importance of the different motivators, much of the literature suggests CSR activities are driven by a combination of multiple motives.

Ethical motivation. Most CSR scholars acknowledge an ethical reason for engaging in CSR activity (Campbell, 2007; Carroll \& Shabana, 2010). However, there are few proponents for a purely ethical motivation. Vogel (2005) claimed that "the old style CSR of the 1960's and 1970's was motivated by social consideration" (p.2) and "the new world of CSR emphasizes the link between CSR and corporate financial success" (p.3). In his early work Carroll (1979) proposed a pyramid with four ascending dimensions of CSR - economic, legal, ethical, and discretionary -and emphasized all were important. However, his later works focused mostly on the economic domain with more limited discussion of ethics (Carroll \& Shabana, 2010). While the recent academic literature does not disregard the ethical motivations for responsible behavior, it does not advocate CSR for purely ethical reasons (Aguilera et al. 2007).

Economic motivation. Given the predominant financial interests of a business, it is not surprising that the majority of CSR research promotes economic motivators - both cost savings and revenue generation - for engaging in CSR.

Carroll and Shabana's (2010) article "The Business Case for Corporate Social Responsibility" specified four economic reasons to engage in CSR: 1) reduce risk and cost 2) strengthen legitimacy and reputation 3) build competitive advantage, and 4) create win-win situations through synergistic value creation. They concluded "Firms which engage in CSR activities will be rewarded by the market in economic and financial terms" (p. 101). Similarly, Devinney (2009) argued for both the cost savings and revenue benefits of CSR. He cautioned that CSR may have positive and negative consequences 
for society but identified multiple economic reasons why corporations and managers would take on CSR initiatives concluding that CSR would both improve profits and reduce risk. Even an industry study focused on privately held companies found cost management of resources among the top factors driving corporate responsibility (Grant Thornton, 2008).

Some researchers argued for revenue generation as the principal motivator for CSR. Porter and Kramer (2006) proposed competitive advantage that leads to financial benefit as the primary reason for corporations to be socially responsible. They claimed that CSR "can be a source of opportunity, innovation and competitive advantage" (p. 80) instead of a cost, constraint or charitable deed. McWilliams and Siegel's (2001) work proposed CSR as an investment in product differentiation that helps maximize revenue and profits.

Stakeholder motivation. Much of the CSR literature references R. Edward Freeman's 1984 work on stakeholder theory regarding "persons or groups with legitimate interests in procedural and/or substantive aspects of corporate activity" (Donaldson \& Preston, 1995, p. 67). Stakeholders are distinguished from shareholders with the understanding that they have different, and potentially conflicting, needs and demands. Stakeholder theory applied to CSR suggests that any group such as customers, employees, partners, suppliers, communities, or governments could motivate a corporation to behave responsibly.

Within Carroll and Shabana's (2010) economic justification of CSR, they acknowledged the relevance of stakeholders including shareholders, activists, governments, and consumers. Their work claimed, "effective CSR rests on developing 
the appropriate CSR strategy where CSR activities are those directed at improving stakeholder relations" (p. 101). Barnett (2007) also claimed that firms benefit from meeting the needs of their stakeholders. He wrote, "CSR increases the trustworthiness of a firm and so strengthens relationships with important stakeholders" (p. 796). In their comprehensive review of CSR, Aguinis and Glavas found "firms engage in CSR due to institutional pressures, particularly from stakeholders (2012). Aguilera et al. (2007) found stakeholders pressured firms into CSR based on self-interest, relations, and morals. Since the 1990's most CSR literature has incorporated some reference to stakeholders. In 2008, Freeman even proposed that the term corporate social responsibility be replaced with "corporate stakeholder responsibility"

Complementary motivation. It is important to note that the ethical, economic, and stakeholder motivations are not inherently in opposition to each other. Many CSR activities that are driven by economics would also appease stakeholders and be ethically sound and many socially responsible behaviors addressing stakeholder demands would be ethical and have economic benefits. A research forum dedicated to Stakeholders and Social Responsibility noted this relationship when it debated "whether organizations pursue the satisfaction of stakeholder interests for economic reasons or simply because doing so has intrinsic merit" (Harrison \& Freeman, 1999, p. 479). Harrison and Freeman (1999) also concluded; "one of the original ideas behind the stakeholder management approach was to try to find a way to integrate the economic and the social" suggesting that ethical, economic, and stakeholder motivations are inherently interrelated (p. 484). 


\section{CSR Activities}

The CSR literature often discusses social responsibility in broad terms without providing specific examples of CSR activities. Porter and Kramer (2006) found the CSR literature offered little practical guidance for executives. Fortunately, some authors in the government, academic, and practitioner arenas recognized the need for additional detail and provided specific examples of CSR activities.

Areas of CSR. A green paper from the European Commission documented CSR activities that were either internal or external CSR (2001). Internal CSR activities involved employees, human capital, health and safety, and managing change. External CSR practices extended into the community and involved a wide range of stakeholders. In 2010, the International Organization for Standardization (ISO) created worldwide guidelines for socially responsible organizations. These guidelines, ISO2600, established criteria in seven categories including: human rights, labor practices, the environment, fair operating practices, consumer issues, and community involvement and development.

In the academic arena, Vives' (2006) study of SMEs in Latin America referenced internal, external, and environmental CSR practices. Internal CSR included activities in human resources and the working environment while external CSR covered community involvement and environmental practices addressed the reduction of resource consumption and recycling. Perrini's (2006) study of CSR in Italian SMEs concluded the most frequent CSR initiatives included training, employee health, supporting the local community, supporting cultural activities, controlling product safety, and managing environmental impact. Jenkins (2006) interviewed small businesses in the UK that engage in CSR activities in the areas of the environment, employees, supply chain, and 
community. Some of the specific examples cited in support of these CSR categories included local community projects, environmental management, employment practices, philanthropy, and volunteering. Castka et al. (2004) defined the aspects of CSR along internal and external dimensions. The examples of internal CSR included human capital management, working environment (staffing, skills development, team building, moral and motivation), working health and safety, and managing environmental impact. Examples of external CSR included community relations, human rights, and global environmental concerns. Gellert and de Graaf (2012) conducted a study on the CSR of small and medium Dutch companies that focused on one aspect of CSR - aging workforce management. Most recently, Sanchez's (2015) research on CSR in small companies in Spain referenced internal and external dimensions of CSR. Activities related to employees were considered internal CSR while environmental concerns and relationships with the community were considered external CSR.

Practitioners have also sought to document specific areas and actions of CSR. The World Business Council for Sustainable Development (WBCSD) is a CEO-led association with over 200 member companies including global luminaries such as BP, Kellogg's, Toyota, and McKinsey. In 2013 the WBCSD published Action2020 as roadmap for businesses to engage in nine areas of CSR: 1) climate change; 2) release of nutrient elements; 3) ecosystems; 4) exposure to harmful substances; 5) water; 6) basic needs and rights; 7) skills and employment; 8) sustainable lifestyles and; 9) food, feed, fiber, and biofuels. The publication, Corporate Responsibility Magazine, ranks the 100 best corporate citizens every year based on an evaluation of 298 elements across seven categories - climate change, employee relations, environmental, financial, governance, 
human rights, and philanthropy. The commercial website CSRHub rates the level of CSR for over 15,000 companies in 135 industries and 130 countries. CSRHub proprietary system compiles data from 388 disparate sources to evaluate an organization's level of CSR in four areas: employees, community, environment, and governance.

\section{Small and Medium Business}

Numerous metrics indicate that small and medium business organizations function as the backbone of the U.S. economy. The Small Business Administration (SBA, 2014) reported small businesses account for $99 \%$ of U.S. employer firms and $49 \%$ of private sector employment. As a result, 60,000,000 people are employed in small or medium business (United States Census Bureau, 2008). Job creation is a frequently cited indicator of the U.S. economy and SMEs created 63\% of the net new jobs between 1993 and mid-2013 (Small Business Administration, 2014). These statistics portray the economic and societal significance of SMEs and, consequently, validate the need for research focused on SMEs.

\section{How SMEs Differ from Large Organizations}

While SMEs and large companies face many of the same challenges and opportunities, they are inherently different. SMEs are not merely miniaturized versions of large companies (Baumann-Pauly \& Spence, 2013; Fitjar, 2011; Spence, 1999; Welsh \& White, 1981). A Strategic Management Journal article focused on the differences between large and small firms found "an unquestioning application of models developed by studying large firms to explain small firm behavior is inappropriate (Dean, Brown, \& Bamford, 1998). Apospori (2012) also claimed, "Besides their economic importance, SMEs possess a number of other characteristics that differentiate them from large 
companies in terms of the availability of resources and know-how, their organization and management, and their role in entrepreneurship development and innovation" (p11). Fassin (2008) also noted the fallacy of assuming solutions for large multinationals can be transported to SMEs. In an analysis of SME's, Gibb (2000) highlighted the observed cultural differences between small business and large corporations as summarized in Table 1. 
Table 1

Cultural Comparison of Corporate and Small Business

\begin{tabular}{ll}
\hline Corporate (seeking to achieve) & Small Business (often characterized as) \\
\hline Order & Untidy \\
Formal & Informal \\
Accountability & Trusting \\
Information & Personal Observation \\
Clear demarcation & Overlapping \\
Planning & Intuitive \\
Corporate strategy & 'Tactically strategic' \\
Control measures & 'I do it my way' \\
Formal standards & Personally monitoring \\
Transparency & Ambiguous \\
Functional expertise & Holistic \\
Systems & 'Freely' \\
Positional authority & Owner-managed \\
Formal performance appraisal & Customer/network exposed \\
\hline
\end{tabular}

Gibb, A. A., (2000). SME Policy, Academic Research and the Growth of Ignorance, Mythical Concepts, Myths, Assumptions, Rituals and Confusions. International Small Business Journal. 18, 3, 13-34

Specific to CSR, Russo and Perrini (2009) found "large firms and SMEs must be treated as two different constructs to examine their responsible corporate strategies" (p217). In their study on the impact of firm size on CSR, Lepoutre and Heene (2006) stated, "Small and large firms possess fundamentally different resources and capabilities" and concluded "smaller firms . . . recognize and experience different issues than larger firms" (p261).

Ownership. Small and medium enterprises can also differ in ownership structure as most large companies are publicly traded while SMEs are predominantly owner 
managed (Dawson, Breen \& Satyen, 2002; Jenkins, 2004; Spence, 2007). Public ownership brings with it a primary responsibility to shareholders over managers, employees, or partners as well as onerous legal and reporting requirements that can be cost and resource prohibitive for small businesses. Another ramification of ownership is large companies are able to seek external financing through multiple venues including socially responsible investors (Jenkins, 2004; Russo \& Perrini, 2009), while SME’s primary funding resources are either internal sources or commercial banks focused primarily on risk of default (SBA, 2014).

Several authors reference the influence of the owner-manager's personal values on the actions of the business. (Grayson \&Dodd, 2007; Murillo \& Lozano, 2006; Spence \& Rutherfoord, 2001). Specifically, Lepoutre and Heene (2006) analyze the “peculiarities of small business owner-managers" with regards to their position and personal characteristics (p. 261). Vives' (1996) Latin America study found the single most consistent reason for engaging socially oriented business activities was the ethical and religious values of the owner. While SME owners will inevitably encompass tremendous diversity, the owner is likely a key influence on the organization's activities.

Purpose of the organization. Another key difference between large businesses and SMEs is the underlying purpose. By law, a public corporation's purpose is to benefit shareholders and not any other constituency (Yosifon, 2013). Recent legislation in 27 states has created a new classification, benefit corporation, that allows organizations to legally pursue activities for social benefit in lieu of profit. (BenefitCorp, 2015). By contrast, privately held SMEs can have a variety of motivations that are not tied to profit. Hurst and Pugsley (2011) found over 50\% of new business founders reported non- 
financial benefits such as schedule flexibility and self-management were the primary reason they started their business. Grayson and Dodd (2007) distinguished between the different motivations for small business by labeling them as either a "gazelle" or a "lifestyle" business. A gazelle has aspirations and the potential to grow their business. In contrast, a lifestyle business owner is content to work for him or herself and make personal trade-offs between work, income, and other aspects of their lives. Research suggests that many SMEs are lifestyle businesses as most firms start small and stay small with limited aspirations for growth (Choi \& Spletzer, 2012; Hurst \& Pugsley, 2011). Several others researchers also referenced the distinction between profit-satisficing and profit-maximizing as motivations for business (Fitjar, 2011; Spence, 2007; Vives, 2006).

Resource availability. Economics identifies three types of resources that define a business: natural, human, and capital. The availability of these resources is inherently different for any business but large and small firms possess fundamentally different resources and capabilities (Lepoutre and Heene, 2006). Apospori (2012) found the availability of resources as a differentiator between SMEs and large companies. A Strategic Management article (Cheng, Ioannou, \& Serafeim, 2013) documented the influence of capital constraints on CSR activities. Capital resources, including finances, are often a key issues for SMEs (Tencati et al., 2004)

Interpretation of social. The interpretation of "social" in Corporate Social Responsibility can also differ for SMEs and large business. Most large firms derive a significant portion of their total revenues from foreign sales, (Newman, 2011). SMEs, however, tend to operate in local communities implying they might interpret "social" on a local scale (Jenkins, 2004; Lahdesmaki, 2012). In contrast, Spence's research (1999) 
found that small firms are actually independent of the society in which they are situated while Rutherfoord et al. (2001) described the small companies in their study as "fortress enterprises" and "highly disconnected." Curran, Rutherfoord, and Smith (2000) found that SMEs are often geographically isolated from their local communities in areas such as business parks creating a sense of detachment from the community.

\section{Organization Size and CSR}

While much of the CSR literature is written without regard to the size of an organization, it is relevant to review the literature for insights into how size of an organization relates to CSR.

\section{Focus on Large Organizations}

To date, the preponderance of CSR research has focused on large, publicly traded companies (Jenkins, 2004; Morsing \& Perrini, 2009; Vazquez-Carrasco \& Lopez-Perez, 2013). Ironically, most of the research does not acknowledge this limitation. However, an analysis of the sample, data sources, and methods of studies demonstrates this is the case. For example, a recent article in the top tier Strategic Management journal stated, "Firms with better CSR performance face significantly lower capital constraints" (Cheng, Ioannou, \& Serafeim. 2013, p1.) However, further reading revealed the study was based on publicly listed firms suggesting the findings would not necessarily apply for privately held SMEs.

An analysis of the top 10 most-cited papers on CSR (as of October 2015) found all were focused on large, publicly traded companies. The articles included the following:

- Two articles used the S\&P 500 for their sample (Hillman \& Keim, 2001; Waddock \& Graves, 1997) 
- Two articles referenced shareholders indicating public ownership (Margolis \& Walsh, 2003; Porter, 2006)

- Two articles evaluated corporate social performance based on data only available for publicly traded companies (Russo, 1997; Turban, 1997)

- One study was a meta-analysis of 52 prior studies which were predominantly focused on publicly-traded companies (Orlitzky, Schmidt \& Rynes, 2003)

- One article specified their research only "applies to publicly held firms" (McWilliams \& Siegel, 2001)

- Two studies analyzed CSR for "well known companies" (Brown, 1997; Sen \& Bhattacharya, 2001)

In addition, much of the CSR research makes reference to or conducts case studies on large, public companies. Popular CSR articles have referenced Ford (Schwartz \& Carroll, 2003), Nike (Zadek, 2004), UPS (Margolis, 2003), Microsoft (Brown \& Dacin, 1997), and Nestle (Porter, 2006). These companies provide compelling examples but further reinforce the notion that the existing CSR research is applicable to large companies.

A few select authors acknowledge a focus on large, public companies. Bowen specified his book was for "the managers and directors of these large corporations" (1953, p. 6). Similarly, McWilliams and Siegel stated "our framework applies generally to publicly held firms but not necessarily to privately held companies that may have alternative objectives and are not subject to the market for corporate control.” (2010). Cowen, Ferreri and Parker (1987) claimed larger firms have a bigger social impact 
suggesting the onus to be socially responsible falls on them rather than on small firms. Even the Global Impact initiative of 2000 stated it was primarily focused on large, multinational corporations (Pastrana \& Sriramesh, 2014).

\section{Influence of Firm Size on CSR}

Despite the common exclusion of SMEs in CSR research, several prominent researchers recognized the potential implications of firm size on CSR activity. Unfortunately, this line of research has produced contradictory findings. Some research found CSR is relevant for all size firms. Orlitzky's (2001) meta-analysis of approximately 15,000 observations concluded, "both large and small firms can benefit from CSR" (p176). Similarly, Grayson (2007) found the same basic principles of CSR apply for all size firms.

Other research has found that smaller firms are less likely to engage in CSR. Waddock and Graves (1997) stated smaller firms may not exhibit as many overt socially responsible behaviors as do larger firms. Cowen (1987) also concluded that the onus to be socially responsible falls on larger firms rather than small firms. In addition, Arlow and Ackelsberg (1991) stated that CSR is less important for the small business owner.

In contrast, some research has found SMEs are more likely to engage in CSR. Madden et al. (2006) found many smaller firms tend to be involved in CSR activities in some way. In addition, Sarbutts (2003) claimed SMEs are better placed to engage in CSR, as they are organizationally flatter and quicker to respond. Murillo and Lozano (2006) found that the heightened importance of relationships in SMEs promotes responsible behavior. 
In yet another contrasting perspective, Udayasankar (2007) concluded, "very small and very large firms are equally motivated to participate in CSR" suggesting a Ushaped relationship with medium-sized firms at the bottom (p. 167). Finally, Lepoutre and Heene (2006) referenced the ambiguity around firm size and corporate social responsibility further validating the need for more research in this area.

\section{CSR in SMEs}

Spurred by Jenkins 2004 critique of existing CSR theory ignoring small and medium businesses, a few scholars such as Jenkins, Murillo, Spence, and Tencati began addressing CSR specifically for SMEs. Their works attempted to address how "the grandness of the small business is overshadowed by a focus on the more conspicuous merits or scandals or large multinational companies" (Morsing \& Perrini, 2009, p.1.) As a result of their efforts, a relevant body of literature began to appear in publications in 2004. The year 2009 saw a large uptick in SME CSR publications and the number of published articles has continuously trended higher (Vazquez-Carrasco \& Lopez-Perez, 2013.)

Propensity towards CSR. The nascent literature on CSR in SMEs may have intended to provide clarification but actually produced contradictory findings. Some key areas of disparity involved the propensity and ease with which SMEs adopt CSR. Lepoutre and Heene (2006) concluded, "Small businesses, in general, will experience more difficulties than their larger counterparts when engaging in socially responsible actions (p 268). Similarly, Perrini et al. (2007) found "CSR approaches still seem to be a prerogative of large firms" in Italy and SMEs are less likely to adopt and develop explicit CSR strategies than large firms (p. 293). In contrast, Baumann-Pauly et al. found that 
SMEs are potentially better at actually implementing CSR-related activities (2013). Meanwhile, Udayasankar (2007) found similarities between small and large firms CSR. The continued contradictions emphasize the necessity for further research to investigate how firm size influences CSR practices.

Influences on CSR activity. SME participation in CSR is influenced by a multitude of factors. Small business actions are often limited by their belief that their size renders their impact negligible (Hillary, 2000). Lepoutre and Heene (2006) identified four antecedents of CSR behavior for SMEs: issue, personal, organizational, and context characteristics. Some of these personal characteristics of a SME include the availability of time, knowledge of the topic, personality type, religious beliefs, network of peers, and personal values. A business owner entrenched in day-to-day operations is likely to experience a lack of time and be less likely to engage in CSR (Schaper, 2002.) Vives (2006) study of CSR in Latin American found the most consistent reason SMEs engaged in CSR was the ethic and religious values of the owner/manager. SMEs also cite a lack of financial resources as an important barrier to engaging in CSR (Hillary, 2000) even though not all CSR actions require financial resources.

Geographic Focus. In 2006, The Journal of Business Ethics published a special issue focused on the knowledge gap for CSR and SMEs. This issue included empirical studies in Spain (Murillo \& Lozano, 2006) and the United Kingdom (Jenkins, 2006; Williamson, 2006), an action-research project in England (Roberts et al., 2006), and a theoretical perspective from Italy (Perrini, 2006) - all based in Europe. A resulting paper analyzed CSR and small business with a "distinctively European perspective on the topic" (Spence, 2007, p 534). The ensuing studies on CSR in SMEs expanded globally to 
include a study of motivations in India (Roy et al., 2013), an exploratory study in Singapore (Lee et al., 2012), a survey in Hong Kong (Welford et al, 2007) and Kazakhstan (Baisakalova, 2012), an analysis in Latin America (Vives, 2006), and exploratory research in Lebanon (Jamali, et al., 2008). While these studies provide compelling and actionable findings, there is clearly a void of research around SMEs in the United States. In fact, a search on corporate social responsibility in small business or small and medium enterprises using the Business Source Premier database returned zero results for the United States. It is interesting to note this geographic disparity does not hold for CSR research in general. In fact, scholars have claimed most general CSR studies rely on Western models and perspectives and apply a Western lens (Lee et al. 2012; Pastrana \& Sriramesh, 2014). However, CSR literature related to SMEs in the United States is notably absent.

Global Differences. While SMEs around the world share many of the same challenges with CSR, there are inherently "cultural, economic, social, and political factors that influence the role of business" (Marquez, 2012). As an example, several European studies on CSR for SMEs are framed by the European Commission's Directorate for Enterprise and Industry focused on "how to help more small businesses integrate social and environmental issues" (European Commission, 2011). In addition, multiple studies in Italy were in response to the Italian Government's 2002 CSR initiative to "foster the proactive role of Italian enterprises, with great attention on SME involvement" (Tencati et al., 2004). A study of SME CSR in Singapore concluded the government provides "the impetus for CSR engagement" (Lee et al., 2012) while 
research in Kazakhstan found "there is a strong political will to promote and practice CSR” (Baisakalova, 2012).

In contrast, the United States governments' efforts in the area of CSR are more limited. The United States' government CSR programs are housed under the Department of State's "voluntary recommendations for responsible business conduct" specifically "addressed to MNEs (multinational enterprises)" (United States Department of State, 2014). Meanwhile, the only acknowledgement of corporate social responsibility on the United States government's Small Business Administration's website is under “tax deductions for charitable giving" (SBA, 2014).

As Prieto-Carrón, Lund-Thomsen, Chan, Muro, and Bhushan (2006) noted, "If CSR initiatives are to be legitimate, their content and implementation should be adapted to the particular country or region in which they are taking place" (p.977). While this research study does not specifically address the role of culture or government in CSR for SMEs, the global differences further validate the need for research based in the United States.

\section{Summary of the Literature Review}

This literature review intended to provide an overview of the academic literature relevant for this study. The CSR literature was examined in regards to the debate on definitions, the history of CSR, the different motivations (ethical, economic, and stakeholder) for engaging in CSR, and the types of CSR activities. Within the CSR literature there is a small but burgeoning field of research on CSR for small and mediumsized organizations. This review highlights the literature's findings on differences between large and small firms and their implications for CSR. In addition, the 
geographic focus of the existing work on CSR in SMEs is discussed to present a case for conducting further research in the United States. 


\section{CHAPTER THREE: METHODOLOGY}

This section provides an overview of the processes and procedures used in researching CSR in SMEs in the United States. The chapter begins by reviewing the purpose of the study along with the three research questions. This chapter also covers the tools and instruments used in the research as well as the sample and data used for analysis.

\section{Purpose of the Study}

The purpose of this exploratory study is to begin filling the current gap in CSR and SME knowledge by researching the CSR activity of a sample of SMEs in the United States. Using quantitative analysis, this study identified CSR activities of SMEs and the level of SME participation in these CSR activities. In addition, this study analyzed the extent to which variation in CSR activity among SMEs can be explained by organization characteristics such as size, location, and industry.

The following three research questions guided this study:

1. What are the CSR activities of SMEs in the United States?

2. To what extent, if any, do SMEs in the United States participate in these CSR activities?

3. What organization characteristics contribute to varying levels of CSR activity in SMEs?

\section{Survey Tool}

Considering the number and diversity of small and medium businesses in the United States, a survey was determined to be the most appropriate method for data collection as surveys can be "a first effort to try to learn something about a population" 
(Fowler, 2009, p.3). A pre-existing, annual survey conducted by an independent thirdparty, Best Companies Group (BCG), was identified as a relevant source of data to answer the research questions. The specificity and the narrowness of the survey questions warranted a quantitative analysis focused on observing and measuring select variables with the use of the SPSS statistical software.

Since 2004, Best Companies Group has partnered with approximately 40 business associations and media publishing groups around the world to "identify and recognize places of employment that are leading the way in defining the employee experience of the 21st century" (Best Companies Group, 2015). As a result, BCG recognizes organizations through their "Best Places to Work" awards. Examples of these partner organizations include the San Diego Business Journal, Accounting Today, MaineBiz, the Texas Association of Business, and the Ohio Society for Human Resource Management State Council. These different partnerships enable the BCG survey to reach a wide variety of SMEs in the United States.

\section{Survey Participants}

In 2014, Best Companies Group conducted surveys in 28 geographic regions of the United States as well as 13 industry and specialty groups nationwide. The data used in this study was a compilation of all 41 surveys. Combined, these surveys generated 3,911 responses including 3,005 responses from SMEs that served as the basis for this study's analysis. The 906 surveys of organizations with between 501 and 265,000 employees were excluded from this study as they were beyond the scope of studying SMEs.

Regardless of which survey was completed, participants were assigned a location based on the U.S state provided in response to the question asking for business address. 
As a result, participants were grouped by states as well as geographic divisions (numbered one through nine) and geographic regions - Northeast, Midwest, South and West - as defined by the U.S. Census Bureau.

\section{Representativeness of Sample}

Considering there are more than 7,000,000 SMEs in the United States it is difficult for any survey to be representative of the total SME population. The 3,005 responses to this survey provided a large sample for analysis but cannot be considered representative of all SMEs in the U.S. Specifically, organizations opted to complete this survey hoping to be recognized with a Best Places to Work award. As a result, these selfselected organizations are more likely to be proactive implementing practices that benefit their employees and the workplace.

Following the example of other CSR researchers who chose to study leading companies (Tencati, Perrini \& Pogutz, 2004), data-rich companies (Baumann-Pauly et. Al, 2013), or exemplars of CSR (Jenkins, 2006), this study elected to analyze the SMEs in contention for a Best Place to Work award as they provided a data rich sample for the study of CSR.

\section{Survey Administration}

Between January and December 2014 Best Companies emailed approximately 6,500 survey invitations to companies that requested to be part of the survey. The survey requests were emailed from the Director of Market Research at BCG, Mary Plissey, with an introduction to the survey, a link to the online version of the survey, and a unique access code for each organization. Human Resource managers were the most common employees to complete the surveys. However, the online survey included the ability to 
save and revisit the survey allowing for any number of people (with the given access code) to complete survey responses.

Survey recipients were given two weeks to complete the survey and received up to three email reminders from BCG encouraging participation. There was no direct incentive for participation other than receipt of a summary of responses and a benchmarking report. However, many organizations were motivated to complete the survey for the prospect of being recognized as a "best place to work" in their region or industry. Fifty-six percent of the companies completing the survey were ultimately recognized as a best place to work either in a region or industry.

\section{Survey Instrument}

The survey included 80 closed-ended questions with the option of including additional supporting information for 16 of the questions. The proprietary survey instrument was created by a team of BCG researchers with expertise in workplace assessment. The instrument has been in use continuously since 2004 with limited modifications.

The survey takes approximately three hours to complete but can be saved and revisited over the two-week period. According to BCG, the surveys had around a $60 \%$ response rate. Surveys must have at least 75 of the 80 closed-ended questions completed to be included in the data analysis. Completing the sub-questions requesting additional detail was not a requirement for inclusion although the majority of respondents completed these additional sub-questions.

Survey language. Prior research has shown "the term 'Corporate Social Responsibility' is unattractive and off-putting for many SMEs" (Grayson, 2007). In 
addition, many small businesses claim they do not understand or use the term "CSR" even when engaging in CSR activities (Jenkins, 2006, Lee, 2012, Giovanna et al, 2012). The language in this survey made no reference to "CSR" or "social responsibility" or any similar terms choosing instead to use "sustainable or green" practices or "community service initiatives." In order to clarify the interpretation of these terms the survey provided specific examples. Questions focused on community service initiatives listed examples such as "Boy/Girl Scouts, Big Brothers/Big Sisters, United Way, Habitat for Humanity and local initiatives such as food banks, anti-littering programs, literacy programs, local shelters or kitchens, disaster relief programs etc." Similarly, the questions on "sustainable or green practices" included a list of examples such as "recycling aluminum cans, paper products and ink/toner cartridges; shifting to more paperless work processes, purchasing products made from recycled materials; turning off lights, using renewable energy (e.g., solar or wind power); constructing new facilities using sustainable building practices, etc."

Content of Survey Question. The survey included questions categorized in the following six areas: organization and contact information (28 questions), hiring and employment practices (six questions), pay and benefits (15 questions), work/life balance and wellness (10 questions), training and career development (nine questions), and corporate culture and communications (seven questions). Responses to questions from all six areas were used in the final analysis. Included in the organization and contact information section were demographic questions about location, industry, executive, number of employees, and gender diversity. In addition, further questions covered company specific information such as annual salaries, number new positions created, 
voluntary turnover, and level of involuntary separation. The Appendix includes the complete survey instrument.

Questions for Analysis. Of the 80 questions in the survey, 51 questions were considered relevant for inclusion in this study. Of these, 18 questions provided organization characteristics while 33 questions involved activities relevant to CSR.

Organization Characteristic Questions. The survey included questions on number of employees, location, industry, and percent of employees that are male or female. However, the survey also included numerous questions addressing topics such as leadership, employee benefits, Human Resource practices, performance-related outcomes, and communication. Table 2 presents the survey questions identified as relevant organization characteristics. 
Table 2

Survey Questions Identified as Organization Characteristics

\begin{tabular}{|c|c|}
\hline Characteristic Area & Survey Question \\
\hline \multirow[t]{5}{*}{ Demographics } & Q5. Business address \\
\hline & Q8. Industry \\
\hline & Q13. Total number of full-time and part-time employees \\
\hline & Q17. Percent male employees \\
\hline & Q18. Percent female employees \\
\hline \multirow[t]{4}{*}{ Leadership } & Q12. Name of highest ranking official \\
\hline & Q12d. Tenure of highest ranking official \\
\hline & Q19. Percent of executive team male \\
\hline & Q20. Percent of executive team female \\
\hline \multirow[t]{2}{*}{ Human Resources } & Q15. How many full-time Human Resources staff employed? \\
\hline & Q16. Number Human Resource Certifications held by HR staff \\
\hline \multirow[t]{3}{*}{ Benefits/Policies } & Q14f. Minimum number of hours to be considered full-time? \\
\hline & Q48. Number of paid holidays per year? \\
\hline & $\begin{array}{l}\text { Q57. What dress code applies to the majority of your } \\
\text { employees? }\end{array}$ \\
\hline \multirow[t]{5}{*}{ Performance Outcomes } & Q21. Average annual salary for exempt employees \\
\hline & Q22. Average annual salary for non-exempt employees \\
\hline & Q23. Number new positions created in recent fiscal year \\
\hline & Q26. Percentage voluntary turnover in recent fiscal year \\
\hline & $\begin{array}{l}\text { Q28. Percentage employees involuntarily separated in recent } \\
\text { fiscal year }\end{array}$ \\
\hline \multirow[t]{3}{*}{ Communication } & Q7. Twitter Handle \\
\hline & $\begin{array}{l}\text { Q34. Have formal policy regarding employee blogging, online } \\
\text { social networking, or use of employer equipment for personal } \\
\text { email access, etc.? }\end{array}$ \\
\hline & $\begin{array}{l}\text { Q74. How often does your CEO/President host regularly- } \\
\text { scheduled employee meetings? }\end{array}$ \\
\hline
\end{tabular}

Calculated Organization Characteristics. In addition to the extensive information gathered through survey questions, this analysis necessitated calculating six additional organization characteristics based on information provided in the survey responses. 
Gender of Top Executive. The first calculated variable, gender top executive, was derived from question 12 asking for the first and last name of the highest-ranking official. First names were analyzed and categorized as male or female based on the traditional gender association in the United States. First names that did not have a clear gender association were entered into the online database genderchecker.com. Names that were considered unisex or did not have a gender association were left blank. Ultimately, this variable showed 2,995 male executives ( $85 \%$ of the sample) and 363 executives female ( $10 \%$ of the sample) leaving 157 records with no gender assigned ( $5 \%$ of the sample.)

Geographic Region. The next calculated variable, geographic region, mapped the state given in the organization address to one of nine geographic divisions (numbered one to nine) and four regions (Midwest, Northeast, South and West) as defined by the United States Census Bureau (Census Bureau, 2015). While the survey included data for all 50 states, the limited representation in some states warranted consolidation by geographic region.

Industry Classification. Survey respondents selected one of 29 industry options. These responses were used to create an additional variable that corresponded to the industry classifications defined by the Bureau of Labor Statistics (BLS.) While the BLS has 10 industry classifications there were no survey participants in the Natural Resources and Mining category indicating the sample represented nine of the BLS categories. Two of the survey industry categories (construction and manufacturing) corresponded directly with the BLS categories. The remaining survey industry categories were manually matched to BLS categories based on the participant's open-ended overview of the organization products/services and the explanatory detail of industries provided on the 
BLS website.

Human Resources to Employee Ratio. The fourth calculated variable, HR to employee ratio, was created by dividing the number of Human Resources staff (question 15) by the number of employees (question 13) and multiplying the number by 100 . This created a variable representing the number of HR staff for every 100 employees. This metric is used by the Society for Human Resources Management (Krell, 2013) to allow for comparisons across different size organizations. Considering the number of Human Resources staff for participating organizations varied from 0 to 393, this new metric, HR to employee ratio, was determined a more meaningful variable for comparative analysis.

Dress Code. Question 57 of the survey asked what dress code applied to the majority of employees with the response set including Business, Business Casual, Casual, and Uniforms. Recognizing there is no universal understanding of business casual or casual, this variable was converted into a dummy variable indicating whether the organization's employees wore a uniform $($ value $=1$ ) or no uniform $($ value $=0$.)

Salary Differential. Finally, the questions on average annual salary for exempt employees (question 21) and nonexempt employees (question 22) were combined to create a new variable that reflected the percentage difference between annual salaries for exempt and nonexempt employees. Creating a variable based on percentages instead of actual values allowed for an improved basis of comparison.

CSR Questions. None of the survey questions explicitly focused on CSR. Instead, the questions focused on specific organization practices or policies, some of which are CSR activities. As a result, it was necessary to identify which survey questions would be most relevant for a CSR analysis. Using the CSR literature for guidance, 33 
survey questions were identified as CSR activities. These questions corresponded to nine categories of CSR. Table 3 lists the survey questions identified as CSR activities.

Table 3

Survey Questions Identified as Indicators of CSR

\begin{tabular}{|c|c|}
\hline Area of CSR & Survey Question \\
\hline \multirow[t]{4}{*}{ Diversity } & $\begin{array}{l}\text { Q29. Actively recruit/retain employees of varying ethnic and } \\
\text { cultural backgrounds? }\end{array}$ \\
\hline & Q30. Actively recruit/retain members of the disabled community? \\
\hline & Q31. Actively recruit/retain an aging workforce? \\
\hline & Q68. Offer formal diversity training? \\
\hline \multirow[t]{6}{*}{ Wealth Distribution } & Q36. Offer employee bonus or incentive program? \\
\hline & Q37. Offer bonuses to employees who refer new hires? \\
\hline & Q38. Offer a Profit Sharing Program? \\
\hline & Q39. Offer an Employee Stock Option (ESOP)? \\
\hline & Q40. Offer a retirement savings program such as $401(\mathrm{k})$ ? \\
\hline & Q40b. Match employee contributions to retirement savings plan? \\
\hline \multirow[t]{3}{*}{ Benefits } & Q42a. Offer choice of health care plans? \\
\hline & Q47. Offer domestic partner benefits? \\
\hline & $\begin{array}{l}\text { Q61.Provide cafeteria or meal subsidies, free daily snacks or } \\
\text { beverages? }\end{array}$ \\
\hline \multirow[t]{3}{*}{ Community } & $\begin{array}{l}\text { Q52. Allow employees additional paid time off for community } \\
\text { service activities/volunteer work? }\end{array}$ \\
\hline & Q53. Actively support any community service initiatives? \\
\hline & $\begin{array}{l}\text { Q53. Describe the top three community service initiatives your } \\
\text { organization sponsors or actively supports }\end{array}$ \\
\hline \multirow[t]{5}{*}{ Work/Life Balance } & Q54. Offer telecommuting options? \\
\hline & Q55. Offer job-sharing options? \\
\hline & $\begin{array}{l}\text { Q56. Offer employees option to work flexible hours/compressed } \\
\text { work week? }\end{array}$ \\
\hline & $\begin{array}{l}\text { Q77. Provide family-friendly benefits to employees? (12 } \\
\text { examples) }\end{array}$ \\
\hline & $\begin{array}{l}\text { Q78. Provide programs or practices to promote a healthy work/life } \\
\text { balance? }\end{array}$ \\
\hline \multirow[t]{2}{*}{ Health \& Wellness } & $\begin{array}{l}\text { Q32. Provide resources/support to employees feel they were } \\
\text { treated unfairly? }\end{array}$ \\
\hline & Q42a. Offer a choice of health care plans? \\
\hline
\end{tabular}




\begin{tabular}{ll}
\hline Area of CSR & Survey Question \\
\hline & Q58. Provide any workplace facilities to promote exercise and \\
fitness? & Q59. Provide any fitness and/or wellness programs/practices in the \\
& workplace? \\
& Q60. Pay all or part of employee's costs for health club \\
membership or fitness or wellness programs? & Q79. Activities to relieve stress and promote fun? \\
Q62. Promote any sustainable or "green" practices? & Q62. Describe up to 3 sustainable or "green" practices within your \\
Sustainability & Qorkplace \\
& Q69. Offer tuition reimbursement? \\
Q70. Offer formal career development/job advancement \\
programs? \\
Q72. Offer programs practices focused on leadership \\
training/development? \\
Q76. Offer formal employee recognition/appreciation programs?
\end{tabular}

Health Insurance. Questions addressing health care benefits were intentionally omitted from the list of CSR indicators. In 2010, the Affordable Care Act (ACA) legislation implemented comprehensive health care reform in the United States. More specifically, the ACA required businesses with 50 or more full-time employees to provide health insurance to their full-time employees or pay a penalty (Small Business Administration, 2015). While the deadline for implementation was delayed to $2015 / 2016$, many employers began working towards the requirements with the launch of the health insurance open marketplace in Fall 2014. As a result, the survey questions on offering healthcare insurance were not included as indicators of CSR activity.

An additional question asked if the organization offered a choice of health care plans. Offering numerous health care options was not a part of the ACA requirements so this question was included in the survey analysis as an indicator of CSR activity. 


\section{Survey Data}

The survey data was received as an excel spreadsheet via email attachment and imported into version 23 of the SPSS statistical software for descriptive and inferential statistical analysis. The data were reviewed and cleaned to ensure consistency in formatting, terminology, and accuracy. The initial data set contained 3,911 records. However, records were systematically removed if they were outside the geographic scope of this study, had invalid data, were duplicates, or had more than 500 employees -- the threshold for a SME. The final data set included responses for 3,005 SMEs.

\section{Data Validation}

During the initial analysis it was discovered that some companies had submitted their information more than once. For example, an accounting company in Dallas, TX submitted survey response for consideration in both the accounting category and the Texas category. Duplicate records were excluded to ensure each company had only one entry in the database.

An additional concern involved companies that had submitted surveys for multiple regions. For example, a staffing company headquartered in Maryland submitted the same survey response six times to be considered for six different locations where they had offices. To prevent over counting, companies that provided the same data for multiple locations were only allowed one entry associated with the geographic region of their headquarters. Companies that submitted multiple surveys with information unique to each location had all locations included in the dataset.

\section{Sample Size}

This study focused on small and medium companies leading to the exclusion of 
the 510 participants with more than 500 employees. The final analysis included data for 3,005 organizations with between 15 and 500 employees located across the United States.

While there is no consensus on the optimal sample size for quantitative research, Fowler (2009) expressed the common sentiment that increasing sample size increases the reliability of the survey estimates. Meyers, et al. (2006) specified that a sample size greater than 500 is "very good" suggesting this sample of 3,005 is more than sufficient for a meaningful analysis.

\section{Missing Data}

Participants were only included in the study if they provided responses to over $50 \%$ of the survey questions. On average, respondents completed $95 \%$ of the survey questions. Questions with the most missing data still had responses from $80 \%$ of survey participants representing over 2,400 data points. Considering all participants provided extensive data it was not considered appropriate to use list-wise deletion. Instead, the analysis used pair-wise deletion to maximize the availability of data on an analysis-byanalysis basis. 


\section{CHAPTER FOUR: RESEARCH FINDINGS}

The purpose of this study was to develop insights on CSR in SMEs in the United States. The three guiding research questions were 1) What activities are the CSR activities of SMEs in the United States? 2) To what extent, if any, do SMEs in the United States participate in these CSR activities? And, 3) What organization characteristics contribute to varying levels of CSR activity in SMEs?

This chapter presents the results of descriptive and inferential analysis conducted on data gathered from the 2014 Best Places to Work survey. This chapter initially focuses on the descriptive statistics of SMEs in the sample. The second section of this chapter presents the findings on activities that constitute CSR for SMEs. Next, this chapter presents the analysis on the extent of SME participation in CSR. Finally, this chapter presents the findings on the organization characteristics that influence levels of CSR activity.

\section{Descriptive Statistics on Survey Participants}

The 80-question online survey captured extensive information about the participating organizations. This section provides detail on the organization characteristics of survey respondents.

\section{Number of Employees}

While this survey was not specifically targeted by organization size, the final sample included data for 3,005 SMEs (500 employees or fewer.) For the total sample, the mean number of employees was 114 with a standard deviation of 104 . The median value of 75 employees was lower than the mean indicating the distribution was asymmetrical with a positive skew. 
One third of respondents, 988 organizations, had 50 or fewer employees. Eightyeight percent of respondents, 2,650 organizations, had 250 or fewer employees. Even though this study opted to analyze SMEs using the U.S. definition of 500 or less employees, half of the respondents had 75 or fewer employees indicating this analysis represents the smaller spectrum of SMEs. Figure 1 demonstrates the distribution of participating organizations by number of employees.

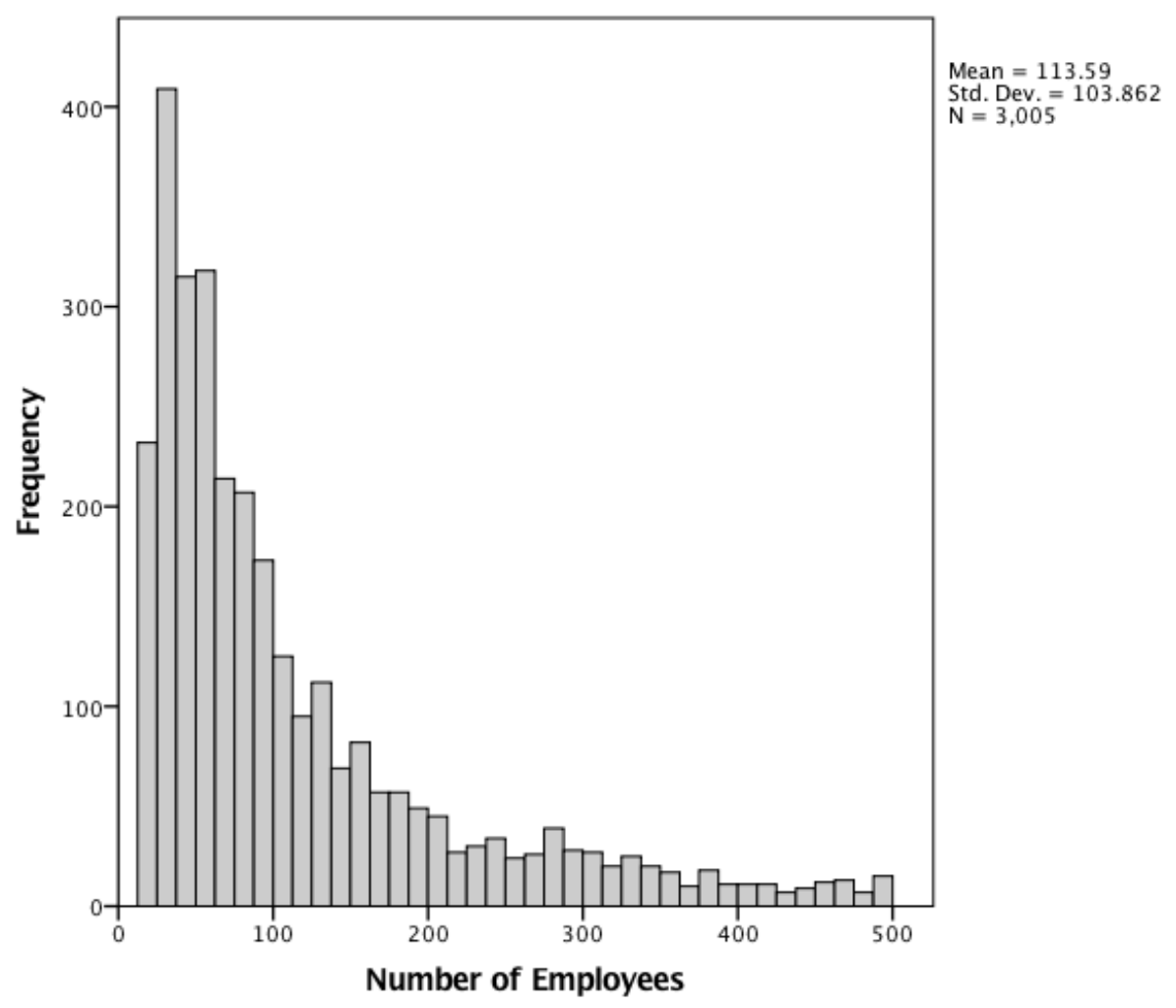

Figure 1. Distribution of participants by number of employees.

\section{Location}

The survey data was constrained by the location of organizations opting to participate in the Best Companies survey programs. However, the final data included participants from all 50 states and the District of Columbia. California was the most heavily represented state with 560 participants followed by Florida with 404 participants. 
Together, California and Florida represented $27 \%$ of the total sample. Eighteen states had fewer than 20 participants. Given the small number of respondents in these states, all participants were assigned additional geographic information. Based on the State provided in the business address, each participant was mapped to a geographic division and region as defined by the U.S. Census. Each of the four geographic regions had sufficient data to warrant analysis at the region level. Table 4 displays the sample representation by geographic division and region.

\section{Table 4}

Geographic Distribution of Respondents (based on U.S. Census Divisions and Regions)

\begin{tabular}{lrr}
\hline Geographic Region & $\begin{array}{r}\text { Number of } \\
\text { Respondents }\end{array}$ & $\begin{array}{r}\text { \% of } \\
\text { Respondents }\end{array}$ \\
\hline Northeast & 786 & 26.2 \\
Division 1: CT, ME, MA, NH, RI, VT & 242 & 8.1 \\
Division 2: NY, NJ, PA & 544 & 18.1 \\
Midwest & 567 & 18.9 \\
Division 3: IL, IN, MI, OH, WI & 485 & 16.1 \\
Division 4: IA, KS, MN, MO, NB, ND, SD & 82 & 2.7 \\
South & 916 & 30.5 \\
Division 5: DE, FL, GA, MD, NC, SC, VA, DC, WV & 586 & 19.5 \\
Division 6: AL, KY, MS, TN & 139 & 4.6 \\
Division 7: AR, LA, OK, TX & 191 & 6.4 \\
West & 736 & 24.5 \\
Division 8: AZ, CO, ID, MT, NV, NM, UT, WY & 201 & 6.7 \\
Division 9: AK, CA, HI, OR, WA & 535 & 17.8 \\
\hline N=3,005 & &
\end{tabular}

Survey respondents were also mapped to the county in their state, with representation from 405 counties. Applying the U.S. Census classification of counties by 
population density (U.S. Census Bureau, 2015) revealed 79\% of participants were located in the highest density metro areas, $16 \%$ of participants were urban, while only $5 \%$ of participants were located in rural counties.

\section{Industry}

Question eight in the survey asked respondents to choose from a list of 28 industries (with an additional open-ended "other" option) that best described their organization. While there were respondents in all 28 industries, the accounting and technology industry were the most populated representing $24 \%$ of the sample. A small number of respondents self-identified their industry as government (4), publishing/printing (14), or restaurant (8). The low number of participants in each these industries led to their being folded together into the "other" industry category.

Auto Dealers. A further investigation into the "other" industry identified a large number of organizations that provided additional detail indicating they were auto dealers. This classification contrasted with the 275 auto dealers that identified with the retail industry. As a result, 343 auto dealers were extracted from the other group, combined with the auto dealers that had self-identified as retail, transportation, or services, and added to a newly created auto dealer industry group with 657 participants.

Industry Representation. In the survey data the most represented industries were auto dealers (657 organizations), accounting firms (452 organizations), other (278 organizations), technology firms (260 organizations), and advertising/public relations/marketing firms (177 organizations.) The smallest industry groups were telecommunications and transportation firms with 19 and 16 organizations respectively. The final distribution of participants by industry is summarized in Table 5 . 
Table 5

Industry Distribution of Respondents

\begin{tabular}{|c|c|c|}
\hline Industry & $\begin{array}{r}\text { Number of } \\
\text { Respondents }\end{array}$ & $\%$ of Respondents \\
\hline Accounting & 452 & 15.0 \\
\hline Advertising/Public Relations/Marketing & 177 & 5.9 \\
\hline Architecture & 58 & 1.9 \\
\hline Auto Dealer & 657 & 21.9 \\
\hline Banking & 80 & 2.7 \\
\hline Construction & 53 & 1.8 \\
\hline Consulting & 65 & 2.2 \\
\hline Distribution & 36 & 1.2 \\
\hline Education & 35 & 1.2 \\
\hline Engineering & 40 & 1.3 \\
\hline Financial Services - Other & 93 & 3.1 \\
\hline Healthcare - Insurance Services & 30 & 1.0 \\
\hline Healthcare - Provider & 72 & 2.4 \\
\hline Insurance (non healthcare) & 56 & 1.9 \\
\hline Legal & 70 & 2.3 \\
\hline Manufacturing & 80 & 2.7 \\
\hline Non-profit - Health and Human Services & 50 & 1.7 \\
\hline Non-profit Other & 87 & 2.9 \\
\hline Other & 278 & 9.3 \\
\hline Real Estate & 45 & 1.5 \\
\hline Retail & 19 & 0.6 \\
\hline Services - Other & 83 & 2.8 \\
\hline Staffing & 61 & 2.0 \\
\hline Technology & 260 & 8.7 \\
\hline Telecommunications & 19 & 0.6 \\
\hline Transportation & 16 & 0.5 \\
\hline Total & 3,005 & 100 \\
\hline
\end{tabular}

BLS Industry Classifications. The large number of some industries and small representation within some other industries called for an additional way to classify the 
participating organizations. As a result, the survey participants were systematically mapped to nine industry groups identified by the Bureau of Labor Statistics (2015.) Table 6 demonstrates the distribution of SME survey participants in BLS industry categories.

Table 6

Distribution of Respondents by Industry Categories (Bureau of Labor Statistics)

\begin{tabular}{lrr}
\hline BLS Industry Category & $\begin{array}{r}\text { Number of } \\
\text { Respondents }\end{array}$ & $\begin{array}{r}\% \text { of } \\
\text { Respondents }\end{array}$ \\
\hline Construction & 55 & 1.8 \\
Education and health services & 215 & 7.2 \\
Financial activities & 321 & 10.7 \\
Information & 26 & 0.9 \\
Leisure and hospitality & 48 & 1.6 \\
Manufacturing & 113 & 3.8 \\
Other services & 90 & 3.0 \\
Professional and business services & 1,357 & 45.2 \\
Trade, transportation, and utilities & 780 & 26.0 \\
\hline
\end{tabular}

The largest number of sample respondents was assigned to the professional and business services industry. According to the BLS, this industry classification encompasses legal services, accounting, architecture, engineering, computer systems, consulting, advertising, and other professional services.

\section{Gender}

An additional theme to explore in the sample was the role of gender. Three variables addressed gender: gender of top executive, gender distribution of the executive team, and gender distribution of employees. The gender distribution analysis revealed the sample is predominantly male in the top executive role ( $85 \%)$, majority male in the 
executive team (69\%), and a slight majority (54\%) of males in the employee workforce. Table 7 displays the gender representation of SMEs in the sample.

Table 7

Gender Characteristics

\begin{tabular}{lrrr}
\hline Variable & \% Male & \% Female & \% Unknown \\
\hline Top executive & 84.9 & 10.5 & 4.6 \\
Executive team (average) & 69.2 & 30.7 & 0.3 \\
Employees (average) & 54.4 & 44.7 & 0.9 \\
\hline
\end{tabular}

$\mathrm{N}=3,005$

\section{Additional Organization Characteristics}

Beyond questions on number of employees, location, industry, and gender, sixteen survey questions addressed additional characteristics of the participating organizations. These questions covered the demographics, leadership, human resources, benefits and policies, communication practices, and outcomes of the organization. The descriptive statistics for these sixteen questions is represented in Table 8. 
Table 8

Descriptive Statistics for Additional Organization Characteristics

\begin{tabular}{|c|c|c|c|c|}
\hline $\begin{array}{l}\text { Characteristic } \\
\text { Grouping }\end{array}$ & Organization Characteristic & $\begin{array}{l}\text { Mean } \\
\text { Value }\end{array}$ & $\begin{array}{c}\text { Median } \\
\text { Value }\end{array}$ & $\begin{array}{l}\text { Mode } \\
\text { Value }\end{array}$ \\
\hline Leadership & Tenure top executive (years) & 13.15 & 11.00 & 14.00 \\
\hline \multirow{3}{*}{$\begin{array}{l}\text { Human } \\
\text { Resources }\end{array}$} & HR staff have HR certifications & $56 \%$ & $100 \%$ & $100 \%$ \\
\hline & Number HR certifications (1 - 9) & 0.99 & 1.00 & 0.00 \\
\hline & HR to employee ratio & 1.85 & 1.35 & 0.00 \\
\hline \multirow[t]{3}{*}{ Benefits/Policies } & Hours to be full-time & 34.17 & 31.00 & 30.00 \\
\hline & Number paid holidays per year & 8.30 & 8.00 & 6.00 \\
\hline & Have uniform dress code & $9 \%$ & $0 \%$ & $0 \%$ \\
\hline \multirow[t]{6}{*}{ Outcomes } & $\begin{array}{l}\text { Average annual salary exempt } \\
\text { employees }\end{array}$ & $\$ 86,945$ & $\$ 80,000$ & $\$ 80,000$ \\
\hline & $\begin{array}{l}\text { Average annual salary non-exempt } \\
\text { employees }\end{array}$ & $\$ 40,581$ & $\$ 36,623$ & $\$ 36,000$ \\
\hline & $\begin{array}{l}\text { Difference between average exempt } \\
\text { and non-exempt employees salary }\end{array}$ & $80 \%$ & $55 \%$ & $50 \%$ \\
\hline & Yes, create new jobs & $88 \%$ & $100 \%$ & $100 \%$ \\
\hline & $\%$ voluntary turnover & $16 \%$ & $10 \%$ & $0 \%$ \\
\hline & $\%$ involuntary separated & $3 \%$ & $0 \%$ & $0 \%$ \\
\hline \multirow[t]{3}{*}{ Communication } & Have Twitter handle & $14 \%$ & $0 \%$ & $0 \%$ \\
\hline & Have social media policy & $88 \%$ & $100 \%$ & $100 \%$ \\
\hline & $\begin{array}{l}\text { Frequency executive led employee } \\
\text { meetings }(6=\text { monthly, } 5=\text { quarterly, } \\
4=\text { bi-annually, } 3=\text { annually, } 2=\text { less } \\
\text { than once a year, } 0=\text { never })\end{array}$ & 5.03 & 5.0 & 6.0 \\
\hline
\end{tabular}

\section{Relationship Between Size And Organization Characteristics}

This study emphasized the role of size (number of employees) suggesting it relevant to measure the strength of the relationship between size and the other organization characteristics. A correlation matrix demonstrated that number of employees 
had a statistically significant and positive relationship with the percent of female employees, the presence and number of HR certifications, the number of paid holidays a year, a uniform dress code, average annual salaries, having a twitter handle, and having a formal policy on social media. Other organization characteristics had a statistically significant but negative relationship with number of employees; tenure of the highest executive, ratio of HR staff to employees, hours to be considered a full-time employee, and the frequency of executive-led employee meetings.

The absolute value of the correlations ranged from a low of 0.05 to a high of 0.30 . Correlations need to be above 0.20 to be indicative of a relationship suggesting only the two variables addressing HR certifications had a significant relationship to number of employees. Table 9 displays the significant correlations between select organization characteristics and number of employees. 
Table 9

Significant Correlations For Number of Employees and Organization Characteristics

\begin{tabular}{lrr}
\hline Organization Characteristic & $\begin{array}{r}\text { Correlation to } \\
\text { Number of } \\
\text { Employees }\end{array}$ & $\begin{array}{c}\text { Significance } \\
\text { Number HR certifications }\end{array}$ \\
Yes, HR certification & 0.34 & .00 \\
Female employee \% & 0.23 & .00 \\
Uniform dress code & 0.11 & .00 \\
Yes, social media policy & 0.10 & .00 \\
Number paid holidays per year & 0.06 & .00 \\
Average annual salary, exempt employee & 0.05 & .01 \\
Yes, twitter handle & 0.05 & .00 \\
Tenure highest executive & -0.07 & .00 \\
HR to employee ratio & -0.14 & .00 \\
Frequency executive employee meetings & -0.16 & .00 \\
\hline
\end{tabular}

\section{Organization Characteristic Variables}

The 80-question survey provided extensive data on participating organizations.

However, an analysis with so many variables can be difficult to interpret. Therefore, this study opted to conduct factor analysis - a statistical data reduction technique to summarize and synthesize the relationship between variables (Meyers, Gamst \& Guarino, 2006). Factor analysis is only applicable for large samples and this sample of 3,005

SMEs was considered an excellent size. The intent of factor analysis in this study was to identify a reduced number of variables that explained the majority of variance in participating SMEs. 


\section{Selecting Variables}

A review of the survey data found twenty-two variables were potentially relevant organization characteristics. While the literature suggested number of employees, location, and industry were central to this analysis, the remaining organization characteristics were subjected to a factor analysis to determine the optimal variables for inclusion.

Prior to conducting the factor analysis, it was necessary to review the sampling adequacy. The dimension reduction tool in SPSS provides the Kaiser-Meyer-Olkin measure of sampling adequacy along with the results of the Bartlett's test of sphericity. Unfortunately, the group of organization characteristic variables had a KMO of 0.53, which fell below the 0.7 recommended for factor analysis. A low KMO suggests there is not sufficient redundancy or duplication in the variables to warrant a reduction of variables. However, the Bartlett's test had a significance of 0.00 indicating there is a high probability of significant relationships between the variables.

Factor Analysis. Despite the low KMO value, the factor analysis results were reviewed for potential insights. The factor analysis used varimax rotation that converged in seven iterations to return eight components with an eigenvalue greater than 1 (the minimum threshold for consideration) (Meyers, Gamst \& Guarino, 2006). Each component represented a construct or potential theme of related variables. The eight components together explained $60 \%$ of the variance between the organizations.

Ideally, a component should have at least three variables load to the component with a coefficient value of 0.7 but a coefficient of 0.3 is considered the minimum acceptable (Meyers, Gamst \& Guarino, 2006). However, none of the eight components 
had three or more variables load at a value equal to or greater than 0.3. In addition, some of the variables that loaded to a component covered unrelated topics suggesting they did not appear to represent a single construct or theme. Finally, three of the nineteen additional organization characteristic variables did not load to any component. The low number of loaded variables along with the disparate content of variables that loaded to a component did not provide clear guidance to eliminate variables from this analysis. As a result, the factor analysis did not reduce the number of variables and all 22 organization characteristics were retained for future analysis.

\section{Research Question One: CSR Activities}

Using the CSR literature as guidance, thirty-three survey questions representing 50 activities were identified as CSR. All 50 variables were analyzed to identify the most relevant indicators of CSR activity for this sample.

\section{Factor Analysis}

This survey had not been previously studied in the context of CSR activity suggesting it appropriate to analyze which variables best captured the variation in level of CSR activity in the sample.

Before conducting this factor analysis it was necessary to determine the adequacy of the sample with the KMO score and Bartlett's test for sphericity. The KMO measure of this sample was 0.85 , above the 0.70 value recommended as a threshold for a factor analysis. In addition, the Bartlett's test of sphericity score was significant at the 0.00 level further validating the use of factor analysis. As a result, the factor analysis could proceed with all 50 variables of CSR activity.

The initial factor analysis used varimax rotation, converging at 12 iterations, to 
return 16 components with an eigenvalue greater than one. These 16 components explained $54 \%$ of the total variance in CSR activities among the participating organizations. A scree plot of the factor analysis results demonstrates the high eigenvalue of the first component (6.71) with diminishing values for components two through 16, beyond which the eigenvalues dropped below the required 1.0 value. Figure 2 presents the scree plot of eigenvalues.

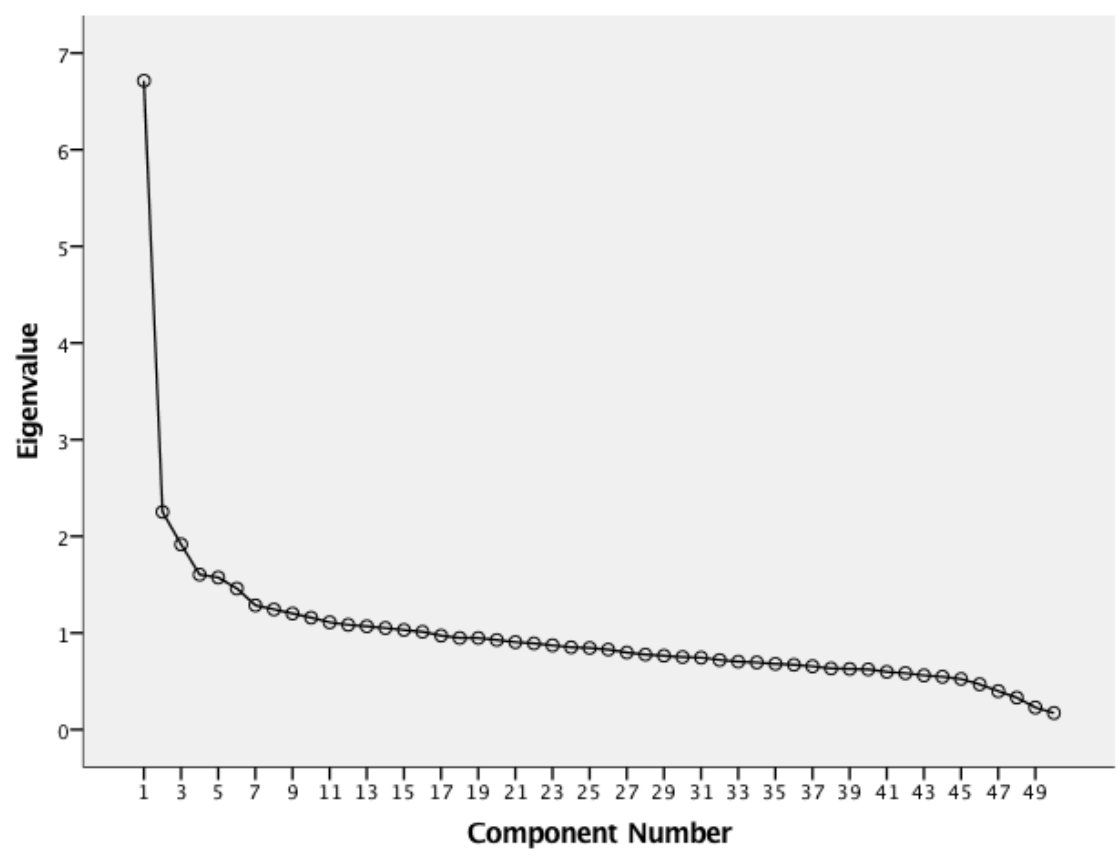

Figure 2. Scree plot of eigenvalues for factor analysis on 50 CSR activities. For each component, variables were considered loaded if they had a coefficient value greater than 0.3 (Meyers, Gamst \& Guarino, 2006). Twelve variables did not load to any component above 0.3 . However, a qualitative review of these variables identified two that appeared to be relevant indicators of CSR activity. These two variables were 1) offer employees paid time off for community service activities/volunteer work and 2) offer support of leadership roles within volunteer organizations outside of your 
organization. While both variables loaded to the same component at a value of 0.27 , the qualitative assessment of their relevance to CSR and the literature (Oplhert, 2015) justified retention for future analysis. The remaining ten variables that loaded at less than 0.3 were excluded from future analysis. Table 10 lists the CSR activities excluded from future analysis following the first round of factor analysis.

Table 10

CSR Activities Excluded After First Factor Analysis on All CSR Variables

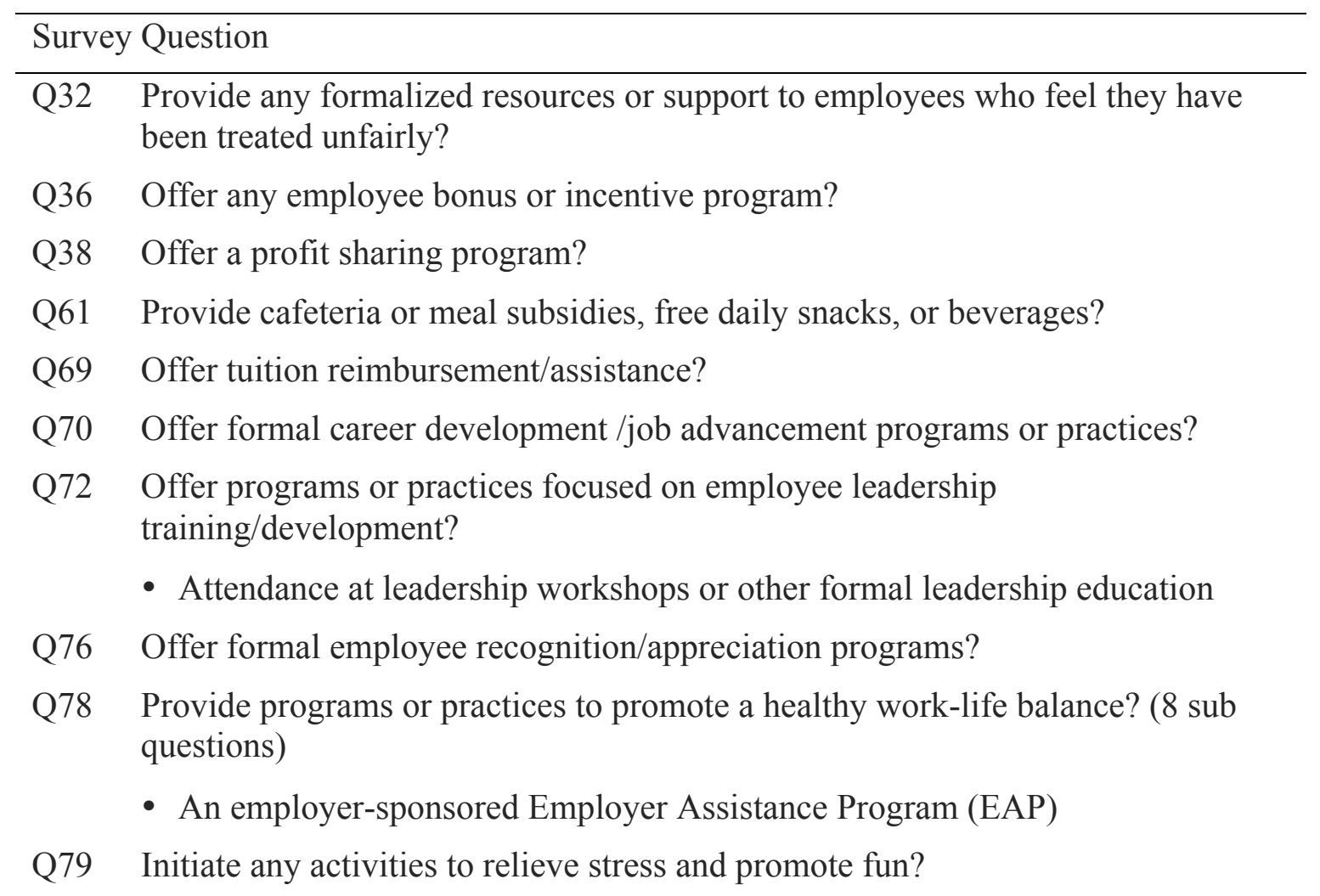

With the reduced number of variables the sample now had a KMO of 0.82 that still exceeded the 0.7 recommendation. The resulting factor analysis returned 14 components with an eigenvalue greater than one. Using 0.3 as the threshold for loading resulted in three additional variables being dropped from the analysis: offering an 
employee stock ownership program (ESOP), matching employee retirement savings, and offering free/discounted tickets to family entertainment or sporting events. Factor analyses were repeatedly run eliminating the variables that didn't load from the previous factor analysis. Each additional round of factor analysis returned fewer components and loaded variables. After four iterative rounds of factor analysis, 22 variables remained with a KMO of .82 and a Bartlett's of 0.0. This latest factor analysis had all 22 variables load to at least one of seven components. Table 11 includes the final factor analysis results for 22 CSR activities. 
Table 11

Final Factor Analysis Results for CSR Activity Variables

\begin{tabular}{|c|c|c|c|c|c|c|c|}
\hline \multirow[b]{2}{*}{ CSR Activity } & \multicolumn{6}{|c|}{ Component } & \multirow[b]{2}{*}{7} \\
\hline & 1 & 2 & 3 & 4 & 5 & 6 & \\
\hline $\begin{array}{l}\text { Actively recruit/retain varying ethnic and } \\
\text { cultural background? }\end{array}$ & .69 & & & & & & \\
\hline $\begin{array}{l}\text { Actively recruit/retain members of } \\
\text { disabled community? }\end{array}$ & .83 & & & & & & \\
\hline Actively recruit/retain aging workforce? & .82 & & & & & & \\
\hline Offer formal diversity training? & .54 & & & & & & \\
\hline $\begin{array}{l}\text { Offer productivity or time management } \\
\text { workshops, seminars or classes? }\end{array}$ & & .78 & & & & & \\
\hline $\begin{array}{l}\text { Offer on-site personal development and/or } \\
\text { stress management workshops, seminars } \\
\text { or classes? }\end{array}$ & & .74 & & & & & \\
\hline $\begin{array}{l}\text { Offer financial education workshops, } \\
\text { seminars or classes? }\end{array}$ & & .65 & & & & & \\
\hline Support community service initiatives? & & & .92 & & & & \\
\hline $\begin{array}{l}\text { Number of community support initiatives } \\
(0-3)\end{array}$ & & & .89 & & & & \\
\hline $\begin{array}{l}\text { Offer additional PTO for community } \\
\text { service/volunteer work? }\end{array}$ & & .38 & .31 & & & & \\
\hline $\begin{array}{l}\text { Support leadership roles within volunteer } \\
\text { organizations? }\end{array}$ & & .49 & .30 & & & & \\
\hline $\begin{array}{l}\text { Provide facilities to promote exercise and } \\
\text { fitness? }\end{array}$ & & & & .71 & & & \\
\hline $\begin{array}{l}\text { Provide fitness and/or wellness programs } \\
\text { within the workplace? }\end{array}$ & & & & .60 & & & \\
\hline Pay all or part of health club membership? & & & & .66 & & & \\
\hline Promote sustainable practices? & & & & & .89 & & \\
\hline Number of sustainable practices $(0-3)$ & & & & & .85 & & \\
\hline Offer telecommuting? & & & & & & .77 & \\
\hline Offer job sharing? & & & & & & .64 & \\
\hline $\begin{array}{l}\text { Offer flexible hours or a compressed } \\
\text { workweek? }\end{array}$ & & & & & & .80 & \\
\hline Provide adoption assistance? & & & & & & & .65 \\
\hline Provide back-up childcare or elder care? & & & & & & & .67 \\
\hline Sponsor eldercare assistance? & & & & & & & .67 \\
\hline
\end{tabular}


While all the CSR variables in the final factor analysis appeared to be relevant indicators of CSR activity, there were other variables that were unexpectedly omitted. Specifically, organization practices around paternity leave, tuition reimbursement, domestic partner benefits, mentoring programs, employee recognition, and flexible hours to accommodate family events were not included in the final CSR activities. While the literature suggests these practices are still valid CSR activities, the factor analysis results didn't statistically warrant their inclusion in this analysis of SMEs.

\section{Defining CSR Constructs}

The final factor analysis applied statistical tools to identify seven components but defining the conceptual meaning of these components involved some qualitative insight. Applying knowledge of the CSR literature and the survey instrument led to defining the components as constructs that represent the following areas of CSR: diversity, personal development, health and wellness, flexible work arrangements, family support, community service, and sustainability. The first five constructs represented internally focused CSR activities while the community service and sustainability initiatives represented CSR activities external to the organization.

\section{Variables in a CSR Construct}

Ideally, the results of a factor analysis would have variables load to one of the components with a value greater than 0.3 . However, the final factor analysis on CSR activities included two variables that cross-loaded to both the personal development and community constructs. These two variables addressed the organization's practices around offering employees paid time off for community service/volunteer work and supporting 
employees in leadership roles within volunteer organizations. Given there were only two variables in the community service construct and the content of these variables was directly related to community service activities, they were ultimately placed in the community service construct.

A valid construct should have at least three variables load with a value greater than or equal to 0.3 (Meyers, Gamst \& Guarino, 2006). Six of the final seven constructs met this criteria. However, the sustainability construct included only two variables that both loaded above 0.85 . A review of all the CSR variables found the next highest load value was -0.15 and those variables did not appear related to sustainability. A qualitative review of the original survey questions determined there were only two questions with content relevant to sustainability. Considering sustainability is integral to CSR it was decided to retain this two-variable construct in the analysis.

Reliability of Constructs. The constructs were created using both statistical data and qualitative insights suggesting the appropriateness of an additional reliability test. The output of this test, a Cronbach's Alpha value, measures how well a group of variables represents a single construct. The preferred alpha coefficient is greater than 0.7 although an alpha greater than 0.5 is considered adequate. Table 12 presents the reliability test results for each of the seven CSR constructs. 


\section{Table 12}

Reliability of Variables in CSR Constructs (Cronbach's Alpha)

\begin{tabular}{lrr}
\hline CSR Construct & $\begin{array}{r}\text { Number } \\
\text { Variables }\end{array}$ & $\begin{array}{r}\text { Alpha } \\
\text { Coefficient }\end{array}$ \\
\hline Diversity & 4 & .76 \\
Health and wellness & 3 & .58 \\
Personal development & 3 & .73 \\
Flexible work arrangements & 3 & .61 \\
Family support & 3 & .47 \\
Community service & 4 & .62 \\
Sustainability & 2 & .61 \\
\hline
\end{tabular}

One CSR construct, family support, did not meet the minimum alpha coefficient criteria. This construct had an internal reliability alpha of 0.47 suggesting the three variables may not reliably measure family support. The three variables were the organization's offering of adoption assistance, back-up childcare assistance, and eldercare support. These CSR activities also had low participation among SMEs in this sample. Only $13 \%$ of SMEs offered adoption assistance while 3\% of SMES offered back up childcare, and $6 \%$ offered eldercare assistance. Alpha coefficients are influenced by intercorrelations and these three variables had significant but low correlations ranging from 0.08 to 0.24 . Despite the lower alpha values, the relevance of these variables to internal CSR and their perceived fit with the family support construct warranted their continued inclusion in the analysis.

The community service construct, with four variables, had an adequate Cronbach's Alpha coefficient of 0.62. However, the analysis showed that the alpha 
coefficient of the construct would have decreased to 0.60 and 0.57 without the two questions that were added at the discretion of the researcher suggesting their inclusion was beneficial.

\section{Resource Requirement}

The 22 CSR activities identified represented seven areas of CSR (diversity, health and wellness, personal development, family support, flexible work arrangements, community service, and sustainability) that corresponded to internal or external CSR. However, these CSR activities could also be classified by their resource requirement. McWilliams and Siegel (2011) referenced resource-based theory when noting that organizations employ capital, materials and services, and labor in their CSR actions. For this study, CSR activities that required organizations to use or spend capital or materials were labeled capital intensive. CSR activities that were most dependent on the services and labor of employees were labeled human resource intensive. Activities that did not require significant capital or human resources were labeled not resource intensive. Most activities required some combination of capital and human resources but were identified by the most prominent resource requirement. The 22 CSR activities in this study were predominantly capital intensive but there were CSR activities in all levels of resource requirement. Table 13 presents the classification of CSR activities by the predominant resource requirement. 
Table 13

Resource Requirement of CSR Activities

\begin{tabular}{|c|c|c|c|}
\hline \multirow[b]{2}{*}{ CSR Activity } & \multicolumn{3}{|c|}{ Predominant Resource Required } \\
\hline & Capital & Human & Neither \\
\hline Recruit for diversity & & $\checkmark$ & \\
\hline Recruit disabled & & $\checkmark$ & \\
\hline Recruit aging & & $\checkmark$ & \\
\hline Offer formal diversity training & & $\checkmark$ & \\
\hline $\begin{array}{l}\text { Offer productivity or time management } \\
\text { workshops, seminars or classes }\end{array}$ & $\checkmark$ & & \\
\hline $\begin{array}{l}\text { Offer on-site personal development and/or stress } \\
\text { management workshops, seminars or classes }\end{array}$ & $\checkmark$ & & \\
\hline $\begin{array}{l}\text { Offer financial education workshops, seminars or } \\
\text { classes }\end{array}$ & $\checkmark$ & & \\
\hline Support community service initiatives & & $\checkmark$ & \\
\hline Offer additional PTO for community service work & & & $\checkmark$ \\
\hline $\begin{array}{l}\text { Support leadership roles within volunteer } \\
\text { organizations }\end{array}$ & & & $\checkmark$ \\
\hline Provide facilities to promote exercise and fitness & $\checkmark$ & & \\
\hline $\begin{array}{l}\text { Provide fitness and/or wellness programs within } \\
\text { the workplace }\end{array}$ & $\checkmark$ & & \\
\hline Pay all or part of health club membership & $\checkmark$ & & \\
\hline Promote sustainable practices & & $\checkmark$ & \\
\hline Offer telecommuting & & & $\checkmark$ \\
\hline Offer job sharing & & & $\checkmark$ \\
\hline Offer flexible hours or a compressed workweek & & & $\checkmark$ \\
\hline Provide adoption assistance & $\checkmark$ & & \\
\hline Provide back-up childcare or elder care & $\checkmark$ & & \\
\hline Sponsor eldercare assistance & $\checkmark$ & & \\
\hline
\end{tabular}




\section{Summary: An Answer to the First Research Question}

The prior findings helped answer the first research question: what are the CSR activities of SMEs in the United States? Over 50 activities covered in the Best Places to Work survey were initially identified as CSR, but not all were statistically relevant for this sample of SMEs. This research applied factor analysis to identify 22 activities that were statistically significant indicators of CSR activity. These 22 activities represented five constructs under internal CSR (diversity, health and wellness, personal development, family support, and flexible work arrangements) and two constructs under external CSR (community initiatives and sustainability) for this analysis of 3,005 SMEs.

\section{Research Question Two: CSR Participation}

The previous pages of this chapter explained which variables were indicators of CSR activity. In order to conduct further statistical analysis on these CSR activities, each of the CSR constructs needed an associated numerical value

\section{Coding Variables}

Twenty of the 22 CSR variables were derived from survey questions with a yes/no response. Coding these questions assigned a one for a "yes" response and zero for a "no." Five constructs - diversity, health and wellness, personal development, flexible work arrangements, and family support -- included only binary questions that returned values of 0 or 1 . As a result, the coded responses to the questions under each construct could be added together to create a single numerical value for the construct. Each construct value was then modified to a 10-point scale to provide a constant frame of reference regardless of the number of variables in a construct. For example, an organization that answered "yes" to two of the questions and "no" to two of the questions 
under the four-question diversity construct would add up to two which would scale to five on a 10-point scale. This process created a numerical value between zero and 10 for the five constructs covering diversity, health and wellness, personal development, flexible work arrangements, and family support.

Two constructs - community service and sustainability - included one question that asked respondents to describe up to three of their practices. When coding these variables, each example received a value of one. If a respondent submitted three examples, they would receive a value of three for this question. There was no subjective judgment applied when assigning a value to the examples. The value given for the examples (between zero and three) was added to the binary values from the yes/no questions to create a total value for the community service construct and sustainability construct. Again, these numbers were modified to a 10-point scale so the community service and sustainability values each ranged from zero to 10 .

It is important to note that only two variables fed the sustainability value. These variables included 1) if the organization promoted any sustainable practices, and 2) a description of up to three sustainable practices. The survey instrument provided examples of sustainable practices but the responses relied on the organization's understanding and self-assessment of their sustainability practices. The other constructs used responses from specific organization practices (Do you offer telecommuting? Do you offer diversity training) to determine if they were participating in CSR activities. This may explain why the sustainability values are higher than the other CSR constructs. The sustainability value still serves as a valid data point for comparison between organizations. However, comparisons of CSR participation in internal and external CSR should take the different 
level of questioning into account.

\section{CSR Indexes}

Five constructs - diversity, health and wellness, personal development, flexible work arrangements, and family support - represented internal CSR as they primarily impacted employee stakeholders. The values for these five constructs were averaged to create a single internal CSR index that ranged from zero to 10.

The two constructs for external CSR - community service and sustainability were averaged to create an external CSR index between zero and 10 . The values for internal CSR and external CSR were averaged to create a total CSR value between zero and 10. Figure 3 demonstrates the relationship between the seven CSR constructs and the internal, external, and total CSR indexes. 
$\underline{\text { CSR Constructs (range of values) } \quad \text { CSR Indexes (range of values) }}$

Diversity $(0-10)$

Health and Wellness $(0-10)$

Personal Development $(0-10)$

Family Support $(0-10)$

Flexible work $(0-10)$

Community Service $(0-10)$

Sustainability $(0-10)$

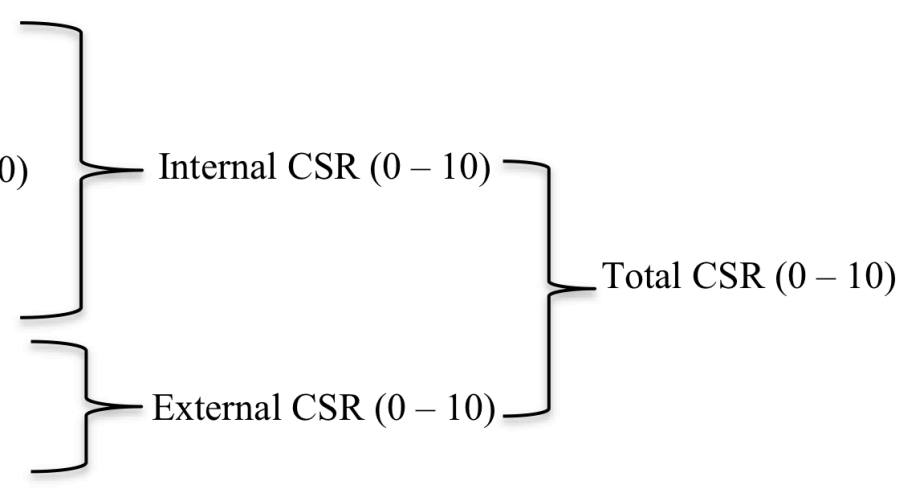

Figure 3. CSR constructs relationship to CSR indexes

\section{Participation in CSR Activity}

The second research question asked: To what extent, if any, do SMEs participate in CSR activities? The prior analysis identified the CSR activities for this sample. The extent of participation in these activities is represented by the values of the CSR indexes. A CSR index value greater than zero indicates the SME had some level of participation in CSR activities.

Over $99 \%$ of the SMEs in the sample participated in at least one of the 22 identified CSR activities. The specific activities that constituted internal CSR had over $96 \%$ of SMEs participating in at least one internal CSR activity. The values for the external CSR showed $97 \%$ of SMEs in the sample participated in at least one external CSR activity.

Given the high participation rates in CSR, this analysis proceeded to focus on the different levels of participation among SMEs rather than focusing on the differences between the organizations that did or did not participate in CSR. 
Total CSR. Only 20 respondents, $0.7 \%$ of the sample, earned a 0 value for total CSR suggesting they did not participate in any CSR activities. At the other end of the spectrum, two respondents, $0.1 \%$ of the sample, had a total CSR index of 10 indicating they participated in all the CSR activities analyzed. The mean value for total CSR among all SMEs was 5.69 with a standard deviation of 2.05. In addition, total CSR values had a negative skew of -0.65 suggesting the distribution is asymmetric with the mean greater than the median value. A histogram displaying the distribution of total CSR index values for SMEs is shown in Figure 4.

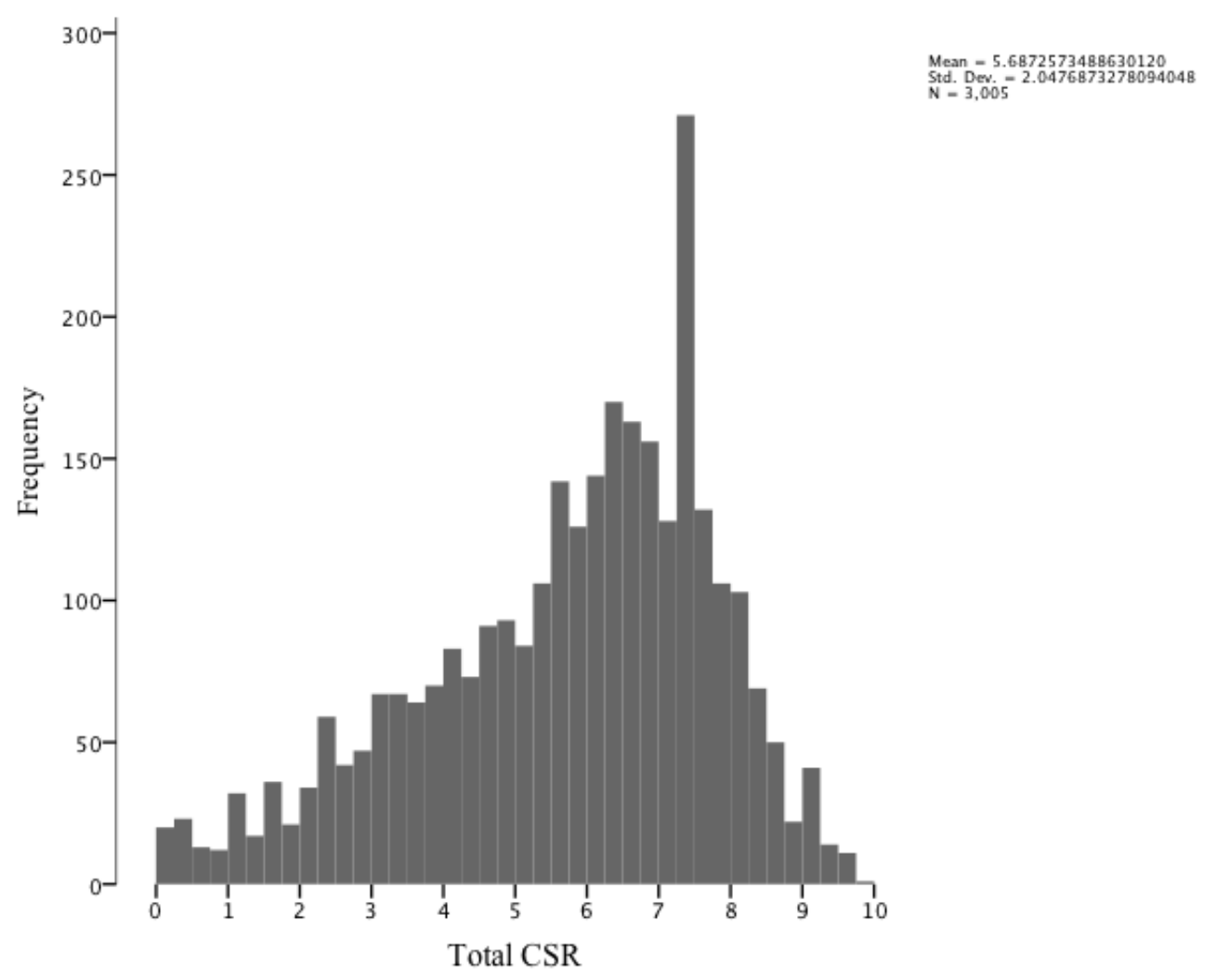

Figure 4. Distribution of total CSR index values (0 to 10)

The total CSR index value was derived from the average of the internal and external CSR values that represent different CSR activities. As a result, it is relevant to review the extent of participation in internal and external CSR separately. 
Internal CSR. The internal CSR value for all SMEs had a mean of 3.65 and skewed positive indicating a longer tail on the right hand of the distribution curve. Among SMEs, 101 (3\%) participants had an internal CSR value of zero, while only two organizations, representing $0.1 \%$ of SMEs, earned an internal CSR value of 10 . Figure 5 displays the distribution of internal CSR values.

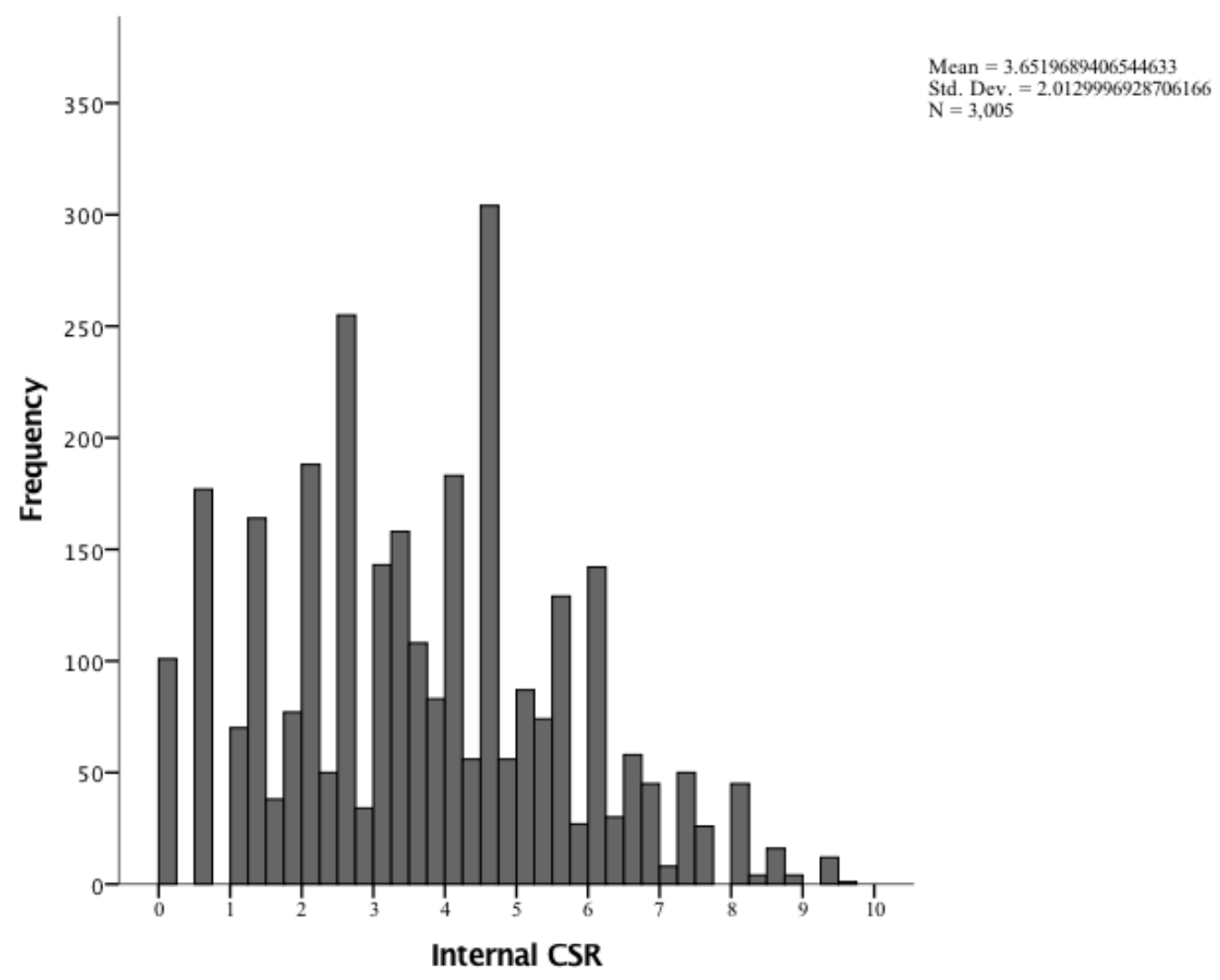

Figure 5. Distribution of internal CSR index values

Internal CSR constructs. Subsumed within the internal CSR Index was additional detail on the SME's level of participation in each of the five constructs for internal CSR. Personal development and health and wellness had the highest levels of participation while activities around family support had the lowest level of participation. The family support construct had the lowest mean value, 0.74 , and the smallest standard deviation, 
0.170 , indicating this construct had the least dispersion in the sample. Table 14 displays the mean, standard deviation, and outlier representation for each of the internal CSR constructs with a range of zero to 10 .

Table 14

Internal CSR Construct Values (0 to 10)

\begin{tabular}{lccccrr}
\hline Internal CSR Construct & Mean & Median & Mode & SD & $\begin{array}{r}\text { \% SMEs } \\
\text { with Index } \\
\text { of 0 }\end{array}$ & $\begin{array}{r}\text { \% SMEs } \\
\text { with Index } \\
\text { of 10 }\end{array}$ \\
\hline Diversity & 3.59 & 2.50 & 0.00 & 3.54 & 36.0 & 12.3 \\
Health and wellness & 5.51 & 6.66 & 6.66 & 3.54 & 18.1 & 27.1 \\
Family support & 0.74 & 0.00 & 0.00 & 1.70 & 81.8 & 0.4 \\
Personal development & 4.89 & 3.33 & 0.00 & 4.02 & 31.0 & 29.3 \\
Flexible work arrangements & 3.53 & 3.33 & 0.00 & 3.28 & 37.3 & 8.2 \\
Total internal CSR & 3.65 & 3.50 & 4.50 & 2.01 & 3.4 & 0.1 \\
\hline
\end{tabular}

Of the five internal CSR constructs, activities under family support were the least implemented. Only 13 of the 3,005 participating SME's participated in all three family support activities and $82 \%$ of SMEs did not participating in any family support activities.

By contrast, health and wellness activities were the most prevalent with a mean of 5.51. Over $27 \%$ of SMEs participated in all three of the health and wellness activities while $18 \%$ of SMEs did not participate in any health and wellness CSR activities.

Sixteen specific activities fed the five internal CSR constructs suggesting a further look at the participation levels for each of the internal CSR activities. The most frequently implemented internal CSR activity was offering fitness and/or wellness programs within the workplace. Over $75 \%$ of SMEs participated in this health and wellness activity. By contrast, the least common CSR activity was providing back-up 
childcare or elder care if an employee's regular caregiver is suddenly not available. Only $4 \%$ of participating SMEs participated in this family support activity. Table 15 provides additional detail on the participation rates for the 16 internal CSR activities. 
Table 15

Participation in Internal CSR Activity (Index $>0$ )

Internal CSR Activities $\quad \%$ SME

Participation

Diversity 64.0

Actively recruit/retain employees of varying ethic and cultural backgrounds

Actively recruit/retain an aging workforce

Actively recruit/retain members of the disabled community

Offer diversity training

Health and wellness

Provide workplace facilities to promote exercise and fitness

53.6

Provide fitness and/or wellness programs or practices within the workplace

fitness or wellness programs

Family support

Provide adoption assistance before or after adoption

17.5

Provide back-up child care or elder care if employee's regular caregiver is suddenly not available

Provide employer-sponsored eldercare assistance for employees with aging family members

Personal development

Provide productivity or time management workshops, seminars, or classes

Provide on-site personal development and/or stress management

49.6 workshops, seminars, or classes

Provide financial education workshops, seminars, or classes

Flexible work arrangements

Offer telecommuting option to employees

Offer job sharing options?

Offer the option to work flexible hours or a compressed work week 
External CSR. The external CSR index reflects the extent of an organization's activities in the community and sustainability. Only $81(2.7 \%)$ organizations earned a zero value (no participation) for external CSR while 968 organizations (32\%) had a value of 10 indicating they participated in all the external CSR activities. Overall, the SMEs in the sample had a mean value of 7.72 and standard deviation of 2.65 for external CSR. Figure 6 provides a histogram chart with the distribution of external CSR indexes demonstrating a negative skew.

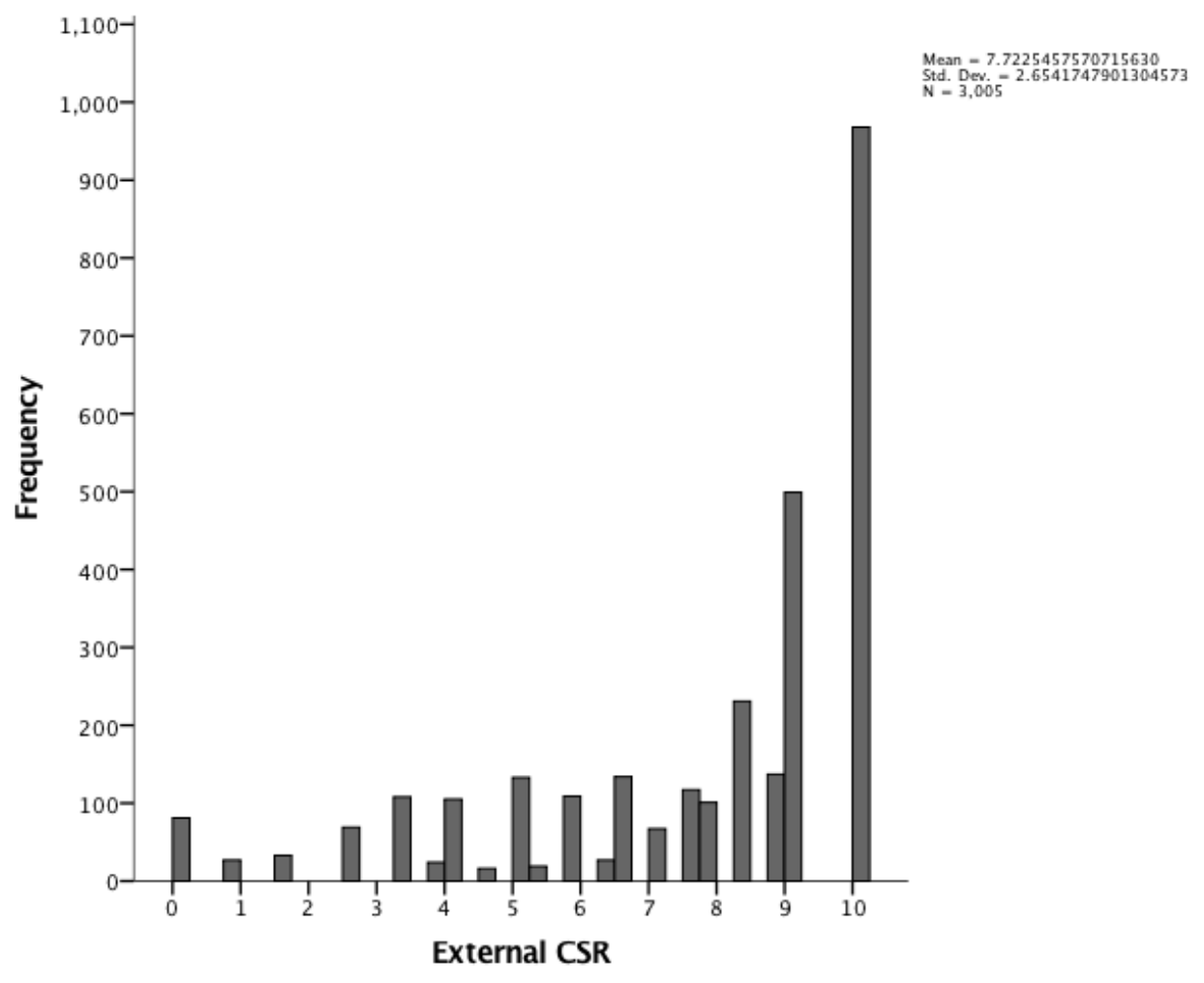

Figure 6. Distribution of external CSR index values

External CSR constructs. The external CSR index encompassed detail on two constructs - community and sustainability. The community index had the highest mean of all constructs, 7.75, and smallest standard deviation, 2.82, while sustainability had a similarly high mean of 7.69 but a larger standard deviation of 3.48. The greater 
dispersion of sustainability values is further reinforced by the high percentage of sustainability values at the lower and upper bounds of zero and 10. Table 16 displays the mean, median, mode, standard deviation, and outlier representation for external CSR constructs.

Table 16

External CSR Construct Values (0 to 10)

\begin{tabular}{lrrrrrr}
\hline External CSR Construct & Mean & Median & Mode & SD & $\begin{array}{r}\text { \% SMEs } \\
\text { with Index } \\
\text { of 0 }\end{array}$ & $\begin{array}{r}\text { \% SMEs } \\
\text { with Index } \\
\text { of 10 }\end{array}$ \\
\hline Community & 7.75 & 8.33 & 10.00 & 2.82 & 6.2 & 41.0 \\
Sustainability & 7.69 & 10.00 & 10.00 & 3.48 & 13.3 & 60.7 \\
External CSR & 7.72 & 8.75 & 10.00 & 2.65 & 2.7 & 32.2 \\
\hline
\end{tabular}

External CSR values were based on six different CSR activities, four concerning community and two addressing sustainability. The most frequently implemented external CSR activity was sponsoring or actively supporting community service initiatives with a $92 \%$ level of participation. The least common external CSR activity was also part of community initiatives: allowing paid time off for employees to participate in community service activities or volunteer work. Table 17 presents the participation rates for the six external CSR activities. 
Table 17

Participation in External CSR Activity

\begin{tabular}{lr}
\hline External CSR Activities & $\begin{array}{r}\text { \% SME } \\
\text { Participation }\end{array}$ \\
\hline Community Initiatives & 93.8 \\
Allow additional paid time off for community service & 59.5 \\
activities/volunteer work? & \\
Sponsor or actively support any community service initiatives & 91.8 \\
Provide examples of community service initiatives & 90.9 \\
Support leadership roles within volunteer organizations & 62.6 \\
Environment Initiatives & 86.7 \\
Promote sustainable or green practices & 87.6 \\
Provide examples of sustainable or green practices & 87.7 \\
\hline
\end{tabular}

The two constructs in external CSR - community support and sustainability each contained a variable derived from open-ended questions that asked for up to three examples of the organization's community and sustainability practices.

Community service detail. Over $90 \%(2,708)$ of the SMEs provided detail for at least one community service initiative. Over $78 \%(2,352)$ of the SMEs provided detail for three examples. Some qualitative examples of community service initiatives from the survey responses included sponsoring local Little League, performing pro bono work, hosting food drives, mentoring in local schools, participating in the Susan G. Komen races, and volunteering with United Way. Some of the recurring words included in these examples were donate, campaign, contributions, cancer, school, community, event and volunteer. Figure 7 presents a word cloud representing the most frequently used text provided in the open-ended examples of an organization's community service initiatives. 


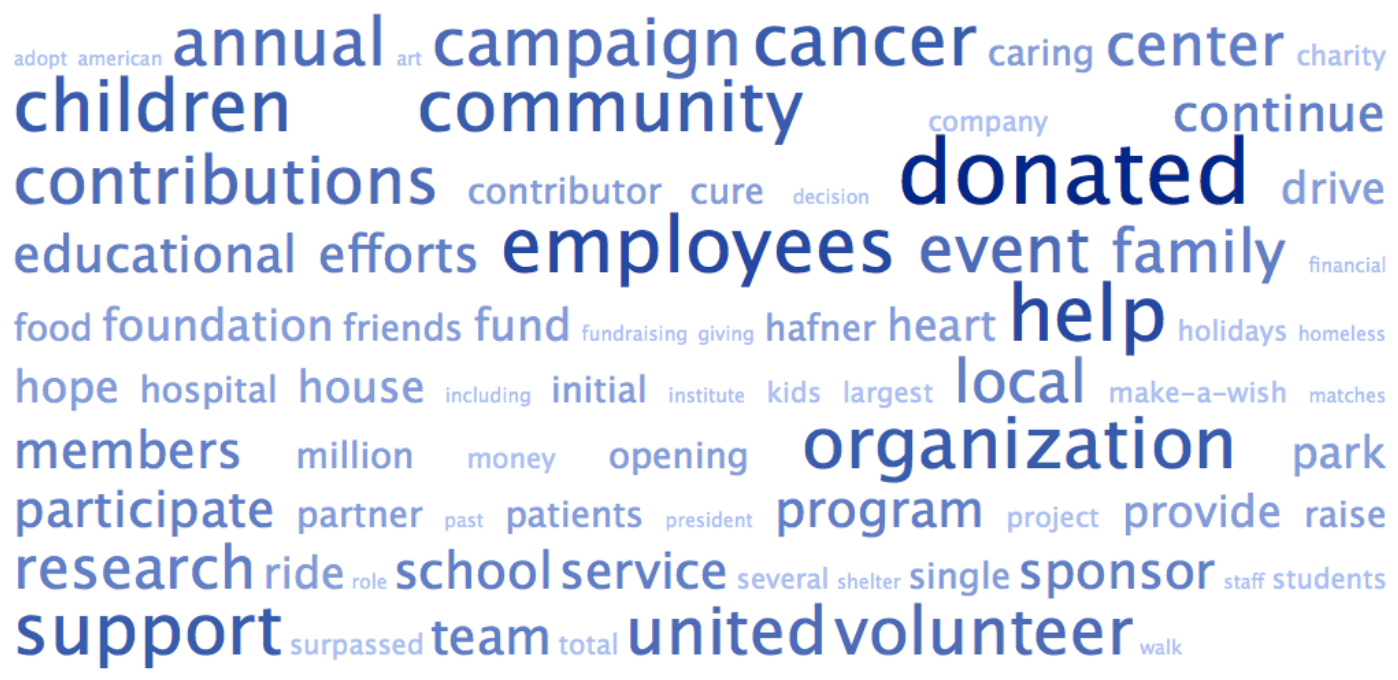

Figure 7. Word cloud for examples of community service initiatives

Sustainability detail. The vast majority, $87 \%$, of participants provided examples of their sustainable or "green" practices. Only 401 organizations, 13\%, did not provide any detail for this question. Examples of sustainable practices included obtaining LEED certification, installing light sensors, using electronic documents, ensuring energy efficient cooling, and providing employees with reusable water bottles. The most frequently cited example of sustainability initiatives was recycling. Among the respondents, 74\% of SME's $(2,214)$ listed some form of recycling as an example of their environmental activities. A visual representation of the survey responses for examples of sustainability initiatives is included in Figure 8. 
adopted aggressive aluminum antifreeze batteries bins bottles building cans cardboard cartridges certified clients collect community computer containers cups dealership disposable documents dont efficient electronic employees encourage energy environment environmental equipment examples facilities files glass green help included initiative ink installed items kitchen leed lighting located management marketing materials metals office oil paper paperless plastic power practices printer printing process products program promote provide recycling reduce room save serice shredding sustainable system throughout tires toner training used utilize Waste water work

Figure 8. Word cloud for examples of sustainability initiatives

The word cloud reiterates the frequency of recycling in the respondent's examples of sustainability initiatives as well as the role of paper, plastic, lighting, energy, and cardboard.

Comparing CSR indexes. While the three CSR index values all ranged between zero and 10, the distributions were different for total, internal, and external CSR values. A summary of the mean and standard deviation of these indexes is provided in Table 18. Table 18 Summary of CSR Index Values (0 to 10)

\begin{tabular}{lcr} 
CSR Index & Mean & SD \\
\hline Total CSR & 5.69 & 2.05 \\
Internal CSR & 3.65 & 2.01 \\
External CSR & 7.72 & 2.65 \\
\hline
\end{tabular}

The mean value for external CSR, 7.72, is more than double the mean of internal CSR, 3.65, indicating a measurable difference in participation rates for the different areas of CSR. The smaller standard deviation for internal CSR suggests organizations are more 
tightly clustered around the mean value. External CSR has the largest standard deviation indicating there is a wider distribution of values.

Resource Requirement. The CSR literature finds a frequently cited impediment to participating in CSR is the requirement of resources - both human and capital. Indeed, some CSR activities are resource intensive while others require only a minimal commitment of resources. Each of the 22 CSR activities in this study were evaluated for their resource commitment and categorized by their predominant resource requirement: human, capital, or neither, irrespective of whether they were internally or externally focused. These categories are not mutually exclusive as CSR activities likely involve some amount of all resources. However, the resource label represents the most dominant of the resource requirements.

Nine CSR activities were labeled capital intensive, six activities were considered human resource intensive, and five of the CSR activities were considered not resource intensive. Participation rates were compared for the levels of resource required. The human resource intensive CSR activities had the highest participation rate of $97 \%$ of SMEs as compared to the capital intensive CSR activities participation rate of $91 \%$. However, the five CSR activities that were considered not resource intensive had the lowest SME participation rate of $89 \%$. Table 19 shows the participation rate for CSR activities grouped by resource requirement. 
Table 19

Participation by CSR Resource Intensity

\begin{tabular}{ll}
\hline CSR Activity $\%$ SMEs \\
\hline
\end{tabular}

participating

Human resource intensive

97.3

Actively recruit/retain employees of varying ethnic and cultures

Actively recruit/retain members of the disabled community

Actively recruit/retain an aging workforce

Offer diversity training

Sponsor or actively support community service initiatives

91.8

Promote sustainable or green initiatives

87.6

Capital resource intensive

90.5

Provide workplace facilities to promote exercise and fitness $\quad 53.6$

Provide fitness and/or wellness programs within the workplace $\quad 75.4$

Pay all or part of the employee's health club membership 44.3

$\begin{array}{lc}\text { Provide adoption assistance } & 17.5\end{array}$

$\begin{array}{ll}\text { Provide back-up childcare or eldercare } & 4.5\end{array}$

$\begin{array}{ll}\text { Provide employer-sponsored eldercare } & 7.7\end{array}$

Provide productivity or time management workshops, seminars, or $\quad 55.5$ classes

Provide on-site personal development, and/or stress management workshops

Provide financial education workshops, seminars or classes

Allow additional paid time off for community service/volunteer work $\quad 59.5$

Support employees in leadership roles with volunteer organizations $\quad 62.6$

Offer telecommuting options to employees $\quad 44.5$

$\begin{array}{ll}\text { Offer job sharing option } & 13.9\end{array}$

Offer option to work flexible hours or a compressed work week $\quad 51.2$ 


\section{Summary: An Answer to Research Question Two}

The analysis found that more than $99 \%$ of SMEs in the survey participated in some CSR activity as measured by a CSR index greater than zero. However, only two of the 3,005 organizations participated in all 22 of the identified CSR activities.

Internal CSR activities (focused on employees) had a 97\% participation rate among the SMEs in the sample with participation rates for specific activities ranging from a low of $18 \%$ (family support activities) to a high of $82 \%$ (health and wellness activities.) External CSR activities focused outside the organization had a 97\% participation rate.

\section{Research Question Three: CSR Activity and Organization Characteristics}

The third research question guiding this study asked what organization characteristics contribute to varying levels of CSR activity among SMEs. This section presents the analysis on organization characteristics and their relation to total, internal, and external CSR indexes.

\section{Number of Employees}

Organization size, as determined by number of employees, was analyzed to discern any relationship to total CSR, internal CSR, and external CSR.

Total CSR. The smallest organizations (0 to 50 employees) had a mean value for total CSR of 5.39 with a standard deviation of 2.06. The slightly larger organizations with 51 to 100 employees had a higher mean of 5.64 and a smaller standard deviation of 2.02. As a point of reference, the mean total CSR for all SMEs (up to 500 employees) was 5.69. Overall, an increase in the number of employees showed an increase in the mean for total CSR and a smaller standard deviation. Plotting the total CSR index values 
by number of employees demonstrated a positive linear relationship between these two variables. Figure 9 presents the scatter plot of the relationship between number of employees and total CSR for all SMEs.

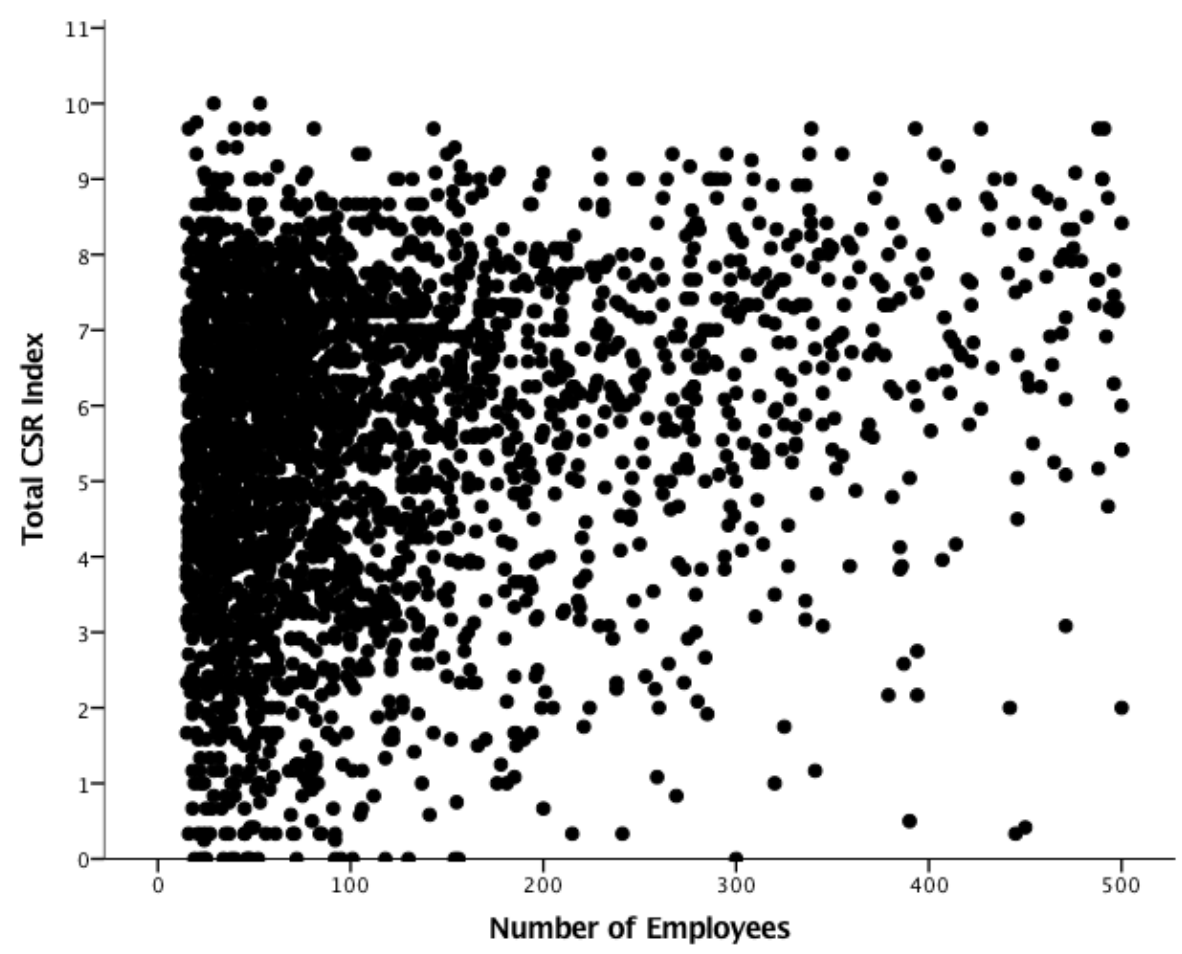

Figure 9. Scatter plot for number of employees and total CSR.

Internal CSR. The sample mean for internal CSR was 3.65 but organizations

with 50 or fewer employees had a lower mean value of 3.28 for internal CSR while organizations with more than 250 employees had a higher mean value of 4.70 for internal CSR. Despite the suggestion of a linear relationship, the graphical representation of internal CSR values demonstrated that internal CSR has only a slightly positive relationship with the number of employees in the organization. Figure 10 presents the scatter plot showing the relationship between internal CSR and number of employees. 


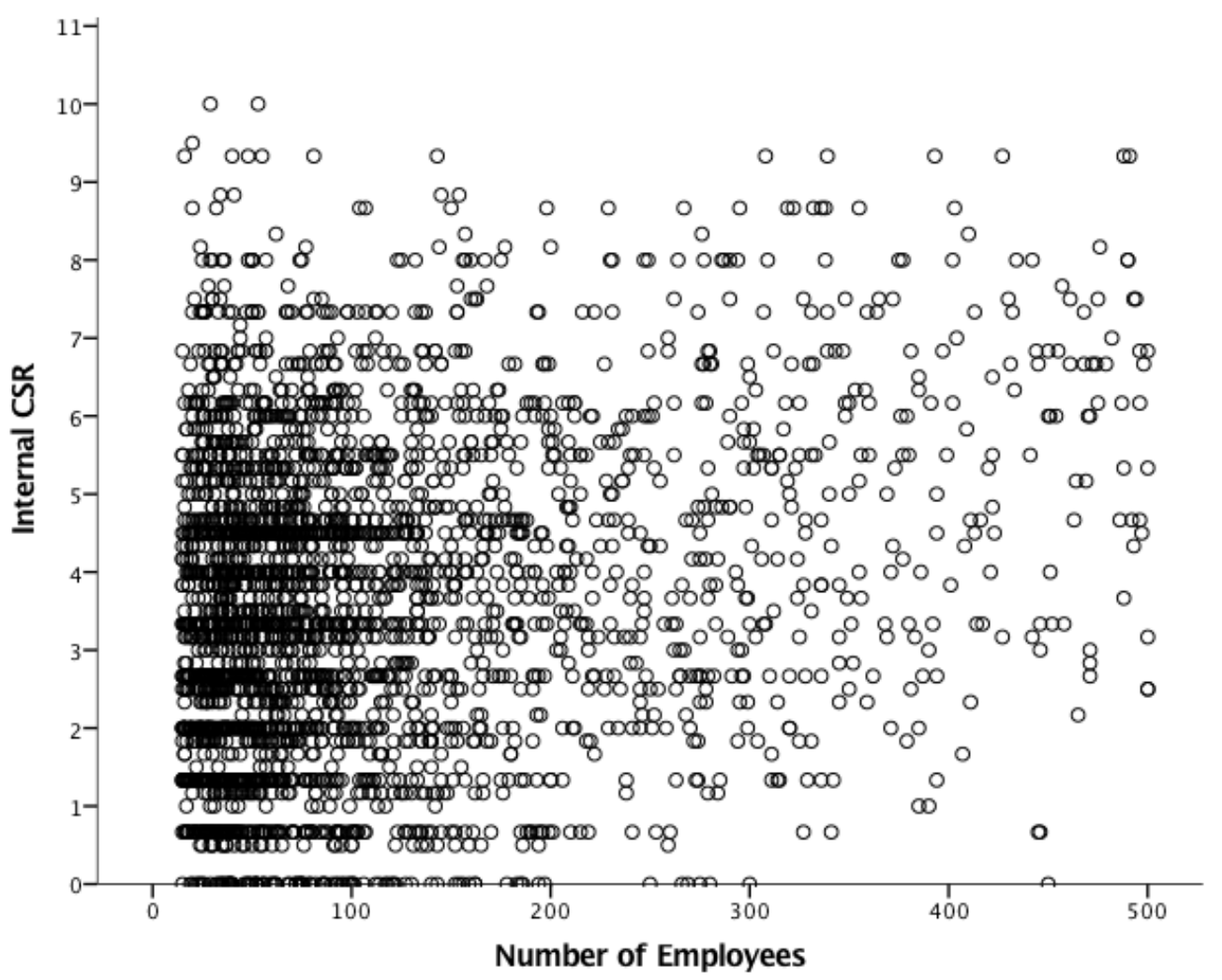

Figure 10. Scatter plot of internal CSR and number of employees.

External CSR. For external CSR, the overall sample mean was 7.72. However, organizations with less than 50 employees had a lower mean value of 7.49 for external CSR while SMEs with more than 250 employees had a higher mean of 8.23 for external CSR. While external CSR values increased with more employees, this relationship was also examined graphically. While the graph suggests there is no linear relationship, it also shows a slight positive relationship as organizations with more employees had less representation in the lowest external CSR values. Figure 11 displays the scatter plot for external CSR and number of employees 


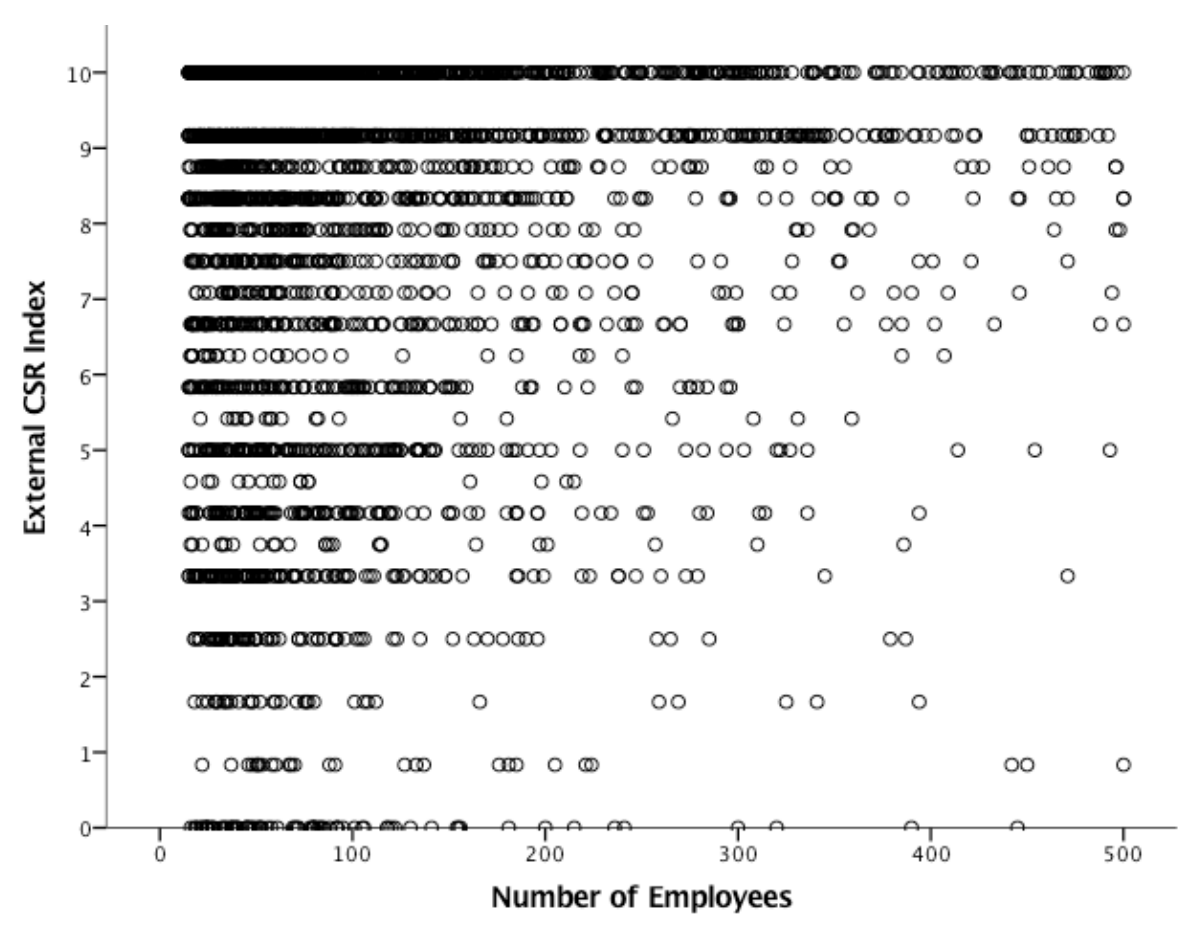

Figure 11. Scatter plot for external CSR and number of employees.

Resource intense CSR. By nature of their SME status, small and medium

organizations inherently have less resources available to conduct business activities. As a result, SME participation in CSR activities with different resource requirements was analyzed considering organization size.

Organizations with less than 50 employees had the lowest level of participation, $24 \%$, in capital intensive CSR activities compared to a $51 \%$ participation rate for SMEs with more than 250 employees. Similarly, organizations with fewer than 50 employees had a lower participation rate, $84 \%$, in human resource intensive CSR activities while organizations with more than 250 employees has a $94 \%$ participation rate in human resource intensive CSR. SMEs of all size had a similarly high level of participation in CSR activities that were not resource intensive. 


\section{Geographic Region}

The SMEs in this study were also analyzed for their level of CSR activity based on different geographic regions. The total CSR index ranged from a low of 5.41 for the Western region to a high of 6.08 for the Midwest region. However, the standard deviation of the Western region was the highest of all regions at 2.14 indicating the respondents in this region had a greater dispersion of values.

Even though the sample size was large for each region, the difference in means was analyzed for significance with an independent samples t-test. Independent samples ttests are used to compare the means of two groups. For this analysis, the mean of each region was compared to the mean of all other regions combined resulting in four different t-tests. The t-tests showed the difference in means for the CSR indexes is only significant for the Midwest and West. The difference in the mean values of the CSR indexes for other geographic regions cannot be attributed to the region of the participating organization.

Table 20 displays the mean and significance of the difference in means for the three CSR indexes by geographic region. 
Table 20

Summary of CSR Activity by Geographic Region

\begin{tabular}{lccccccr}
\hline \multirow{2}{*}{ Geographic Region } & \multicolumn{2}{c}{ Total CSR } & \multicolumn{2}{c}{ Internal CSR } & \multicolumn{2}{c}{ External CSR } \\
Midwest $(\mathrm{n}=567)$ & Mean & Sig. & Mean & Sig. & Mean & Sig. \\
Northeast $(\mathrm{n}=786)$ & 6.08 & $\mathbf{. 0 0}$ & 3.99 & $\mathbf{. 0 0}$ & 8.16 & $\mathbf{. 0 0}$ \\
South $(\mathrm{n}=916)$ & 5.60 & .16 & 3.58 & .25 & 7.62 & .20 \\
West $(\mathrm{n}=736)$ & 5.75 & .28 & 3.63 & .63 & 7.87 & .04 \\
Total $(\mathrm{n}=3,005)$ & 5.41 & $\mathbf{. 0 0}$ & 3.50 & $\mathbf{. 0 2}$ & 7.31 & $\mathbf{. 0 0}$ \\
\hline
\end{tabular}

Note: significant values in boldface.

State. A further analysis by geographic location looked at the CSR index values by state. While not all states had a sufficient sample size, the seven states with more than 100 participants were reviewed. California (West) and New York (Northeast) had the lowest total CSR index at 5.25 while Indiana (Midwest) had the highest total CSR index at 6.22. California also had the lowest internal CSR index, 3.41, while New York had the lowest external CSR value of 7.08. Table 21 includes the CSR index details for ten select states.

Table 21

Summary of CSR Activity for Most Represented States

\begin{tabular}{lrrrrrrrr}
\hline & \multicolumn{2}{c}{ Total CSR } & & \multicolumn{2}{c}{ Internal CSR } & & \multicolumn{2}{c}{ External CSR } \\
States/Region & Mean & SD & Mean & SD & & Mean & SD \\
\hline California/West $(\mathrm{n}=477)$ & 5.25 & 2.20 & 3.39 & 1.97 & & 7.11 & 2.94 \\
Florida/South $(\mathrm{n}=374)$ & 6.21 & 1.85 & 3.96 & 1.76 & 8.45 & 2.38 \\
Indiana/Midwest (n=131) & 6.22 & 1.88 & 4.11 & 2.13 & 8.32 & 2.24 \\
Michigan/Midwest (n=121) & 5.91 & 1.95 & 3.72 & 1.99 & 8.10 & 2.42 \\
New Jersey/Northeast $(\mathrm{n}=141)$ & 5.57 & 1.90 & 3.53 & 1.96 & 7.61 & 2.44 \\
\hline
\end{tabular}




\begin{tabular}{lllllll}
\hline New York/Northeast $(\mathrm{n}=214)$ & 5.25 & 1.98 & 3.41 & 1.78 & 7.08 & 2.76 \\
Pennsylvania/Northeast $(\mathrm{n}=189)$ & 5.58 & 2.13 & 3.48 & 2.02 & 7.68 & 2.83 \\
Total $(\mathrm{n}=3,005)$ & 5.68 & 2.05 & 3.65 & 2.01 & 7.72 & 2.65 \\
\hline
\end{tabular}

Population density. The CSR of SMEs was also evaluated by the population density of the organization's location. The mean values for total CSR ranged from a low of 5.63 for the most densely populated metro areas to a high of 6.01 for rural areas with urban areas in the mid-range at 5.87. Independent sample t-tests found the difference in means by population density was significant for total CSR and external CSR but not internal CSR. Table 22 presents the CSR index values by population density.

Table 22

CSR Index Values by Population Density

\begin{tabular}{|c|c|c|c|c|c|c|}
\hline \multirow[b]{2}{*}{ Population Density } & \multicolumn{2}{|c|}{ Total CSR } & \multicolumn{2}{|c|}{ Internal CSR } & \multicolumn{2}{|c|}{ External CSR } \\
\hline & Mean & SD & Mean & SD & Mean & SD \\
\hline Metro areas $(n=2,378)$ & 5.63 & 2.09 & 3.61 & 2.00 & 7.65 & 2.74 \\
\hline Urban areas $(n=474)$ & 5.87 & 1.88 & 3.77 & 2.13 & 7.97 & 2.25 \\
\hline Rural areas $(\mathrm{n}=137)$ & 6.01 & 1.88 & 3.84 & 1.91 & 8.17 & 2.31 \\
\hline Total $(n=3,005)$ & 5.68 & 2.05 & 3.65 & 2.01 & 7.72 & 2.65 \\
\hline
\end{tabular}

The comparative means suggest there might be an inverse relationship between population density and CSR activity. As a result, external CSR activity for community and sustainability was evaluated further as these activities would likely involve the organization's surroundings, which would vary, by population density. At this level of analysis, the trend was consistent where a higher population density had a lower level of 
participation in CSR activities. Table 23 presents the mean and standard deviation values for the external CSR constructs by population density.

Table 23

External CSR Construct Values by Population Density

\begin{tabular}{lrrrrr}
\hline & \multicolumn{2}{c}{ Community } & \multicolumn{2}{c}{ Sustainability } \\
\cline { 2 - 5 } Population Density & Mean & SD & Mean & SD \\
\hline Metro areas $(n=2,378)$ & 7.66 & 2.92 & 7.64 & 3.52 \\
Urban areas $(n=474)$ & 8.10 & 2.39 & 7.84 & 3.31 \\
Rural areas $(n=137)$ & 8.24 & 2.31 & 8.10 & 3.26 \\
Total $(n=3,005)$ & 7.75 & 2.82 & 7.69 & 3.48 \\
\hline
\end{tabular}

\section{Industry}

The CSR literature references the role of industry in CSR activity warranting a review of CSR index values by industry. This analysis initially used the BLS Industry categories but also reviewed some of the self-selected industry classifications from the survey instrument.

The values for total CSR ranged from a low of 4.66 in the information industry to a high of 6.22 in the leisure and hospitality industry. The standard deviation for the leisure and hospitality was on the lower end at 1.89 indicating there was less variation around the mean even though the mean was higher. For internal CSR, the information industry showed the lowest mean value, 3.10, while leisure and hospitality had the highest mean value at 4.15 . The analysis of external CSR revealed the information industry had the lowest value at 6.22 while the leisure and hospitality industry had the highest value of 8.28 . Table 24 provides the CSR index values by BLS Industry. 
Table 24

Summary of CSR Activity by BLS Industry Category

\begin{tabular}{lrrrrrrrr}
\hline & \multicolumn{2}{c}{ Total CSR } & \multicolumn{2}{c}{ Internal CSR } & & \multicolumn{2}{c}{ External CSR } \\
\cline { 2 - 4 } BLS Industry Category & Mean & SD & Mean & SD & & Mean & SD \\
\hline Construction (n=55) & 5.82 & 1.75 & 3.49 & 1.99 & 8.15 & 2.30 \\
Education and Health Services & 5.50 & 2.13 & 4.02 & 2.00 & 6.98 & 2.93 \\
(n=215) & & & & & & & \\
Financial Activities (n=321) & 5.80 & 1.91 & 3.68 & 1.96 & 7.92 & 2.58 \\
Information (n=26) & 4.66 & 2.02 & 3.10 & 1.85 & 6.22 & 2.91 \\
Leisure and Hospitality (n=48) & 6.22 & 1.89 & 4.15 & 2.14 & 8.28 & 2.26 \\
Manufacturing (n=113) & 5.90 & 1.91 & 3.79 & 1.96 & 8.01 & 2.46 \\
Other Services (n=90) & 5.83 & 2.02 & 3.93 & 1.99 & 7.73 & 2.63 \\
Professional and Business & 5.80 & 2.04 & 3.84 & 2.00 & 7.75 & 2.26 \\
Services (n=1,357) & & & & & & \\
Trade, Transportation, and & 5.45 & 2.12 & 3.15 & 1.97 & 7.75 & 2.70 \\
Utilities (n=780) & & & & & & \\
Total (n=3,005) & 5.69 & 2.05 & 3.65 & 2.01 & 7.72 & 2.65 \\
\hline
\end{tabular}


The outlier CSR index values were from industries with a smaller sample size information (26 participants), and leisure and hospitality (48 participants). As a result, the difference in means was subjected to an independent sample t-test. For this analysis, the mean of a BLS industry was compared to the mean of all other industries combined. The results showed not all differences were statistically significant. Only three industries - information, professional and business services, and trade transportation and utilities had a statistically significant difference for total CSR. However, the significance by industry varied when considering internal and external CSR. The education industry was significant for internal and external, but not total CSR. Professional and business services along with trade, transportation, and utilities were significant for total and internal CSR. The information industry was significant for total and external CSR. Although the leisure and hospitality industry had the highest values for total, internal, and external CSR, these values were not statistically different from other industries. Table 25 displays the t-test results by BLS industry. 
Table 25

Difference in Means of CSR Activity by BLS Industry Category

\begin{tabular}{lrrrrrrr}
\hline & \multicolumn{2}{c}{ Total CSR } & \multicolumn{2}{c}{ Internal CSR } & & \multicolumn{2}{c}{ External CSR } \\
BLS Industry Category & Mean & Sig. & Mean & Sig. & Mean & Sig. \\
\hline Construction & 5.82 & .62 & 3.49 & .56 & 8.15 & .23 \\
Education and Health Services & 5.50 & .16 & 4.02 & $\mathbf{. 0 1}$ & 6.98 & $\mathbf{. 0 0}$ \\
Financial Activities & 5.80 & .29 & 3.68 & .79 & 7.92 & .16 \\
Information & 4.66 & .01 & 3.10 & .16 & 6.22 & $\mathbf{. 0 0}$ \\
Leisure and Hospitality & 6.22 & .07 & 4.15 & .08 & 8.28 & .14 \\
Manufacturing & 5.90 & .26 & 3.79 & .46 & 8.01 & .24 \\
Other Services & 5.83 & .51 & 3.93 & .19 & 7.73 & .99 \\
Professional and Business & 5.80 & $\mathbf{. 0 1}$ & 3.84 & $\mathbf{. 0 0}$ & 7.75 & .64 \\
Services & & & & & & \\
Trade, Transportation, and & 5.45 & $\mathbf{. 0 0}$ & 3.15 & $\mathbf{. 0 0}$ & 7.75 & .78 \\
Utilities & & & & & & \\
\hline
\end{tabular}

Note. Significance $<=.01$ are in boldface.

Industry detail. Two of the significant BLS industry categories -- trade, transportation and utilities, and professional and business services -- encompassed over $75 \%$ of the sample warranting a more detailed analysis of the industries within these categories. Accounting alone represented $33 \%$ of the professional and business services category. Over $84 \%$ of the trade, transportation, and utilities industry were auto dealers. Among the 15 industries represented in these two BLS industry categories, total CSR values ranged from a low of 4.69 for transportation (BLS: trade, transportation, and utilities) to a high of 6.36 for accounting (BLS: professional and business services.) Internal CSR by industry detail provided further insight into CSR participation. The retail industry (BLS: trade, transportation, and utilities) had the lowest internal CSR 
index at 2.67 while consulting (BLS: professional and business services) was at the top with an internal CSR index of 4.39 .

Comparing the external CSR indexes across industries revealed transportation had the lowest value at 6.48 while accounting had the highest value at 8.43 . Table 26 displays the mean CSR values for industries within the top two BLS industry categories. 
Table 26

Summary of CSR Activity by BLS Category with Industry Detail

\begin{tabular}{|c|c|c|c|c|c|c|}
\hline \multirow[b]{2}{*}{ Industry } & \multicolumn{2}{|c|}{ Total CSR } & \multicolumn{2}{|c|}{ Internal CSR } & \multicolumn{2}{|c|}{ External CSR } \\
\hline & Mean & SD & Mean & SD & Mean & SD \\
\hline \multicolumn{7}{|l|}{$\begin{array}{l}\text { BLS: Professional and } \\
\text { Business Services }(n=1,345)\end{array}$} \\
\hline Accounting $(n=452)$ & 6.36 & 1.82 & 4.29 & 1.97 & 8.43 & 2.29 \\
\hline $\begin{array}{l}\text { Advertising/Public } \\
\text { Relations ( } \mathrm{n}=177)\end{array}$ & 5.33 & 2.15 & 3.53 & 1.88 & 7.14 & 2.98 \\
\hline Architecture $(\mathrm{n}=58)$ & 6.00 & 1.76 & 3.91 & 1.85 & 8.09 & 2.36 \\
\hline Consulting $(\mathrm{n}=65)$ & 6.22 & 1.89 & 4.36 & 2.11 & 8.08 & 2.21 \\
\hline Engineering $(n=34)$ & 6.01 & 1.52 & 4.10 & 1.66 & 7.93 & 1.79 \\
\hline Legal $(n=70)$ & 5.90 & 2.19 & 3.77 & 2.51 & 8.02 & 2.45 \\
\hline Other $(n=107)$ & 5.63 & 2.06 & 3.66 & 1.91 & 7.60 & 2.63 \\
\hline Services Other $(n=61)$ & 5.45 & 2.01 & 3.39 & 1.84 & 7.51 & 2.69 \\
\hline Staffing $(n=61)$ & 5.69 & 2.12 & 3.74 & 2.20 & 7.64 & 2.48 \\
\hline Technology $(n=260)$ & 5.08 & 2.11 & 3.31 & 1.90 & 6.85 & 2.81 \\
\hline \multicolumn{7}{|l|}{$\begin{array}{l}\text { BLS: Trade, Transportation, } \\
\text { and Utilities }(n=772)\end{array}$} \\
\hline Auto Dealer $(\mathrm{n}=657)$ & 5.49 & 2.16 & 3.16 & 2.01 & 7.82 & 2.72 \\
\hline Distribution $(n=27)$ & 5.23 & 2.04 & 3.23 & 1.94 & 7.24 & 2.71 \\
\hline Other $(n=53)$ & 5.54 & 1.77 & 3.22 & 1.71 & 7.86 & 2.56 \\
\hline Retail $(n=19)$ & 4.70 & 1.53 & 2.67 & 1.56 & 6.73 & 2.19 \\
\hline Transportation $(\mathrm{n}=16)$ & 4.69 & 1.87 & 2.90 & 1.45 & 6.48 & 2.60 \\
\hline
\end{tabular}

Testing the difference in means for this level of industry detail found not all industries were significant. The independent samples t-test compared the mean of one industry against the mean of all other industries combined. Only five industries: accounting, advertising/public relations, consulting, technology, and transportation had 
any significant results. Table 27 displays the statistical significance of the difference in means by industry.

Table 27

Significance of Difference in Means by Industry (from Independent Samples T-Test)

Significance

Total CSR Internal CSR External CSR

Professional and Business Services $(\mathrm{n}=1,345)$

Accounting $(\mathrm{n}=452)$

.00

Advertising/Public Relations ( $\mathrm{n}=177)$

.00

.00

.00

Architecture $(\mathrm{n}=58)$

.43

.02

.00

Consulting $(\mathrm{n}=65)$

.29

Engineering $(\mathrm{n}=34)$

.52

.79

.31

Legal $(\mathrm{n}=70)$

.68

.03

.09

Other $(\mathrm{n}=107)$

.38

.46

.68

Services Other $(n=63)$

.18

.74

.36

Staffing $(\mathrm{n}=61)$

.68

.32

.55

Technology $(n=260)$

.00

.07

.47

.68

.75

Trade, Transportation, and Utilities $(n=772)$

Auto Dealer $(\mathrm{n}=657)$ .21

.69

.09

Distribution $(\mathrm{n}=27)$

.59

.84

.32

Other $(\mathrm{n}=53)$

.74

.79

.75

Retail ( $\mathrm{n}=19)$

.12

.28

.10

Transportation $(\mathrm{n}=32)$

.01

.09

.01

Note. Significance $<=.05$ are in boldface. 
Industry Sector. The industries in the sample could also be recognized as part of the service sector or manufacturing sector. The majority of participants (94\%) were part of the service sector reflective of the national trend where the service sector represents approximately two thirds of U.S. economic activity (U.S. Census, 2012). However, the underrepresentation of manufacturing led to statistically insignificant results. As a result, further analysis comparing CSR between the service and manufacturing sector was not appropriate for this study.

\section{Additional Characteristics}

While size, location, and industry are important organization characteristics, the sample also included detail on additional organization characteristics that were analyzed for relation to CSR activity.

Executive gender. The role of executive gender was analyzed against CSR activity. Organizations with a female top executive had slightly higher total and internal CSR values. Table 28 demonstrates how gender of the top executive related to CSR index values.

Table 28

Summary of CSR Activity by Gender of Top Executive

\begin{tabular}{lrrrrrrrr}
\hline \multirow{2}{*}{ Gender } & \multicolumn{2}{c}{ Total CSR } & & Internal CSR & & \multicolumn{2}{c}{ External CSR } \\
& Mean & SD & & Mean & SD & Mean & SD \\
\hline Male top executive & 5.69 & 2.05 & 3.63 & 2.02 & 7.75 & 2.65 \\
Female top executive & 5.82 & 1.95 & 3.94 & 1.93 & 7.70 & 2.58 \\
\hline $\mathrm{N}=2,867$ & & & & & &
\end{tabular}


The Independent samples t-test revealed that the difference in means was only significant for internal CSR suggesting gender of the executive is not a meaningful indicator of total or external CSR activity.

Other organization characteristics. Questions covering the presence of a twitter handle, professional Human Resources certifications, and the creation of new jobs were also analyzed for different levels of CSR. Having a twitter handle, holding professional Human Resource certifications, and creating new jobs in the most recent fiscal year all returned higher CSR index values. Table 29 displays the total, internal, and external CSR values for these variables.

Table 29

Summary of CSR Activity for Additional Organization Characteristics

\begin{tabular}{|c|c|c|c|c|c|c|}
\hline \multirow[b]{2}{*}{ Organization Characteristics } & \multicolumn{2}{|c|}{ Total CSR } & \multicolumn{2}{|c|}{ Internal CSR } & \multicolumn{2}{|c|}{ External CSR } \\
\hline & Mean & SD & Mean & SD & Mean & SD \\
\hline $\begin{array}{l}\text { HR staff have professional } \\
\text { certifications }(\mathrm{n}=1,677)\end{array}$ & 6.08 & 1.97 & 4.09 & 2.02 & 8.07 & 2.48 \\
\hline $\begin{array}{l}\text { HR staff do not have } \\
\text { professional certifications } \\
(\mathrm{n}=1,327)\end{array}$ & 5.19 & 2.04 & 3.10 & 1.86 & 7.28 & 2.80 \\
\hline $\begin{array}{l}\text { Created new jobs in recent } \\
\text { fiscal year }(n=2,635)\end{array}$ & 5.76 & 2.02 & 3.73 & 2.00 & 7.79 & 2.59 \\
\hline $\begin{array}{l}\text { Did not create new jobs in } \\
\text { fiscal year }(n=366)\end{array}$ & 5.16 & 2.22 & 3.08 & 1.97 & 7.24 & 3.04 \\
\hline $\begin{array}{l}\text { Have a twitter handle } \\
(\mathrm{n}=434)\end{array}$ & 6.04 & 1.96 & 4.08 & 2.01 & 80.1 & 2.46 \\
\hline $\begin{array}{l}\text { Do not have a twitter handle } \\
(\mathrm{n}=2,571)\end{array}$ & 5.63 & 2.06 & 3.58 & 2.01 & 7.67 & 2.68 \\
\hline
\end{tabular}


While the CSR index values varied, it was necessary to test if the difference was statistically significant. The independent samples t-test found all differences significant with $\mathrm{p}<0.02$.

\section{Organization Characteristic Relation to CSR}

The prior analysis demonstrated that SMEs of all sizes, in all locations, and in all industries participated in CSR activities. However, the third research question required a further examination of the relationship between the characteristics of an organization and the level of CSR activity. The first step of this analysis looked at the correlations between organization characteristics and CSR Index values to ascertain the presence and directionality of a relationship. Next, linear regression was used to determine the extent that organization characteristics explained the variation in CSR index values.

Number of Employees. The central question of this study concerned the relationship between the size of an organization, as measured by number of employees, and the organization's level of CSR activity.

Correlation. The correlation variable measured the relationship between an organization's number of employees and CSR indexes. All three CSR indexes were positively and significantly correlated with number of employees (significant at the 0.01 level.) However, the Pearson correlation values of 0.23 for total CSR and 0.29 for internal CSR indicated a weak relationship. The 0.11 correlation for external CSR was considered a negligible, or non-relevant, relationship.

Linear Regression. The relationship between number of employees and total CSR was also measured through a liner regression. Using number of employees as the independent variable and total CSR as the dependent variable, the regression model 
showed that the number of employees predicted only $3 \%$ of the variation in total CSR for SMEs. With a standardized coefficient of .22, the number of employees was statistically significant variable $(p<.01)$ for total CSR.

The number of employees was also analyzed for its relationship with internal and external CSR. The linear regressions showed number of employees explained $6 \%$ of the variance in internal CSR $\left(\mathrm{R}^{2}=.06\right)$ but only $0.6 \%$ of the variation in external CSR. For both regressions, the coefficient for number of employees was positive and statistically significant with $\mathrm{p}<.01$.

Geographic Region. Next, the relationship between the geographic region of the SMEs and their level of CSR activity was reviewed.

Correlation. Three regions, the Midwest. South, and West, showed a correlation with at least one of the CSR indexes. However, the absolute value of the Pearson correlations ranged from 0.04 to 0.09 , all of which were so weak as to be considered negligible. As a result, geographic region was not considered related to CSR index values. Table 30 presents the statistically significant but negligible correlations for region and CSR Indexes. 
Table 30

Significant Correlations Between Geographic Location and CSR Indexes

\begin{tabular}{lrrr}
\hline Geographic Region & Total CSR & Internal CSR & External CSR \\
\hline Midwest & .09 & .08 & .08 \\
Northeast & & & \\
South & & & .04 \\
West & -.08 & -.04 & -.09 \\
\hline
\end{tabular}

All results significant at the 0.05 level or greater (2-tailed)

Linear Regression. A linear regression with geographic region as the independent variable and total CSR as the dependent variable showed that region explained $1 \%$ of the variation in total CSR. Region explained only $0.6 \%$ of the variance in internal CSR and $1 \%$ of external CSR. Only the coefficient for the Midwest was statistically significant at the $95 \%$ level. The correlation and regression results both indicate that geographic region is not a meaningful predictor of CSR activity.

Industry. The literature also suggested an examination of the relationship between the SME industry and participation in total, internal, and external CSR.

Correlation. The correlations proved significant for only four of the nine BLS industry categories. In addition, the correlations for the education and health services industry and the trade, transportation and utilities industry were negative suggesting these industries had a negative impact on CSR activity. However, the significant correlations ranged in absolute value from 0.03 to 0.19 , all of which are considered negligible. Table 31 demonstrates the statistically significant, but negligible, correlations between industry and CSR indexes. 


\section{Table 31}

Significant Correlations between BLS Industry and CSR Indexes

\begin{tabular}{lcrr}
\hline BLS Industry & $\begin{array}{r}\text { Total } \\
\text { CSR }\end{array}$ & $\begin{array}{r}\text { Internal } \\
\text { CSR }\end{array}$ & $\begin{array}{r}\text { External } \\
\text { CSR }\end{array}$ \\
\hline Construction $(\mathrm{n}=55)$ & & .03 & -.05 \\
Education and Health Services $(\mathrm{n}=215)$ & & \\
Financial Activities $(\mathrm{n}=321)$ & & \\
Information $(\mathrm{n}=26)$ & & \\
Leisure and Hospitality $(\mathrm{n}=48)$ & & \\
Manufacturing $(\mathrm{n}=113)$ & & .09 & \\
Other Services ( $\mathrm{n}=90)$ & & \\
Professional and Business Services $(\mathrm{n}=1,357)$ & .05 & -.19 & \\
Trade, Transportation, and Utilities $(\mathrm{n}=780)$ & -.11 & & \\
\hline
\end{tabular}

Significant at $\mathrm{p}<.05$

Considering only five of the nine BLS categories were significantly correlated with CSR, the analysis also considered the correlations of the 28 specific industries identified in the survey. Only 13 of the 28 industries had a significant correlation to any of the CSR indexes. None of the industries had a correlation above the 0.2 threshold indicating a meaningful relationship.

Table 32 demonstrates these significant correlations by industry. 


\section{Table 32}

Significant Correlations between Industry and CSR Indexes

\begin{tabular}{|c|c|c|c|}
\hline Industry & $\begin{array}{c}\text { Total } \\
\text { CSR }\end{array}$ & $\begin{array}{r}\text { Internal } \\
\text { CSR }\end{array}$ & $\begin{array}{r}\text { External } \\
\text { CSR }\end{array}$ \\
\hline Accounting $(n=455)$ & .14 & .13 & .11 \\
\hline Advertising/Public Relations/Marketing $(\mathrm{n}=177)$ & .04 & & .06 \\
\hline \multicolumn{4}{|l|}{ Architecture $(n=58)$} \\
\hline Auto Dealer $(\mathrm{n}=657)$ & -.05 & -.13 & \\
\hline Banking $(\mathrm{n}=80)$ & -.05 & & .05 \\
\hline \multicolumn{4}{|l|}{ Construction $(n=53)$} \\
\hline Consulting $(n=65)$ & .04 & .05 & \\
\hline \multicolumn{4}{|l|}{ Distribution $(\mathrm{n}=36)$} \\
\hline Education $(\mathrm{n}=35)$ & & & .04 \\
\hline \multicolumn{4}{|l|}{ Engineering $(n=40)$} \\
\hline \multicolumn{4}{|l|}{ Financial Services: Other $(\mathrm{n}=93)$} \\
\hline Healthcare: Insurance Services $(n=30)$ & .04 & .04 & \\
\hline Healthcare: Provider $(\mathrm{n}=72)$ & & & -.05 \\
\hline \multicolumn{4}{|l|}{ Insurance: Non Healthcare $(n=56)$} \\
\hline \multicolumn{4}{|l|}{ Legal $(n=70)$} \\
\hline Manufacturing $(\mathrm{n}=80)$ & & & .04 \\
\hline Non-profit: Health and Human Services $(n=50)$ & & & -.06 \\
\hline Non-profit: Other $(\mathrm{n}=87)$ & & .04 & \\
\hline \multicolumn{4}{|l|}{ Other $(n=278)$} \\
\hline \multicolumn{4}{|l|}{ Real Estate $(n=45)$} \\
\hline Retail (n=19) & .04 & & \\
\hline \multicolumn{4}{|l|}{ Services: Other $(n=83)$} \\
\hline \multicolumn{4}{|l|}{ Staffing $(n=61)$} \\
\hline Technology $(n=260)$ & -.09 & -.05 & -.10 \\
\hline Telecommunications $(n=19)$ & -.04 & & -.04 \\
\hline Transportation $(n=16)$ & & & \\
\hline
\end{tabular}

Significant at $\mathrm{p}<.05$ 
Linear Regression. Further analysis used a linear regression with BLS industry category as the independent variable and total CSR as the dependent variable. The resulting $\mathrm{R}^{2}$ of .007 suggested BLS industry category predicts only $0.7 \%$ of the variation in CSR activity. The coefficients for construction, other services, leisure and hospitality, manufacturing, and finance were not significant indicating they do not explain variation in CSR values.

Specific industry was also included in a linear regression with total CSR as the dependent variables. The 28 industries returned a model with a $\mathrm{R}^{2}$ or 0.03 explaining $3 \%$ of the variance in total CSR values. Only seven industries - accounting, technology, banking, health care insurance, consulting, manufacturing, insurance (non healthcare) -were included in the linear regression model for total CSR.

Additional Organization Characteristics. The survey provided additional characteristics for each organization that could be analyzed regarding their relationship to CSR activity.

Correlation. Nineteen additional characteristics were analyzed for correlations with CSR. Only the variables on HR certifications exceeded the 0.2 threshold for correlations to be meaningful. The correlations for the remaining variables were significant but negligible. Two variables, average annual salary non-exempt employees and difference between average exempt and non-exempt employee salaries, were found to have no significant correlation with any of the CSR indexes. As a result, these two variables were excluded from future analysis. Table 33 presents the statistically significant correlations for each of these organization characteristics. 
Table 33

Significant Correlations for Additional Organization Characteristics and CSR Indexes

\begin{tabular}{|c|c|c|c|c|}
\hline $\begin{array}{l}\text { Characteristic } \\
\text { Group }\end{array}$ & Characteristic & $\begin{array}{l}\text { Total } \\
\text { CSR }\end{array}$ & $\begin{array}{r}\text { Internal } \\
\text { CSR }\end{array}$ & $\begin{array}{r}\text { External } \\
\text { CSR }\end{array}$ \\
\hline Demographics & Female employees $\%$ & .13 & .19 & .06 \\
\hline \multirow[t]{3}{*}{ Leadership } & Top executive male & & -.04 & \\
\hline & Executive team male $\%$ & & -.07 & \\
\hline & Tenure top executive & .08 & .06 & \\
\hline \multirow{3}{*}{$\begin{array}{l}\text { Human } \\
\text { Resources }\end{array}$} & HR to employee Ratio & .04 & .04 & .04 \\
\hline & $\begin{array}{l}\text { HR staff have HR } \\
\text { certifications }\end{array}$ & .25 & .28 & .17 \\
\hline & Number HR certifications & .30 & .33 & .20 \\
\hline \multirow[t]{3}{*}{ Benefits/Policies } & Hours to be full-time & -.13 & -.09 & -.13 \\
\hline & $\begin{array}{l}\text { Number paid holidays per } \\
\text { year }\end{array}$ & .08 & .11 & .04 \\
\hline & Uniform dress code & -.06 & -.07 & \\
\hline \multirow[t]{6}{*}{$\begin{array}{l}\text { Performance } \\
\text { Outcomes }\end{array}$} & $\begin{array}{l}\text { Average annual salary } \\
\text { exempt employees }\end{array}$ & .08 & .09 & .05 \\
\hline & $\begin{array}{l}\text { Average annual salary non- } \\
\text { exempt employees }\end{array}$ & & & \\
\hline & $\begin{array}{l}\text { Difference between average } \\
\text { exempt and non-exempt } \\
\text { salary }\end{array}$ & & & \\
\hline & Create new jobs & .09 & .11 & .07 \\
\hline & Voluntary turnover \% & -.11 & -.12 & -.07 \\
\hline & Involuntarily separated \% & -.06 & -.03 & -.06 \\
\hline \multirow[t]{3}{*}{ Communication } & Have Twitter handle & .07 & .09 & .04 \\
\hline & Have social media policy & .14 & .11 & .14 \\
\hline & $\begin{array}{l}\text { Frequency executive -led } \\
\text { employee meetings }\end{array}$ & .09 & .11 & .06 \\
\hline
\end{tabular}


Linear Regression. Linear regression also calculated the relationship between CSR values and the additional organization characteristic variables. A separate regression was created for each of the additional organization characteristics with total CSR as the dependent variable. These models explained between $1 \%$ and $4 \%$ of the variance in total CSR. Only three characteristics - gender of top executive, average annual salary for nonexempt employees, and difference between annual salaries for exempt and nonexempt employees -- were not significant. Table 34 shows the $\mathrm{R}^{2}$, standardized coefficient, and significance for each of the linear regressions predicting total CSR. 


\section{Table 34}

Individual Regression Results for Organization Characteristics and Total CSR

\begin{tabular}{|c|c|c|c|c|}
\hline $\begin{array}{l}\text { Characteristic } \\
\text { Group }\end{array}$ & $\begin{array}{l}\text { Characteristic } \\
\text { (Independent Variable) }\end{array}$ & $\mathrm{R}^{2}$ & $\begin{array}{r}\text { Standardized } \\
\text { Coefficient }\end{array}$ & Significance \\
\hline Demographics & Female employees $\%$ & .01 & .10 & .00 \\
\hline \multirow[t]{3}{*}{ Leadership } & Top executive male & .00 & -.02 & .28 \\
\hline & Executive team male \% & .00 & -.04 & .02 \\
\hline & Tenure top executive & .01 & .10 & .00 \\
\hline \multirow[t]{3}{*}{$\begin{array}{l}\text { Human } \\
\text { Resources }\end{array}$} & $\begin{array}{l}\text { HR staff have HR } \\
\text { certifications }\end{array}$ & .05 & .22 & .00 \\
\hline & Number HR certifications & .06 & .25 & .00 \\
\hline & HR to employee ratio & .01 & .08 & .00 \\
\hline \multirow[t]{3}{*}{ Benefits/Policies } & Hours to be full-time & .02 & -.13 & .00 \\
\hline & $\begin{array}{l}\text { Number paid holidays per } \\
\text { year }\end{array}$ & .00 & .07 & .00 \\
\hline & Uniform dress code & .01 & -.11 & .00 \\
\hline \multirow[t]{6}{*}{$\begin{array}{l}\text { Performance } \\
\text { Outcomes }\end{array}$} & $\begin{array}{l}\text { Average annual salary } \\
\text { exempt employees }\end{array}$ & .00 & .05 & .02 \\
\hline & $\begin{array}{l}\text { Average annual salary non- } \\
\text { exempt employees }\end{array}$ & .00 & .03 & .15 \\
\hline & $\begin{array}{l}\text { Difference between average } \\
\text { exempt and non-exempt } \\
\text { salary }\end{array}$ & .00 & -.01 & .55 \\
\hline & Create new jobs & .01 & .10 & .00 \\
\hline & Voluntary turnover \% & .01 & -.11 & .00 \\
\hline & Involuntarily separated \% & .00 & -.07 & .00 \\
\hline \multirow[t]{3}{*}{ Communication } & Have Twitter handle & .01 & .07 & .00 \\
\hline & Have social media policy & .02 & .14 & .00 \\
\hline & $\begin{array}{l}\text { Frequency executive -led } \\
\text { employee meetings }\end{array}$ & .01 & .09 & .00 \\
\hline
\end{tabular}

Note: Significance $<=.05$ in boldface. 
Overall, the analysis on the relationship between specific organization characteristics and CSR activity showed several organization characteristics had no relationship to CSR activity. A few individual organization characteristics had a significant, but minimal influence on CSR. The next stage of analysis considered combinations of multiple organization characteristics and their influence on levels of CSR activity.

\section{Models Predicting CSR Activity}

Based on knowledge of the weak or negligible relationship between individual organization characteristics and CSR activity, the analysis progressed to consider combinations of organization characteristics through linear regression models.

Total CSR. From the literature and prior analysis, it was not clear which organization characteristic variables would be most predictive of CSR activity suggesting the use of a stepwise regression. Stepwise regression is considered especially useful with a large number of potential independent variables, which applies for the 20 independent variables in this model. The stepwise regression built predictive models by successively adding or subtracting variables based on the t-statistic of their coefficients.

The stepwise, linear regression used total CSR as the dependent variable with the 20 organization characteristics correlated to CSR entered as independent variables (omitting the two variables with no correlation.) The first model returned number of employees as the first variable predicting $5 \%$ of the variation in total CSR. Adding the second variable, BLS: trade, transportation, and utilities, further increased the adjusted $\mathrm{R}^{2}$ to .07. The regression's final model included 16 significant variables that combined, explained $17 \%$ of the variance in total CSR activity. Table 35 includes the results for 
model 16 of this stepwise, linear regression for total CSR.

Table 35

Stepwise Regression Results for Total CSR

Organization Characteristic Standardized Significance

Coefficient

\begin{tabular}{|c|c|c|}
\hline Number employees & .20 & .00 \\
\hline Voluntary turnover $\%$ & -.12 & .00 \\
\hline Number HR certifications & .11 & .00 \\
\hline Social media policy & .10 & .00 \\
\hline Frequency executive employee meetings & .10 & .00 \\
\hline Female employee $\%$ & .10 & .00 \\
\hline Tenure highest executive & .09 & .00 \\
\hline Midwest & .09 & .00 \\
\hline BLS Industry: Trade, Transportation, and Utilities & -.09 & .00 \\
\hline HR to employee Ratio & .08 & .00 \\
\hline Number paid holidays per year & .08 & .00 \\
\hline BLS Industry: Education and health & -.08 & .01 \\
\hline Executive team male \% & -.06 & .02 \\
\hline Average annual salary exempt employees & .06 & .01 \\
\hline BLS Industry: Information & -.05 & .02 \\
\hline BLS Industry: Finance & -.05 & .03 \\
\hline Adjusted $\mathrm{R}^{2=} \cdot 17$ & & \\
\hline
\end{tabular}

Seven organization characteristics were not included in the final model for total CSR: gender of top executive, hours to be full-time, having professional HR certifications, creation of new jobs, uniform dress code, having a twitter handle, and involuntary separation percentage.

Four industry variables (trade, transportation, and utilities; education and health; 
information; and finance) were in the final model. However, these broader BLS industries subsumed more specific industry detail. As a result, the stepwise, linear regression was run again using the more specific self-selected industry variables in lieu of the assigned BLS industry categories. This revised regression returned 15 models with the final model predicting $18 \%$ of the variance in total CSR. The change to the industry variable also impacted other variables inclusion or exclusion in the predictive models. This revised regression included four industry variables in the final model: auto dealer, accounting, transportation and technology, suggesting this level of industry information was more predictive of CSR activity. Using the self-selected industry detail slightly improved the predictive value of the model (higher adjusted $\mathrm{R}^{2}$ ) suggesting future regressions would also use this level of industry detail. Table 36 presents the revised regression results with industry detail. 
Table 36

Industry Detail for Stepwise Regression Results for Total CSR

\begin{tabular}{|c|c|c|}
\hline Organization Characteristic & $\begin{array}{r}\text { Standardized } \\
\text { Coefficient }\end{array}$ & Significance \\
\hline Number of employees & .19 & .00 \\
\hline Industry: Accounting & .14 & .00 \\
\hline Number HR certifications & .12 & .00 \\
\hline Voluntary turnover $\%$ & -.12 & .00 \\
\hline Frequency executive-led employee meetings & .12 & .00 \\
\hline Number paid holidays per year & .09 & .00 \\
\hline Social media policy & .09 & .00 \\
\hline Tenure highest executive & .09 & .00 \\
\hline HR to employee ratio & .09 & .00 \\
\hline Industry: Auto dealer & -.10 & .00 \\
\hline Midwest & .09 & .00 \\
\hline Executive team male $\%$ & -.07 & .00 \\
\hline Average annual salary exempt employees & .06 & .01 \\
\hline Industry: Transportation & -.05 & .03 \\
\hline Industry: Technology & -.05 & .04 \\
\hline Adjusted $\mathrm{R}^{2}=\cdot 18$ & & \\
\hline
\end{tabular}

Eight organization characteristics were not included in this final model for total CSR: percent female employees, gender of top executive, HR staff have professional certifications, hours to be full-time, creation of new jobs, involuntary separation percentage, uniform dress code, and use of a twitter handle.

Alternate regression model. To establish another point of reference, an additional regression was run using the simultaneous approach of the enter method in lieu of the sequential, stepwise method used previously. The independent variables for this 
regression were the 20 organization characteristics that had some level of correlation to total, internal, or external CSR. Fortunately, the regression results were very similar with the enter method delivering a comparable adjusted $\mathrm{R}^{2}$ of 0.19 . In addition, both models shared the same top three variables (as determined by standardized coefficient): number of employees, frequency of executive led employee meetings, and the accounting industry. However, the enter method included 12 variables in the final model, 10 of which were also in the stepwise model. The two independent variables that were unique to the enter method were industry variables: banking and insurance. The five independent variables present in the stepwise regression results but not included in the enter method were the number of HR certifications, average annual salary of exempt employees, and the auto dealer, transportation, and technology industries.

Internal CSR. A stepwise, linear regression was also run with all 20 organization characteristics correlated to CSR, including the more specific industry detail, to predict internal CSR Activity. The final model included 15 variables and an adjusted $\mathrm{R}^{2}$ of 0.22 . Number of employees was the first variable with a standardized coefficient of 0.25 . Industries represented four of the 15 variables in the final model. Two industries (auto dealer and services) had a negative standardized coefficient for internal CSR while the accounting and nonprofit industries had a positive coefficient for internal CSR. Table 37 presents the result of the stepwise linear regression for internal CSR. 
Table 37

Stepwise Regression Results for Internal CSR

\begin{tabular}{|c|c|c|}
\hline Organization Characteristic & $\begin{array}{r}\text { Standardized } \\
\text { Coefficient }\end{array}$ & Significance \\
\hline Number employees & .25 & .00 \\
\hline Number HR certifications & .18 & .00 \\
\hline Frequency executive employee meetings & .13 & .00 \\
\hline Industry: Accounting & .13 & .00 \\
\hline Industry: Auto Dealer & -.11 & .00 \\
\hline Voluntary turnover \% & -.11 & .00 \\
\hline Executive team male \% & -.09 & .00 \\
\hline HR to employee ratio & .09 & .00 \\
\hline Midwest & .08 & .00 \\
\hline Social media policy & .07 & .00 \\
\hline Number paid holidays per year & .06 & .01 \\
\hline Tenure highest executive & .06 & .00 \\
\hline Average annual salary exempt employees & .05 & .01 \\
\hline Industry: Services other & -.04 & .03 \\
\hline Industry: Nonprofit other & .04 & .04 \\
\hline Adjusted $\mathrm{R}^{2=} 0.22$ & & \\
\hline
\end{tabular}

Alternate regression model. As with total CSR, an additional regression was run for internal CSR using the enter method instead of the stepwise method. This regression had an adjusted $\mathrm{R}^{2}$ of 0.23 , similar to the results of the stepwise model. The enter method produced a model with 11 variables, all of which were part of the stepwise model. Four independent variables were included in the stepwise model but not the enter model: number of paid holidays per year and the auto dealer, services other, and nonprofit industries. The variable for number of employees had the highest standardized coefficient 
in both models.

Recognizing five constructs fed the internal CSR Index warranted additional analysis for each of the internal CSR constructs.

Diversity. The relevant survey questions generated four variables that covered active recruitment and retention of varying ethnic and cultural background, members of the disabled community, and the aging, as well as diversity training for the workforce. A linear regression found 15 organization characteristics predicted $16 \%$ of the variance in the diversity index. Number of employees was the first variable with the highest standardized coefficient. Table 38 displays the regression results for CSR activities in the area of diversity. 
Table 38

Stepwise Regression Results for Internal CSR: Diversity

\begin{tabular}{|c|c|c|}
\hline Organization Characteristic & $\begin{array}{l}\text { Standardized } \\
\text { Coefficient }\end{array}$ & Significance \\
\hline Number employees & .28 & .00 \\
\hline Industry: Non-profit Other & .11 & .00 \\
\hline Industry: Accounting & .10 & .00 \\
\hline HR to employee ratio & .10 & .00 \\
\hline Number HR certifications & .09 & .00 \\
\hline Social media policy & .09 & .00 \\
\hline Executive team male $\%$ & -.08 & .00 \\
\hline Tenure highest executive & .07 & .00 \\
\hline Midwest & .06 & .00 \\
\hline Industry: Banking & .06 & .01 \\
\hline Industry: Auto dealer & .05 & .04 \\
\hline Frequency executive employee meetings & .05 & .02 \\
\hline Industry: Non-profit health and human services & .05 & .02 \\
\hline Voluntary turnover $\%$ & -.04 & .04 \\
\hline Adjusted $\mathrm{R}^{2}=.16$ & & \\
\hline
\end{tabular}

The significant variables for diversity activities include size, location, and industry as well as HR staff and certifications. Surprisingly, the model only returned one of the three gender variables - percent of men on the executive team - while the variables for top executive gender and female representation in employees were not found to be significant.

Personal development. The survey questions under personal development asked if employers provided productivity or time management workshops, seminars or classes; on-site personal development and/or stress management workshops, seminars or classes; 
and financial education workshops, seminars, or classes. The linear regression provided a model with 12 organization characteristics including four industry variables. Number of professional human resources certifications was the first variable with the highest standardized coefficient followed by number of employees. The final model predicted $15 \%$ of the variance in personal development as shown in Table 39 .

Table 39

Stepwise Regression Results for Internal CSR: Personal Development

\begin{tabular}{|c|c|c|}
\hline Organization Characteristic & $\begin{array}{l}\text { Standardized } \\
\text { Coefficient }\end{array}$ & Significance \\
\hline Number HR certifications & .16 & .00 \\
\hline Number of employees & .14 & .00 \\
\hline Frequency executive employee meetings & .13 & .00 \\
\hline Industry: Auto Dealer & -.10 & .00 \\
\hline Industry: Technology & -.10 & .00 \\
\hline Industry: Accounting & .09 & .00 \\
\hline Tenure highest executive & .08 & .00 \\
\hline Female employee $\%$ & .08 & .00 \\
\hline Social media policy & .08 & .00 \\
\hline Voluntary turnover $\%$ & -.06 & .00 \\
\hline Average annual salary exempt employees & .05 & .02 \\
\hline Industry: Insurance (non-healthcare) & .05 & .02 \\
\hline & & \\
\hline
\end{tabular}

The final model for personal development CSR did not include variables on geographic region, gender of the top executive and executive team, hours to be full time, paid holidays per year, new job creation, or twitter use.

Health and wellness. The three questions under the health and wellness construct 
asked: Does your organization provide any workplace facilities to promote exercise and fitness? (a gym, workout room, exercise equipment, lockers, a shower, walking/jogging trail, bike racks, etc.); Does your organization provide any fitness/and or wellness programs or practices within the workplace?; and Does your organization pay all or part of employee's costs for health club memberships or fitness or wellness programs?

The linear regression results presented a model with 10 organization variables that predicted $12 \%$ of the variance in this area of CSR. Table 40 shows the final regression model that included number of employees as the first variable along with three industry variables.

Table 40

Stepwise Regression Results for Internal CSR: Health and Wellness

\begin{tabular}{lrr}
\hline Organization Characteristic & $\begin{array}{c}\text { Standardized } \\
\text { Coefficient }\end{array}$ & Significance \\
\hline Number employees & .19 & .00 \\
Industry: Auto dealer & -.14 & .00 \\
Staff have HR certifications & .12 & .00 \\
Midwest & .09 & .00 \\
Frequency executive employee meetings & .09 & .00 \\
Voluntary turnover \% & -.07 & .00 \\
Industry: Manufacturing & .06 & .00 \\
HR to employee ratio & .06 & .01 \\
Industry: Construction & -.05 & .03 \\
Social media policy & .04 & .05
\end{tabular}

Adjusted $\mathrm{R}^{2=} .12$

The final model for health and wellness did not include variables on gender of top executive, executive team, or employees; tenure of executive, average salary for exempt 
employees, twitter handle, hours to be full time, number of paid holidays per year, involuntary separation, or uniform dress code.

Family support. Three survey questions provided data for the family support construct. Does your organization provide adoption assistance?; Does your organization provide back-up child care if an employee's regular caregiver is suddenly not available?; and Does your employer sponsor eldercare assistance?

The linear model result included 10 variables that predicted $8 \%$ of the variance in the family support construct. Number of employees was the first variable based on the highest standardized coefficient of 0.19 . Table 41 shows the stepwise regression output for family support.

Table 41

Stepwise Regression Results for Internal CSR: Family Support

\begin{tabular}{|c|c|c|}
\hline Variable & $\begin{array}{r}\text { Standardized } \\
\text { Coefficient }\end{array}$ & Significance \\
\hline Number employees & .19 & .00 \\
\hline Number HR certifications & .18 & .00 \\
\hline Yes, HR certifications & -.09 & .01 \\
\hline Frequency executive employee meetings & .09 & .00 \\
\hline HR to employee ratio & .07 & .00 \\
\hline Industry: Services other & -.07 & .00 \\
\hline Industry: Legal & .07 & .00 \\
\hline Industry: Staffing & -.06 & .01 \\
\hline Female employee $\%$ & .06 & .01 \\
\hline Voluntary turnover $\%$ & -.05 & .05 \\
\hline Adjusted $\mathrm{R}^{2=} .08$ & & \\
\hline
\end{tabular}


Organization characteristics not in the model for family support activities include gender of the top executive and executive team and the number of paid holidays per year - three variables that might have been expected to influence activities around family support.

Flexible work arrangements. The fifth construct of internal CSR, flexible work arrangements, was populated by the following survey questions. As a standard practice, does your organization offer telecommuting options to your employees?; As a standard practice, does your organization offer job sharing options?; and As a standard, year-round practice, does your organization offer employees the option to work flexible hours or a compressed work week?

The linear regression returned a model with 18 variables and an adjusted $\mathrm{R}^{2}$ of 0.12. The independent variable, number of employees, did not appear in this model. Table 42 displays the regression results for flexible work arrangements. 
Table 42

Stepwise Regression Results for Internal CSR: Flexible Work Arrangements

\begin{tabular}{|c|c|c|}
\hline Organization Characteristic & $\begin{array}{r}\text { Standardized } \\
\text { Coefficient }\end{array}$ & Significance \\
\hline Industry: Accounting & .18 & .00 \\
\hline Voluntary turnover $\%$ & -.10 & .00 \\
\hline Number HR certifications & .10 & .00 \\
\hline Industry: Auto dealer & -.09 & .00 \\
\hline Industry: Architecture & .07 & .00 \\
\hline Industry: Technology & .07 & .02 \\
\hline Frequency executive employee meetings & .07 & .00 \\
\hline Executive team male \% & -.07 & .00 \\
\hline Industry: Consulting & .06 & .04 \\
\hline Uniform dress code & -.06 & .01 \\
\hline Industry: Healthcare insurance & .06 & .00 \\
\hline Industry: Transportation & -.05 & .02 \\
\hline Industry: Nonprofit other & .05 & .01 \\
\hline Industry: Engineering & .05 & .04 \\
\hline Industry: Banking & -.05 & .02 \\
\hline Number paid holidays per year & .05 & .03 \\
\hline Average annual salary exempt employees & .05 & .03 \\
\hline Industry: Nonprofit health and human services & .05 & .03 \\
\hline Adjusted $\mathrm{R}^{2}=.12$ & & \\
\hline
\end{tabular}

Eleven industry variables were included in the model for flexible work arrangements suggesting industry is an important variable in predicting an organization's activities in this area of CSR. Eight of these industries had a positive coefficient while three industries had a negative coefficient indicating different industries have a different influence on CSR activities around flexible work arrangements. 
Comparing Internal CSR Results. Reviewing the regression results for each of the internal CSR constructs revealed the models predicted between $8 \%$ and $16 \%$ of the variance in the five areas of internal CSR activity. Number of employees was included in the model for four of the five internal CSR constructs but was absent from flexible work arrangements. Industry variables were present in all five models for internal CSR although no one industry was in more than three models. Three variables, industry, frequency of executive led employee meetings, and voluntary turnover percent, were significant in all five internal CSR models. Table 43 presents a summary of the organization characteristics included in the five predictive models for internal CSR. 
Table 43

Summary of Significant Variables for Internal CSR Constructs

\begin{tabular}{|c|c|c|c|c|c|}
\hline $\begin{array}{l}\text { Organization } \\
\text { Characteristic }\end{array}$ & Diversity & $\begin{array}{l}\text { Health \& } \\
\text { wellness }\end{array}$ & $\begin{array}{c}\text { Personal } \\
\text { development }\end{array}$ & $\begin{array}{l}\text { Family } \\
\text { support }\end{array}$ & $\begin{array}{c}\text { Flexible } \\
\text { work }\end{array}$ \\
\hline $\begin{array}{l}\text { Frequency executive } \\
\text { employee meetings }\end{array}$ & $\sqrt{ }$ & $\checkmark$ & $\sqrt{ }$ & $\checkmark$ & $\checkmark$ \\
\hline Voluntary turnover \% & $\checkmark$ & $\checkmark$ & $\checkmark$ & $\checkmark$ & $\checkmark$ \\
\hline Number employees & $\checkmark$ & $\checkmark$ & $\checkmark$ & $\checkmark$ & \\
\hline Social media policy & $\checkmark$ & $\checkmark$ & $\checkmark$ & & $\checkmark$ \\
\hline $\begin{array}{l}\text { Number HR } \\
\text { certifications }\end{array}$ & $\checkmark$ & & $\checkmark$ & $\checkmark$ & $\checkmark$ \\
\hline $\begin{array}{l}\text { Tenure highest } \\
\text { executive }\end{array}$ & $\checkmark$ & & $\checkmark$ & & \\
\hline Female employee $\%$ & & & $\checkmark$ & $\checkmark$ & \\
\hline Male executive $\%$ & $\checkmark$ & & & & $\checkmark$ \\
\hline HR to employee ratio & $\checkmark$ & & & $\checkmark$ & \\
\hline $\begin{array}{l}\text { Yes, staff have HR } \\
\text { certifications }\end{array}$ & & $\checkmark$ & & & \\
\hline Midwest & $\checkmark$ & $\checkmark$ & & & \\
\hline Industry variables & $\checkmark$ & $\checkmark$ & $\checkmark$ & $\checkmark$ & $\checkmark$ \\
\hline $\begin{array}{l}\text { Number paid holidays } \\
\text { per year }\end{array}$ & & & & & $\checkmark$ \\
\hline $\begin{array}{l}\text { Average annual salary } \\
\text { exempt }\end{array}$ & & & $\checkmark$ & & \\
\hline Uniform dress code & & & & & $\checkmark$ \\
\hline Adjusted $\mathrm{R}^{2}$ & .16 & .12 & .15 & .08 & .12 \\
\hline
\end{tabular}

Two variables -- industry and frequency of executive led employee meetings -appeared in the models for all five areas of CSR. Number of employees, having a social media policy, and the number of professional HR certifications were the next most popular variables appearing in four out of the five models for internal CSR activity. 
Three variables - having a twitter handle, the involuntary separation percent, and creation of new jobs - did not appear in any of the internal CSR models.

External CSR. A linear regression was run to identify the best predictors of external CSR. The most predictive model included 17 variables with an adjusted $\mathrm{R}^{2}=$ 0.11. The accounting industry had the highest standardized coefficient of all independent variables while number of employees was the second variable in this model as shown in Table 44. 
Table 44

Stepwise Regression Results for External CSR

\begin{tabular}{|c|c|c|}
\hline Organization Characteristic & $\begin{array}{r}\text { Standardized } \\
\text { Coefficient }\end{array}$ & Significance \\
\hline Industry: Accounting & .12 & .00 \\
\hline Number employees & .11 & .00 \\
\hline Number paid holidays per year & .10 & .00 \\
\hline Tenure highest executive & .10 & .00 \\
\hline Voluntary turnover $\%$ & -.10 & .00 \\
\hline Social media policy & .08 & .00 \\
\hline HR to employee ratio & .07 & .00 \\
\hline Frequency executive employee meetings & .07 & .00 \\
\hline Midwest & .07 & .00 \\
\hline Executive team male $\%$ & -.07 & .00 \\
\hline Yes, HR certifications & .07 & .00 \\
\hline Industry: Nonprofit health and human services & -.07 & .01 \\
\hline Industry: Education & -.06 & .01 \\
\hline Industry: Technology & -.06 & .01 \\
\hline Uniform dress code & -.05 & .02 \\
\hline Industry: Transportation & -.05 & .03 \\
\hline Hours to be full time & -.04 & .05 \\
\hline Adjusted $\mathrm{R}^{2}=.11$ & & \\
\hline
\end{tabular}

Alternate regression model. The analysis for external CSR also included an alternate regression with the simultaneous enter method instead of the stepwise method. The enter method produced a model with 17 independent variables and an adjusted $\mathrm{R}^{2}$ of 0.102. Sixteen of the 17 variables in the enter model matched the variables from the stepwise model. The only difference was the enter model found the construction industry significant (with a p value of 0.05 ) while the stepwise model found the transportation 
industry significant (with a p value of 0.03 .)

The external CSR index was built around two constructs - community service initiatives and sustainability. Linear regressions were run for each of these constructs to identify the most predictive variables.

Community service. The model for community service included 16 variables that explained $11 \%$ of the variance in the level of community service activity. Industry populated five of the 16 variables while the West region made its first appearance in model results with a small but negative coefficient. Number of employees was only the tenth variable in the model as ranked by the absolute value of standardized coefficient. Table 45 shows the linear regression results for community service. 
Table 45

Stepwise Regression Results for External CSR: Community Service

\begin{tabular}{|c|c|c|}
\hline Organization Characteristic & $\begin{array}{l}\text { Standardized } \\
\text { Coefficient }\end{array}$ & Significance \\
\hline Industry: Accounting & .14 & .00 \\
\hline Tenure highest executive & .09 & .00 \\
\hline Number HR certifications & .09 & .00 \\
\hline Frequency executive employee meetings & .08 & .00 \\
\hline Voluntary turnover $\%$ & -.08 & .00 \\
\hline Industry: Nonprofit health and human services & -.08 & .00 \\
\hline Number paid holidays per year & .07 & .00 \\
\hline Industry: Banking & .07 & .00 \\
\hline Social media policy & .07 & .00 \\
\hline Number of employees & .06 & .01 \\
\hline Industry: Technology & -.06 & .00 \\
\hline Female employee $\%$ & .06 & .01 \\
\hline Hours to be full-time & -.06 & .01 \\
\hline West & -.05 & .00 \\
\hline HR to employee ratio & .05 & .02 \\
\hline Adjusted $\mathrm{R}^{2}=.11$ & & \\
\hline
\end{tabular}

Variables not included in the final model for community service included gender of executive and executive team, HR to employee ratio, uniform dress code, twitter handle, average annual salary for exempt employees, creation of new jobs, and involuntary separation.

Sustainability. The linear regression for sustainability produced a model with 14 variables predicting only $7 \%$ of the variance in sustainability initiatives among SMEs. The sustainability model had the lowest adjusted $\mathrm{R}^{2}$ of all the models in this analysis. 
Number of employees had the highest standardized coefficient with the South region second (and negative) in the model. The sustainability model is the only one with the South region significant. Five industry variables were included - accounting had a positive coefficient while the auto dealer, education, transportation, and health care provider industries had a negative coefficient. Table 46 presents the final regression model for sustainability activities.

Table 46

Stepwise Regression Results for External CSR: Sustainability

\begin{tabular}{|c|c|c|}
\hline Organization Characteristic & $\begin{array}{r}\text { Standardized } \\
\text { Coefficient }\end{array}$ & Significance \\
\hline Number employees & .10 & .00 \\
\hline South & -.09 & .00 \\
\hline Tenure highest executive & .08 & .00 \\
\hline Social media policy & .08 & .00 \\
\hline Voluntary turnover $\%$ & -.08 & .01 \\
\hline HR to employee ratio & .07 & .02 \\
\hline Industry: Accounting & .07 & .00 \\
\hline Number paid holidays per year & .07 & .03 \\
\hline Industry: Auto Dealer & -.06 & .01 \\
\hline Frequency executive employee meetings & .06 & .00 \\
\hline Executive team male $\%$ & -.06 & .01 \\
\hline Industry: Education & -.05 & .02 \\
\hline Industry: Transportation & -.05 & .02 \\
\hline Industry: Health care provider & -.05 & .03 \\
\hline & & \\
\hline
\end{tabular}

Comparing external CSR results. Reviewing the regression results for the external CSR constructs revealed the models predicted between $7 \%$ and $11 \%$ of the 
variance in external CSR activity. Eight variables were present in all of the external CSR models. In contrast with the internal CSR models, the external CSR models included three geographic regions. Table 47 presents a comparative summary of the organization characteristics included in the final predictive models for external CSR and its constructs.

Table 47

Summary of Significant Variables for External CSR Constructs

Organization Characteristic External CSR Community Sustainability

Number employees

Frequency executive employee meetings

Tenure highest executive

Voluntary turnover $\%$

HR to employee Ratio

Social media policy

Number paid holidays per year

Industry variables

Hours to be full-time

Male executive \%

Yes, staff have HR certifications

Number HR certifications

Female employee \%

Uniform dress code

Midwest

South

West

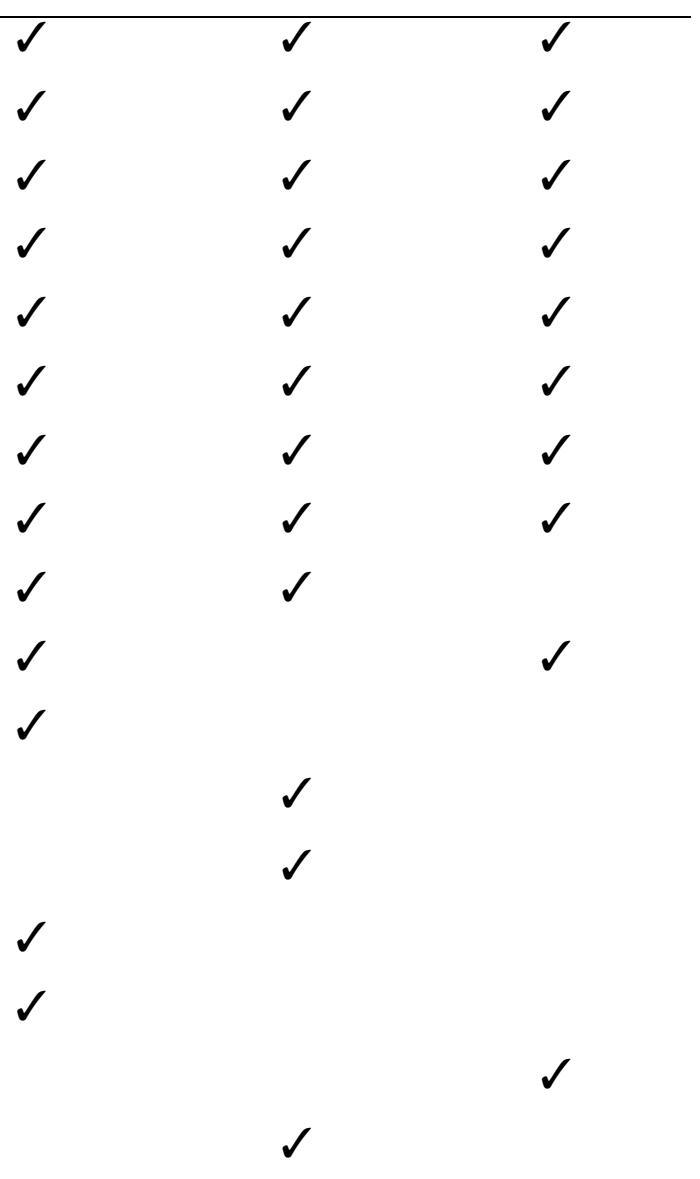
Adjusted $\mathrm{R}^{2}$
.11
.111

.07

\section{Comparing CSR Index Values}

The prior regression results demonstrate a combination of multiple organization 
characteristics predicted between $7 \%$ and $22 \%$ of the variance in different CSR activity. Ten variables were included in the three final models for total CSR, internal CSR, and external CSR. Table 48 presents the ten organization characteristics present in the predictive models for internal, external and total CSR activity.

Table 48

Organization Characteristics in CSR Regression Models

Organization Characteristic

Number employees

Tenure highest executive

Executive team male \%

HR to employee Ratio

Voluntary turnover \%

Number paid holidays per year

Frequency executive employee meetings

Social media policy

Industry variables

Midwest
Total CSR Internal CSR External CSR
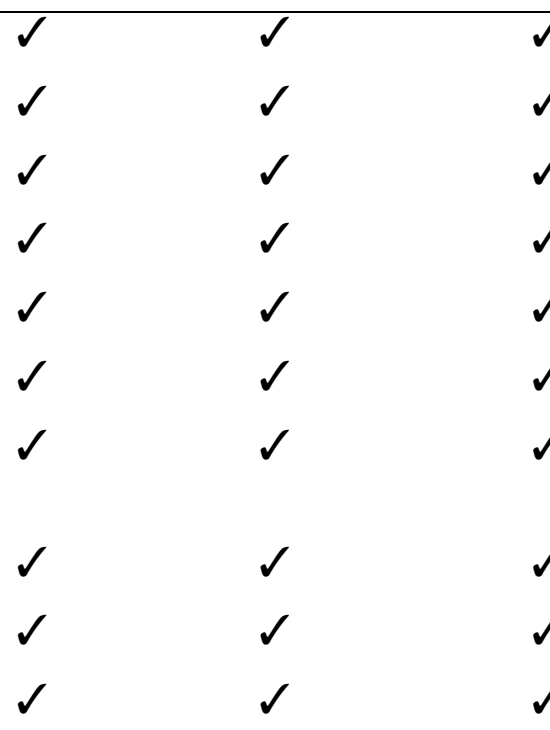

.18
.22

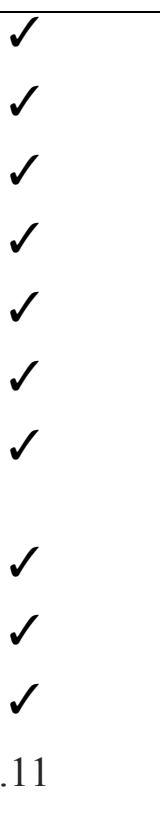

A further look at the standardized coefficients reiterates the significance of number of employees as it had the highest coefficient for total CSR and internal CSR and the second highest coefficient for external CSR. The frequency of executive led employee meetings was one of two variables that appeared in all 10 CSR models. The second variable in all models was voluntary turnover percent although it had a consistently negative coefficient. The only other variable with a consistent negative 
coefficient is the percentage of men on the executive team that is present in six of the 10 CSR models. Table 49 presents a summary of the standardized coefficients for the five most frequently included organization characteristics.

Table 49

Standardized Coefficients of Top Five Organization Characteristics in All CSR Models

\begin{tabular}{|c|c|c|c|c|c|}
\hline \multirow[b]{2}{*}{ CSR Model } & \multicolumn{5}{|c|}{ Standardized coefficients* } \\
\hline & $\begin{array}{r}\text { Number } \\
\text { employees }\end{array}$ & $\begin{array}{r}\text { Frequency } \\
\text { executive } \\
\text { meetings }\end{array}$ & $\begin{array}{r}\text { Voluntary } \\
\text { turnover \% }\end{array}$ & $\begin{array}{r}\text { Tenure } \\
\text { executive }\end{array}$ & $\begin{array}{r}\text { HR to } \\
\text { employee } \\
\text { ratio }\end{array}$ \\
\hline Total CSR & 0.19 & 0.12 & -0.12 & 0.09 & 0.09 \\
\hline Internal CSR & 0.25 & 0.11 & -0.11 & 0.06 & 0.09 \\
\hline Diversity & 0.28 & 0.05 & -0.04 & 0.07 & 0.10 \\
\hline $\begin{array}{l}\text { Personal } \\
\text { development }\end{array}$ & 0.14 & 0.13 & -0.06 & 0.08 & \\
\hline $\begin{array}{l}\text { Health and } \\
\text { wellness }\end{array}$ & 0.19 & 0.09 & -0.07 & & 0.06 \\
\hline $\begin{array}{l}\text { Family } \\
\text { support }\end{array}$ & 0.19 & 0.09 & 0.05 & & 0.07 \\
\hline $\begin{array}{l}\text { Flexible } \\
\text { work }\end{array}$ & & 0.07 & -0.10 & & \\
\hline External CSR & 0.11 & 0.07 & -0.10 & 0.10 & 0.07 \\
\hline $\begin{array}{l}\text { Community } \\
\text { initiatives }\end{array}$ & 0.06 & 0.08 & -0.08 & 0.09 & 0.05 \\
\hline Sustainability & 0.10 & 0.06 & -0.08 & 0.08 & 0.07 \\
\hline
\end{tabular}

*significant at $\mathrm{p}<=.05$

Sixteen different industry variables were analyzed for the CSR models but three industries were most frequently represented. The accounting industry was most prevalent with a significant and positive coefficient in eight of the ten CSR models. By comparison, the auto dealer industry was present in seven models but had a negative coefficient in six 
models, showing a positive coefficient only in the area of diversity. The technology industry also appeared significant in five models of CSR with a negative coefficient in four models and a positive coefficient in the model for flexible work arrangements.

\section{Alternate Organization Characteristic Selection}

The independent variables used in these regression analyses were the 20 organization characteristic variables that had some level of correlation to either total, internal, or external CSR. However, there are alternate, viable methods for selecting the organization characteristic variables for inclusion. One alternate method would be to use only the organization characteristics that emerged from the regression on total CSR in the nine ensuing regression models for different areas of CSR.

Internal CSR. Using the 15 organization characteristic variables from the total CSR model in a regression on internal CSR returned a model with 12 variables and an adjusted $R^{2}$ of 0.21 , slightly lower than the adjusted $R^{2}$ of 0.22 from the original model. Number of employees had the highest standardized coefficient in both methods. Only three organization characteristics from the original internal CSR model were not included in this alternate model: services other industry, technology industry, and average annual salary for exempt employees. Overall, the results from both models are very similar.

External CSR. An additional regression was run for external CSR using the 15 organization characteristics that had emerged from the regression on total CSR instead of all 20 correlated organization characteristics. The final model from this stepwise regression had an adjusted $\mathrm{R}^{2}$ of 0.09 - lower than the $\mathrm{R}^{2}$ of 0.11 from the original regression. Three of the 15 variables were not in the final model for external CSR: auto dealer industry, average annual salary for exempt employees, and percent of males on the 
executive team. Seven organization characteristics were in the original model for external CSR but not in this alternate model including: having human resource certifications, percent of men on the executive team, uniform dress code, banking industry, manufacturing industry, legal industry, and insurance industry.

While there were different results for these two methods predicting internal and external CSR, the outcomes were similar. However, the higher $\mathrm{R}^{2}$ values and inclusion of additional variables suggests greater accuracy from the original models that considered all 20 organization characteristics with a correlation to CSR.

\section{Summary: An Answer to Research Question Three}

Regression analysis focused on identifying which organization characteristics influenced the level of CSR activity for SMEs. The stepwise regression model for total CSR found a combination of 15 organization characteristics explained $18 \%$ of the variance in total CSR activity. Number of employees proved to be the most impactful organization characteristic. The final regression model for internal CSR found sixteen organization characteristics explained $22 \%$ of the variance in internal CSR. Again, number of employees had the largest coefficient of organization characteristics. The stepwise regression model for external CSR included seventeen organization characteristics that explained $11 \%$ of the variance in external CSR activity. Industry proved to be the most significant organization characteristic followed closely by number of employees.

\section{Summary of Research Findings}

The findings in this chapter detailed the CSR activities of 3,005 SMEs across the United States. After validating the sample, the analysis reviewed the internal and external 
CSR activities of SMEs and the level of SME participation in these activities. In addition, statistical analysis calculated which organization characteristics influenced the level of CSR activity among SMEs. The results found SMEs differed in their level of CSR participation based on a combination of multiple organization characteristics. These findings lay the groundwork for further discussion of CSR activity in SMEs in the United States. 


\section{CHAPTER FIVE: DISCUSSION}

As discussed in Chapter Two, the current academic literature provides minimal insight into the CSR activity of SMEs in the United States. This study was designed to address this problem with an exploratory analysis of CSR activity in 3,005 SMEs across the United States. Inferential and descriptive statistics were used to study what CSR activities are practiced by SMEs, the level of participation in these CSR activities, and the organization characteristics that influence participation in CSR activities. Data for this study came from a 2014 survey of self-selected organizations competing for a Best Places to Work award.

This chapter presents a summary of the study including the purpose of the study, the guiding research questions, and an overview of the research methods. The analytical findings from Chapter Four are also summarized in this chapter as a basis for the discussion that is the centerpiece of Chapter Five. This chapter will then focus on discussing the implications of the findings. Finally, this chapter will address the limitations and delimitations of the study as well as recommendations for future academic research and CSR practitioners. The chapter closes discussing the significance of the study.

\section{Purpose of the Study}

The purpose of this study was to begin filling the current gap in knowledge of CSR and SMEs by researching recent activity of SMEs in the United States. This exploratory study analyzed areas of CSR activity for SMEs, the extent of CSR activity among SMEs, and the organization characteristics that contribute to varying levels of CSR activity in SMEs. The guiding research questions were: 
1. What are the CSR activities of SMEs in the United States?

2. To what extent, if any, do SMEs in the United States participate in these CSR activities?

3. What organization characteristics contribute to varying levels of CSR activity in SMEs?

\section{Review of Methodology}

Data for this survey was obtained from a third-party, Best Companies Group, that administer annual surveys as part of their Best Places to Work recognition program. In 2014, 3,005 SMEs in the United States submitted the 80-question online survey providing details on the demographics, practices, and policies of their organization. This survey questions addressed specific actions and policies of these organization without any direct reference to CSR. However, much of the data collected in the survey is associated with the different activities of CSR.

The first research question asked what are the CSR activities of SMEs? While the academic literature discusses the CSR activities of large companies, there is limited discussion of what CSR looked like for an organization with less than 500 employees. An initial qualitative assessment of the survey instrument identified over 50 organizational practices that could be indicators of CSR activity. A factor analysis and reliability test identified 22 CSR activities that were statistically valid for this study. The 22 CSR activities were then classified as internal and external CSR. Internal CSR encompassed activities around diversity, health and wellness, family support, personal development, and flexible work arrangements. External CSR addressed an organization's activities in their community and the environment. 
Research question two addressed the level of SME participation in the previously identified CSR activities. Answering this question required calculating numerical values for each of the CSR activities identified in response to the first research question. Descriptive statistics demonstrated the level of SME participation in internal, external, and total CSR. In this sample, $99 \%$ of organizations participated in some CSR activity, leading the analysis to focus on the different levels of participation rather than the difference between the SMEs that did or did not participate in CSR activities. Independent sample t-tests validated the statistical significance of the different levels of CSR activity.

The final research question employed correlations and linear regressions to measure the relationship between organization characteristics and level of CSR activity. Each organization characteristic was analyzed individually for its relationship to internal, external, and total CSR. Finally, all the organization characteristics were simultaneously entered into a linear, stepwise regression to determine what combination of characteristics had the greatest predictive value for internal, external, and total CSR activity.

\section{Summary of Findings}

Chapter four provided extensive detail on the research findings so only a brief overview of the findings will be presented in this chapter. Each of the three research questions will be addressed separately.

\section{Research Question \#1}

A factor analysis and reliability test identified 22 activities that represented internal and external CSR and therefore, total CSR. 
Internal CSR addressed the organization's policies toward their internal stakeholders - employees. The activities of internal CSR addressed diversity, health and wellness, personal development, family support, and flexible work arrangements. Diversity practices included actively recruiting the aging, the disabled, and varying ethnic and cultural backgrounds as well as offering formal diversity training in the workplace. Socially responsible health and wellness activities involved providing workplace facilities to promote exercise and fitness, provision of fitness and/or wellness programs or practices within the workplace, and covering part or all of an employee's costs for health club memberships or fitness or wellness programs. Activities under personal development CSR included offering productivity or time management workshops, seminars or classes; offering on-site personal development and/or stress management workshops, seminars or classes; and offering financial education workshops, seminars, or classes. Family support practices included providing adoption assistance, providing backup child or elder care if an employee's regular caregiver is suddenly not available, and sponsoring eldercare assistance for employees with aging family members. The fifth and final element of internal CSR involved flexible work arrangements as demonstrated by offering employees the option to work flexible hours or a compressed work week, telecommuting options, and job sharing options.

External CSR involved the organization's activities with external stakeholders the community and the environment. More specifically, CSR in the community involved giving employees paid time off to volunteer, supporting employees taking leadership roles with a volunteer organization, and sponsoring a number of community service 
programs. External CSR towards the environment addressed the organization promoting sustainable practices.

\section{Research Question \#2}

The second research question addressed the level of participation in the activities identified as CSR for SMEs. The analysis found that more than $99 \%$ of SMEs in the survey participated in some CSR activity as measured by a CSR index greater than zero. However, only two of the 3,005 organizations participated in all 22 of the identified CSR activities.

Internal CSR activities (focused on employees) had a 97\% participation rate among the SMEs in the sample. Within internal CSR, health and wellness practices had the highest participation rate of $82 \%$, personal development had a $69 \%$ participation level, diversity activities had a $64 \%$ participation rate, flexible work arrangements showed $63 \%$, while family support practices had the lowest participation rate with $18 \%$ of SMEs. Only two organizations participated in all of the identified internal CSR activities.

Looking to CSR activities outside the organization, 97\% of the sampled SMEs participated in at least one external CSR activity. For example, 93\% of SMEs participated in community activities while $87 \%$ of SMEs engaged in activities focused on the environment. Interestingly, more than $32 \%$ of the sample participated in all the identified external CSR activities.

\section{Research Question \#3}

Extensive analysis focused on discerning which organization characteristics influenced the level of CSR activity for SMEs. Conducting a linear regression for each 
organization characteristic and total CSR found individual organization characteristics explained anywhere between $0 \%$ and $5 \%$ of the variance in total CSR activity. Having staff with Human Resource certifications explained 5\% of the variance total CSR. Size, as measured by number of employees, explained only $3 \%$ of the variance in total CSR values. Gender of the top executive and average salary information were found to be insignificant characteristics for predicting total CSR activity.

The analysis progressed by considering all organization characteristics together to determine how a combination of characteristics could help explain total CSR activity. This stepwise, linear regression found a combination of 15 organization characteristics that explained $18 \%$ of the variance in total CSR activity. Number of employees proved to be the most impactful organization characteristic, while the accounting industry was the second most significant variable in the model for total CSR. Other significant and positive organization characteristics for total CSR were number of Human Resource certifications, tenure of the highest executive, number of paid holidays per year, ratio of human resources staff to employees, the presence of a social media policy, the frequency of executive-led employee meetings, and a Midwest location. Voluntary turnover and male representation on the executive team had a significant but negative relationship to total CSR activity.

Recognizing the diverse types of activities associated with CSR warranted additional analyses of internal and external CSR. The final regression model for internal CSR found sixteen characteristics that explained $22 \%$ of the variance in internal CSR. Number of employees had the largest influence on internal CSR. Two industries (auto dealer and other services) had a significant but negative impact on internal CSR while 
accounting and nonprofit industries had a significant and positive relationship. Three leadership variables were also significant for internal CSR; frequency of executive hosted employee meetings, tenure of highest executive, and gender distribution on the executive team. The additional organization characteristics that predicted internal CSR activity were the number of HR certifications, having a social media policy, the HR to employee ration, a Midwest location, and the number of paid holidays offered per year. By contrast, the voluntary turnover rate had a significant but negative coefficient for internal CSR.

The model for external CSR included seventeen organization characteristics that explained $11 \%$ of the variance in external CSR activity. The accounting industry was the first variable in the model with a standardized coefficient of 0.12 . The next predictive variable was number of employees (standardized coefficient of 0.11 ) followed by number of paid holidays per year. Five industries were included in the final model. Accounting had a positive coefficient for external CSR while the other four industries -- nonprofit health and human services, education, technology, and transportation -- had a negative coefficient. The remaining positive variables included HR certifications, tenure of the top executive, having a social media policy, frequency of executive employee meetings, HR to employees ratio, and Midwest location. Voluntary turnover, a uniform dress code, percent of men on the executive team, and hours to be full time had a significant but negative coefficient for external CSR.

\section{Discussion of Findings}

This study was developed based on the findings and questions from the relevant literature with the intention that the results would contribute to the body of literature on 
CSR. CSR scholars called for increased knowledge about SMEs and CSR (Jamali et al. 2008; Perrini, 2006) and additional research on the role of firm size on CSR (Burton \& Goldsby, 2009; Udayasankar, 2007.) This study addressed both concerns.

First and foremost, this study demonstrated that SMEs in the United States participate in CSR, a finding that addresses the doubts raised by Lepoutre and Heene (2006), Perrini et al (2007), and Waddock and Graves (1997) while corroborating the high prevalence of CSR found in studies of SMEs in Singapore (Leet et al., 2012) and Latin America (Vives, 2006.) In response to the concern that SMEs are unclear about what constitutes CSR (Giovanna et. al, 2012; Grayson, 2007; Lee, 2012) this study provided detail on the specific CSR activities, internal and external, of 3,005 SMEs. This study also suggested that number of employees is the most influential organization characteristic for predicting level of CSR activity although it predicted only $3 \%$ of the variance in CSR.

Existing research has documented variation in CSR activity for SMEs in different countries (Apospori et al., 2012; Vives, 2006), cultures (Baisakalova, 2012), and regions (Graafland et al., 2003; Tencati, et al., 2004.) The findings from this study reinforced the relevance of location as the four geographic regions of the United States had varying levels of significance for CSR activity although the population density (metro, urban, or rural) was not significant for CSR activity. Much of the existing CSR research studied industries with samples too small for a meaningful industry analysis (Jamali et al., 2006; Jenkins, 2009; Murillo \& Lozano, 2006.) This study of 3,005 SMEs in 28 industries found two industries- accounting and auto dealer- with statistically significant relevance for CSR. Reiterating prior research on the influence of leadership on CSR activity 
(Burton \& Goldsby, 2009; Jenkins, 2009), this study found leadership variables around tenure, frequency of employee meetings, and gender distribution were also significant predictors of CSR activity.

\section{SME Participation in CSR}

The primary finding from this study is that SMEs of all sizes engage in CSR. While prior studies have shown the majority of large companies participate in CSR (Accenture, 2013; Smith \& Alexander, 2013), this study of 3,005 SMEs demonstrated that small and medium businesses in the United States also have high rates of CSR participation. In this self-selected sample, over $99 \%$ of organizations engaged in some CSR activity. Analysis of the 22 specific CSR activities revealed participation rates ranged from a low of 5\% in family support practices to a high of $92 \%$ in community initiatives. Overall, the SMEs in this study demonstrated they actively participated in CSR activities.

This analysis also found that the SMEs studied did not just participate in one CSR activity. On average, SMEs participated in 10 different CSR activities. More specifically, SMEs participated in an average of five internal CSR activities and five external CSR activities. By participating in numerous CSR activities, SMEs demonstrated a multifaceted commitment to CSR.

Prior research found a commonly cited constraint for SMEs to participate in CSR involved the perceived amount of time and resources required (Grayson \& Dodd, 2007; Lepoutre \& Heene, 2006.) However, this study found that participation rates were high irrespective of the resource requirements of the CSR activity. Capital intensive CSR activities did have lower levels of participation compared to human resource intensive 
CSR but the lowest level of participation involved CSR activities that were not resource intensive. This finding suggests the notion that resource requirements hinder CSR activity is a perception not justified by the data. Rather, participation in CSR activities appears to be driven by factors other than resource requirements.

\section{Role of Organization Size on CSR Activity}

Once it was determined that SMEs participated in CSR, the analysis could address the role of size, as measured by number of employees, for its relationship to CSR activity. Regression analysis demonstrated a positive, linear relationship between number of employees and level of CSR activity. While the data demonstrated almost all SMEs participated in CSR, the regression results indicated SMEs with more employees participated in more CSR activities corroborating Murillo and Lozano's findings (2006) from a qualitative study of SMEs in Spain. However, these finding counter the research on 401 SMEs in the United States that found a "murky" relationship between number of employees and CSR (Burton \& Goldsby, 2009) and Udayasankar's claim that very small firms are likely to participate in more CSR activities than mid-sized firms (2007.)

The strength of the relationship between number of employees and CSR activity varied based on the type of CSR activity. Specifically, the regression model showed that the number of employees had a stronger relationship to the level of internal CSR activity than external CSR activity. These results suggest that while the majority of SMEs participate in CSR, organizations with more employees are more likely to participate in a greater number of internal CSR activities. However, this trend did not apply for external CSR. Instead, SMEs of all sizes appear equally like to participate in external CSR activities. This finding challenged the results of the European Network for SME Research 
that found SME involvement in external CSR increased with number of employees (Observatory of European SMEs, 2002.)

The regression results obscure the finding that smaller SMEs were overrepresented in the lowest levels of CSR participation. For example, organizations with less than 50 employees represented $33 \%$ of the sample, but accounted for $40 \%$ of the lowest internal CSR index values and $72 \%$ of the lowest external CSR index values. While the overall participation rates are similar for all size SMEs, smaller SMEs are more prevalent in the lower participation rates. This supports the prior finding that the smallest SMEs engage in fewer CSR activities than larger SMEs.

Overall, this analysis demonstrated that number of employees is a significant variable for predicting CSR activity. However, size predicts only a small amount of the variance in CSR activity. As a result, it would not be appropriate to make assumptions about an organization's level of CSR activity based solely on the number of employees in the organization. Rather, any discussion of SMEs CSR activity would need to consider a multitude of interrelated organization characteristics.

\section{Role of other organization characteristics}

The sample of 3,005 SMEs included data on over 50 organization characteristics suggesting further analysis on how these characteristics might influence CSR activity. While number of employees was previously established as the most significant variable, other organization characteristics concerning industry, leadership, employees, and location were also found to have a statistically significant relationship with CSR activity.

Location. The 3,005 participants were classified into four geographic regions Midwest, Northeast, South and West -- as defined by the U.S. Census Bureau. From the 
analysis, geographic region was determined to be a statistically significant variable in seven of the ten regression models. Specifically, the Midwest was found to be a positive indicator for the aggregated internal, external, and total CSR models. A Southern location was significant for only one area of CSR - sustainability - but the negative coefficient indicated SMEs in the South participated in fewer sustainability activities. The West location was only significant for community service CSR, but also with a negative coefficient suggesting organizations in the West engaged in fewer community CSR activities than other regions.

As a point of reference, the Reputation Institute's (2015) global ranking of the top 50 CSR companies (based on citizenship and workplace dimensions) included 21 companies in the United States such as Disney, Intel, HP, and FedEx. Eleven of these 21 companies were headquartered in the West, four were located in the Midwest, and two were in the South. This data would suggest organizations in the West are leaders in CSR activity among large, public companies. CSRHub's global ratings found the top 20 CSR companies in the United States were primarily located in the South or West (2015). However, the results from this study of SMEs indicated contradictory findings for small and medium organizations. For SMEs, a West or South location was either neutral or negative for CSR activity while a Midwest location had a positive relationship with all types of CSR activity.

Industry. The survey data contained information on organizations representing 28 industries. Prior SME research was unclear on the role of industry on CSR as some studies found industry was an important variable linked to CSR activity (Observatory of European SMEs, 2002), other research found industry was not significant for CSR 
activity (Perrini, 2006) and other authors claimed the need for more industry specific research (Kechiche \& Soparnot, 2012.) Only two of the 28 industries in this study were consistently statistically significant for CSR activity. The accounting industry had a positive and significant relationship to total and internal CSR along with the highest coefficient of all variables for external CSR. By contrast, the auto dealer industry was significantly negative for internal and total CSR suggesting auto dealers were less likely to engage in internal CSR activities.

The Reputation Institute's top 21 CSR companies in the United States in 2015 included large, public companies such as Google, Microsoft, and 3M, that primarily represent the manufacturing and technology industries (Reputation Institute, 2015). CSRHub's top 20 CSR companies in the United States were heavily represented by manufacturing and utilities. By contrast, this study of SMEs found the manufacturing industry was not statistically significant for CSR activity and the technology industry had a small but negative relationship with CSR activity. More specifically, the technology industry had a negative coefficient for total CSR, personal development activities, community service activities, and external CSR.

Leadership. Another area of analysis for CSR activity involved the organization's leadership. Prior studies identified the important role of SME leadership in pursuing CSR activities (Jenkins, 2006; Murillo \& Lozano, 2006; Spence, 1999; Vives, 2006) and this study corroborated those findings.

This study analyzed leadership characteristics including frequency of executive hosted employee meetings, tenure of the highest executive, and gender representation on the executive team. The most significant leadership variable was the frequency of 
executive hosted employee meetings (monthly, quarterly, bi-annually, annually, less than once a year, and never) that proved statistically significant and positive for all CSR activities. This finding suggests that organizations with a greater frequency of executive hosted employee meetings participated in more CSR activities. Logically, frequent employee meetings could be considered indicative of an organization's commitment to internal CSR. However, the significant and positive relationship also held true for the frequency of employee meetings and the level of participation in external CSR.

The SMEs in the sample had an average executive tenure of 13 years with a range of one to 57 years. This analysis found longer executive tenure was positively related to higher levels of CSR activity suggesting SME's with a longer-serving chief executive were more likely to engage in CSR activities. Executive tenure was most strongly correlated with external CSR rather than internal CSR. This finding raises questions about how the priorities and interests of executives may evolve over the length of their tenure.

The initial analysis found gender of the top executive was not relevant for predicting CSR activity consistent with the findings of Ede at al. (2000). However, the gender distribution of the executive team proved statistically significant for predicting level of internal, external, and total CSR activity. The SMEs in the sample had an average of 69 percent men on the executive team. However, a higher percentage of men on the executive team was related to a lower level of CSR activity. This significant but negative relationship held true for CSR activities around diversity, flexible work arrangements, and sustainability. 
Overall, this study confirmed the influence of an executive on an organization's level of CSR activity. Leaders of any gender with a longer tenure, more women on the executive team, and more frequent executive hosted employee meetings were more likely to engage in CSR activities.

Employees. One of the espoused benefits of CSR for all sized organizations is increased employee retention (Caroll \& Shabana, 2010; Grayson \& Dodd, 2007; Vitaliano, 2010). This SME-focused study found that an increase in CSR activity was associated with a decrease in voluntary turnover for SMEs similar to Murillo and Lozano's (2006) findings for SMEs in Spain. Many of the internal CSR activities benefit employees, which would appear relevant for voluntary turnover rates. However, voluntary employee turnover was also a significant variable for predicting external CSR activity focused outside the organization. Employee turnover has associated costs (Griffeth et al., 2000) that are detrimental to an organization suggesting CSR activities associated with reduced turnover would be beneficial to the organization.

The variable, ratio of HR staff to employees, measured the number of Human Resources staff for every 100 employees and was found to be a significant and positive for predicting total, internal, and external CSR activity. This finding indicates an increase in the ratio of Human Resources was associated with a positive increase in the level of CSR activity. While Human Resources employees are not inherently responsible for CSR (Gond et al., 2011), an increase in the number of HR staff could generate more time to implement and manage both internal and external CSR activities. An additional variable concerning the attainment of Human Resources certifications was found significant for internal and external CSR. While the Human Resource certifications offered by the HR 
Certification Institute (2015) do not explicitly address CSR practices, the presence of Human Resources certifications was predictive of a higher level of CSR activity.

\section{Characteristics with no Significance to CSR Activity}

This analysis was also meaningful for identifying four of the 20 organization characteristics that did not have a significant relationship to any CSR activity: executive gender, hours to be considered full time, job creation in the recent fiscal year, and involuntary separation rates.

While CSR activities might be associated with caring or compassion that are considered feminine traits (Noddings, 2003), this study found that gender of the top executive was not a significant predictor for any CSR activity. Male and female top executives were equally likely to lead organizations with high or low levels of CSR activity. Similarly, the number of weekly hours required for an employee to be considered full-time (between 20 and 40 hours) was not significant for CSR activity. While full-time employee status is often associated with eligibility for benefits (which could include elements of internal CSR), the analysis found this organization characteristic did not relate to CSR activity.

Recent economic challenges have driven some SMES to focus more on survival (Jenkins, 2009) than CSR. Creating new jobs could be seen as an indicator of business success beyond survival. However, the study findings found new job creation was not a significant variable for predicting CSR activity. Eighty-eighty percent of the participating organizations had created new jobs, but this was not related to any of the CSR activities. No prior research had identified involuntary turnover as a variable that might be related 
to CSR activity and this analysis confirmed involuntary turnover rates were not significant for any CSR activities.

\section{Limitations and Delimitations}

As with all research, it is necessary to acknowledge the inevitable limitations and delimitations. A major delimitation of this study is the explicit focus on SMEs in the United States. While there is much that can be learned from studying organizations of all sizes, this study centered on organizations with less than 500 employees in the United States. While there are SMEs around the world that warrant research, this study considered only the activities of SMEs located in the United States therefore the findings can only be applied to this sub-set of organizations.

Despite careful planning and design, this study also experienced limitations. The sample of 3,005 SMEs obtained from the Best Places to Work programs were not representative of all SMEs in the United States. These self-selected organizations submitted their survey data seeking positive recognition for their workplace practices suggesting they might be outliers among SMEs. It is highly likely that SMEs choosing to participate in the Best Place to Work programs vary systematically from those that do not choose to participate. This selection bias provided a data-rich sample but the study results can not be considered representative of all SMEs in the United States.

The survey instrument also presented some limitations. The 80-question survey took approximately three hours to complete. This extensive time commitment may have led to survey fatigue where respondents did not give equal attention to all questions. In addition, the survey covered a wide variety of topics, some of which may have required knowledge not available to the individual completing the survey. While the survey could 
be saved and worked on over the course of two weeks, some answers may reflect "best guesses" as opposed to specific knowledge.

Another limitation of this study was the reliance on self-reported data. The survey included very specific questions regarding an organization's practices but there was no way to validate the responses. The large number of participants and the lack of publicly available information for many of these organizations rendered data checking nearly impossible. In addition, the responses may have been influenced by a social desirability bias. The participants were all seeking recognition as a best place to work so might be more likely to provide answers that would portray their organization positively.

The design of this study is also limited in that it sought insight into the correlation between variables, but does not make an assessment of causality. While this study analyzed many characteristics of organizations for their relationship to CSR activity, because it was not a randomized control trial, it cannot draw conclusions about specific variables causing a change in CSR activity.

Another limitation of this study is the lack of generalizability of the results. The sample included small and medium businesses in multiple industries across the United States suggesting the study can not be generalized for all sized businesses in all locations.

\section{Future Research}

This study sought to address an existing research gap by investigating CSR activities in SMEs in the United States. However, further research could expand on this study in several ways. First, future research could seek data from a more representative sample of SMEs that could be generalizable to a larger population of SMEs in the United States. The organizations in this study were self-selected as contenders for a Best Place to 
Work award suggesting there could be additional insight gained from studying CSR in SMEs that are not leading employers.

Future studies might also seek to focus on CSR activity by industry. While this study included organizations from 28 industries, only 2 industries, accounting and auto dealers, were statistically significant. However, efforts to implement CSR could be focused by industry suggesting more industry specific findings could be actionable for promoting CSR.

In addition, future studies on CSR in SMEs could focus geographically. While a national sample provides interesting insights regarding geographic differences, individual SMEs may not feel compelled to follow national trends. A study focused on a single geographic area could be considered more relevant and actionable for SMEs in that geographic area.

Finally, this cross-sectional study analyzed SME activities at a point in time, 2014. However, businesses are subject to continuously changing factors, internal and external, that could influence their participation in CSR activities. As a result, future studies could incorporate longitudinal data to analyze how CSR activity changes over time and age of the organization.

\section{Significance of the Study}

This study found that SMEs in the United States participate in CSR and the number of employees in an organization played only a small role in explaining levels of CSR activity. CSR advocates could consider this an exciting finding as it indicates SMEs are not inherently limited in their CSR activities. Instead, SMEs can actively engage in a variety of CSR activities to benefit their organization and society. Along these lines, 
these findings have meaningful implications for two key players who can further advocate for CSR in SMEs - business associations and executives.

\section{Implications for Business Associations}

Research has shown that SMEs are not familiar with CSR or don't think it applies to them (Giovanna et al., 2012; Jenkins, 2006; Lee, 2012) and the lack of know how is a major barrier to implementing CSR (Lepoutre and Heene, 2006). Business associations such as the Small Business Administration, Chambers of Commerce, and industry associations are the most frequently cited enablers of CSR (Apospori et al., 2012) indicating they could play a pivotal role in educating SMEs about CSR (Grayson \& Dodd, 2007; Murillo \& Lozano, 2006). Business associations that work with SMEs could present the findings of this study as validation of the occurrence and viability of CSR for small and medium organizations in the United States. While SMEs may intuitively recognize the social benefits of engaging in CSR (Perrini, 2006; Russo and Tencati; Vives, 2006), business associations could also reinforce the business benefits of CSR including decreased voluntary turnover and improved quality of job applicants (Dineen \& Allen, 2015), along with competitive advantage (Spence, 1999.)

The literature documented a host of reasons why SMEs choose not to engage in CSR activities. In response, business associations need to create CSR education programs that directly challenge these claims. SMEs that believe CSR is only for large companies (Murillo and Lozano, 2006) could be shown that over 99\% of SMEs studied participated in CSR. The most common CSR activities for SMEs included supporting community service initiatives, promoting sustainable practices, and providing wellness programs in the workplace such as onsite flu shots, health screenings or Weight Watchers 
programs. In addition, SMEs that claim they don't have the resources to participate in CSR (Lepoutre \& Heene, 2006) can be given detail on successfully implemented CSR initiatives that require limited resources such as supporting employees in leadership roles with volunteer organizations or offering flexible work hours.

The results of this study also suggest that industry associations for auto dealers such as the National Automobile Dealers Association (NADA) and the National Independent Auto Dealers (NIADA) should be especially vigilant in addressing CSR. Auto dealers had the strongest negative relationship with CSR indicating they have the most room for improvement. Conversely, associations for the accounting industry such as the American Institute of CPAs may want to build on their strong CSR performance and further educate accounting organizations about the viability and benefits of CSR.

\section{Implications for Executives}

The opportunity to promote CSR to SMEs also resides with organization executives who play a critical role in CSR participation (Kechiche and Soparnot, 2001; Vives, 2006). While executives inevitably focus on financial and performance results, CSR still warrants their attention.

Executives need to be aware of the link between tenure and CSR activity. Prior research found that an executive's personal values were of major importance for CSR participation (Murillo \& Lozano, 2006) but didn’t clarify if these values and their corresponding CSR inclination changed over time. This 2014 survey data showed that executives with longer tenure led organizations with a higher level of engagement in CSR activities. Rather than provide an excuse for delayed action, this insight should prompt executives to address CSR earlier in their tenure. Executives should also be aware of how 
their actions influence an organization's CSR activity. The frequency of executive hosted employee meetings was found to be a significant predictor of CSR activity. While hosting employee meetings is not unto itself a CSR activity, it represents an attitude or openness that may be conducive to participating in CSR activities.

Finally, executives need to recognize how the gender distribution of the executive team can influence CSR activity. While survey respondents had an average male to female distribution of $69 \%$ to $31 \%$ on their executive teams, higher male representation was associated with lower CSR activity. While balanced gender distribution on an executive team has many advantages (Oakley, 2000), increased CSR activity would be another positive outcome. When recruiting and promoting executive positions, SME leaders need to recognize the CSR case along with the business case for gender diversity in management.

\section{Conclusion}

In response to unanswered questions in the literature, this exploratory study examined survey responses from 3,005 SMEs in the United States regarding their participation in $22 \mathrm{CSR}$ activities. The initial analysis concluded that SMEs can and do participate in CSR despite the common perception that CSR only applies to large corporations (Jenkins, 2009.) In addition, SMEs participated in a variety of CSR activities that were both internal and external to the organization. More specifically, the internal activities addressed diversity, health and wellness, personal development, family support, and flexible work arrangements while the external activities involved community and sustainability initiatives. While the baseline level of CSR participation was high for all SMEs, the analysis found number of employees was positively associated 
with CSR activity indicating SMEs with more employees participated in more CSR activities.

The inferential analysis also found that organization characteristics regarding industry, geographic region, leadership, and employees had a significant relationship to CSR activity. More specifically, the accounting industry proved to have a positive relationship with CSR activity while auto dealers were negatively associated with CSR activity. In contrast to large corporations, SMEs in the Midwest had a positive association with CSR while the West and South locations had a negative or insignificant relationship with CSR. Regarding leadership, executives with longer tenure and more frequent employee meetings engaged in more CSR. Finally, voluntary turnover rates had a negative coefficient for CSR suggesting more CSR activity was associated with lower turnover rates, a tangible benefit for any organization.

These study findings are relevant to expanding the knowledge of CSR in SMEs in the United States. With this increased understanding, advocates for CSR can develop SME-specific programs to raise awareness and promote implementation of CSR activities. With the powerful combination of awareness, knowledge and interest, SMEs in the United States can increasingly engage in CSR to benefit both their organizations and society. 


\section{REFERENCES}

Accenture. (2013). UN Global Compact CEO Study on Sustainability 2013. Retrieved from https://www.accenture.com/us-en/insight-un-global-compact-ceo-studysustainability-2013

Aguilera, R., Rupp, D.E., Williams, C.A. \& Ganapathi, J. (2007). Putting the S Back in Corporate Social Responsibility: A Multilevel Theory Of Social Change in Organizations. Academy of Management Review, 32, 3, 836-863

Apospori, E., Zografos, K., \& Magrizos, S. (2012). SME corporate social responsibility and competitiveness: a literature review. International Journal of Technology Management. 58, 1/2,10-31

Baisakalova, A. (2012). Survey on Corporate Social Responsibility in Kazakhstan. Journal of Global Management. 4, 1

Barnett, M.L. (2007). Stakeholder Influence Capacity and the variability of financial returns to corporate social responsibility. Academy of Management Review, 32, $784-816$

Baumann-Pauly, D. \& Spence, L. (2013). Organizing Corporate Social Responsibility in Small and Large Firms: Size Matters. Journal of Business Ethics. 115, 693-705

BenefitCorp Information Center. (2015). Retrieved from http://benefitcorp.net/quick-faqs Best Companies Group. (2015). Retrieved from http://www.bestcompaniesgroup.com Bowen, H. (1953). Social Responsibilities of the Businessman. New York. Harper \& Row.

Brown, T.J. \& Dacin, P.A., (1997). The company and the product: Corporate associations and consumer product responses. Journal of Marketing. 61, 1, 68-84 
Burton, B., \& Goldsby, M. (2009). Corporate Social Responsibility Orientation, Goals and Behavior: A Study of Small Business Owners. Business \& Society. 48, 1, 88104

Campbell, J.L. (2007). Why Would Corporations Behave in Social Responsible Ways? An Institutional Theory of Corporate Social Responsibility. Academy of Management Review, 32, 3, 946-967.

Carroll, A.B. (1979). A Three-Dimensional Conceptual Model of Corporate Performance. Academy of Management Review, 4, 4, 497-505.

Carroll, A.B. \& Shabana, K.M. (2010). The Business Case for Corporate Social Responsibility: A Review of Concepts, Research and Practice. International Journal of Management Reviews, 85-105.

Castka, P., Balzarova, M.A., Bamber, C.J. \& Sharp, J.M. (2004). How Can SMEs Effectively Implement the CSR Agenda? A UK Case Study Perspective. Corporate Social Responsibility and Environmental Management. 11, 3, 140-149

Cheng, B., Ioannou, I., \& Serafeim, G. (2013). Corporate Social Responsibility and Access to Finance. Strategic Management Journal. 35, 1-23

Choi, E. \& Spletzer, J.R. (2012). The declining average size of establishments: evidence and explanations. Monthly Labor Review. Bureau of Labor Statistics.

Clark, L. \& Master, D. (2012). Corporate ESG/Sustainability/Responsibility Reporting. Governance \& Accountability Institute

Cowen, S.S., Ferreri, L.B., \& Parker, L.D. (1987). The Impact of Corporate Characteristics on Social Responsibility Disclosure: A Typology and Frequency Based Analysis. Accounting, Organizations and Society. 12, 2, 111-122 
CSRHub. (2015). Global rankings of overall CSR score. Retrieved from http://www.csrhub.com/csrhub/

Curran, J., Rutherfoord, R., \& Smith, S.L. (2000). Is There a Local Business

Community? Explaining the non-participation of small business in local economic development. Local Economy.

Dahlsrud, A. (2006). How Corporate Social Responsibility is Defined: An Analysis of 37 Definitions. Corporate Social Responsibility and Environmental Management. 114.doi: $10.1002 / \mathrm{csr} .132$

Dawson, S., Breen, J., \& Satyen, L. (2002). The Ethical Outlook of Micro Business Operators. Journal of Small Business Management. 40, 4, 302-313

Dean, T.J., Brown, R.L., \& Bamford, C.E. (1998). Differences in Large and Small Firm Responses to Environmental Context: Strategic Implications From a Comparative Analysis of Business Formations. Strategic Management Journal. 19, 709-728

Devinney, T.M. (2009). Is the Socially Responsible Corporation a Myth? The Good, the Bad, and the Ugly of Corporate Social Responsibility. Academy of Management Perspectives. 44-56

Dineen, B., \& Allen, D.G. (2015). Third Party Employment Branding: Human Capital Inflows And Outflows Following ‘Best Places To Work’ Certifications. Academy of Management Journal. published ahead of print July 14, 2015, doi:10.5465/amj.2013.1091

Donaldson, T., \& Preston, L.E. (1995). The Stakeholder Theory of the Corporation: Concepts, Evidence, and Implications. Academy of Management Review. 20,1, $65-91$ 
Ede, F.O., Panigraphi, B., Stuart, J., \& Calcich, S. (2000). Ethics in Small Minority Business. Journal of Business Ethics. 26, 133-146

Elkington, J. (1998). Cannibals with forks: The triple bottom line of $21^{\text {st }}$ century business. Oxford, England: Capstone

European Commission. (2001). Promoting a European framework for corporate social responsibility. Accessed June 28, 2015 from http://www.corporatejustice.org/IMG/pdf/greenpaper_en.pdf

European Commission. (2011). Communication From The Commission To The European Parliament, The Council, The European Economic And Social Committee And The Committee Of The Regions: A Renewed EU Strategy 201114 For Corporate Social Responsibility. Retrieved from http://ec.europa.eu/enterprise/policies/sustainable-business/corporate-socialresponsibility/index_en.htm

Fitjat, R.D. (2011). Little big firms? Corporate social responsibility in small businesses that do not compete against big ones. Business Ethics: A European Review. 20, 2, $30-44$

Fowler, F. J. (2009). Survey Research Methods. Thousand Oaks, CA. SAGE Publications Freeman, R. E. \& Velamuri, S.R. (2008). A New Approach to CSR: Corporate Stakeholder Responsibility. Available at SSRN: http://ssrn.com/abstract=1186223

Friedman, M. (1970). The Social Responsibility of Business is to Increase its Profits. The New York Times Magazine, 1-6

Gellert, F.J. \& de Graaf F.J. (2012). Corporate Social Responsibility and aging workforces: an explorative study of corporate social responsibility 
implementation in small- and medium-sized enterprises. Business Ethics: A European Review. 21,4, 353-363

Gibb, A. A., (2000). SME Policy, Academic Research and the Growth of Ignorance, Mythical Concepts, Myths, Assumptions, Rituals, and Confusions. International Small Business Journal. 18, 3, 13-34

Giovanna, C., Alfredo, A., \& Lucio, C. (2012). Corporate Social Responsibility: A Survey among SMEs in Bergamo. Procedia Social and Behavioral Sciences. 62, $325-341$

Gond, J.P., Igalens, J., Swaen, V., \& Akremi, A. (2011). The Human Resources Contribution to Responsible Leadership: An Exploration of the CSR-HR Interface. Journal of Business Ethics. 98, 1, 115-132

Graafland, J., van de Ven, G., \& Stoffele, N. (2003). Strategies and Instruments for Organising CSR by Small and Large Businesses in the Netherlands. Journal of Business Ethics. 47, 45-60

Grant Thornton. (2008). Corporate Social Responsibility: a necessity not a choice. International Business Report

Grayson, D. \& Dodd, T. (2007). Small is Sustainable (And Beautiful) - Encouraging European Smaller Enterprises To Be Sustainable. Working Paper.

Griffeth, R., Hom, P., and Geartner, S. (2000). A Meta-Analysis of Antecedents and Correlates of Employee Turnover: Update, Moderator Tests, and Research Implications for the Next Millennium. Journal of Management. 26, 3, 463-488 
Harrison, J.S. \& Freeman, R.E. (1999). Stakeholders, Social Responsibility, and Performance: Empirical Evidence and Theoretical Perspectives. Academy of Management Journal, 42, 5, 479-485

Hillman, A. \& Keim, G. (2001). Shareholder value, stakeholder management and social issues: what's the bottom line? Strategic Management Journal, 22, 125-139

Human Resources Certificate Institution. (2015). Retrieved October 2015 from http://www.hrci.org/our-programs/our-hr-certifications

Hurst, E. \& Pugsley, B.W. (2011). What Do Small Business Do? Working Paper 17041. National Bureau of Economic Research. Cambridge, MA

Jamali, D., Zanhour, M., \& Keshishian, T. (2009). Peculiar Strengths and Relational Attributes of SMEs in the Context of CSR. Journal of Business Ethics. 87, 355377

Jenkins, H. (2004). A Critique of Conventional CSR Theory: An SME Perspective. Journal of General Management. 29, 4,

Jenkins, H. (2006). Small business champions for corporate social responsibility. Journal of Business Ethics. 67, 3, 241-256

Kechiche, A. \& Soparnot, R. (2012). CSR within SMEs: Literature Review. International Business Research. 5, 7, 97-104

Krell, E. (2013). Is HR Doing More With Less? HR Magazine. Society for Human Resource Management. 58,9

Lahdesmaki, M. \& Suutaru, T. (2012). Keeping at Arm's Length or Searching for Social Proximity? Corporate Social Responsibility as a Reciprocal Process Between Small Business and Local Community. Journal of Business Ethics. 108, 481-493 
Lee, M., Mak, A., \& Pang, A. (2012). Bridging the Gap: An Exploratory Study of Corporate Social Responsibility among SMEs in Singapore. Journal of Public Relations Research, 24, 299-317

Lepoutre, J. \& Heene, A. (2006). Investigating the Impact of Firm Size on Small Business Social Responsibility: A Critical Review. Journal of Business Ethics, $67,257-273$

Madden, K., Scaife, W., \& Crissman, K. (2006). How and why small to medium sized enterprises (SMEs) engage with their communities: An Australian study. International Journal of Nonprofit \& Voluntary Sector Marketing, 11, 49-60.

Margolis, J.D., Elfenbein, H.A., \& Walsh, J.P. (2007). Does it pay to be good? A metaanalysis and redirection of research on corporate social and financial performance. (Working Paper). Boston: Harvard Business School

Margolis, J.D. \& Walsh, J.P. (2003). Misery Loves Companies: Rethinking social initiatives by business. Administrative Sciences Quarterly. 48, 2, 268-305

Marquez, P. (2012). SMEs in Latin America: a driver of social and environmental responsible business. Working Paper.

McWilliams, A. \& Siegel, D. (2000). Corporate Social Responsibility and financial performance: Correlation or misspecification? Strategic Management Journal, $21,5,603-609$

McWilliams, A. \& Siegel, D. (2001). Corporate Social Responsibility: A Theory of the Firm Perspective. Academy of Management Review, 26, 1, 117-127

McWilliams, A., Siegel, D., \& Wright, P. (2006). Corporate Social Responsibility: Strategic Implications. Journal of Management Studies, 43, 1, 1-18 
McWilliams, A. \& Siegel, D. (2011). Creating and Capturing Value: Strategic Corporate Social Responsibility, Resource-Based Theory, and Sustainable Competitive Advantage. Journal of Management Journal, 37, 5, 1480-1495

Meyers, L., Gamst, G., \& Guarino, C. (2006). Applied Multivariate Research: Design and Interpretation. Sage Publications Inc. Thousand Oaks, California.

Moore, G. \& Spence, L. (2006). Editorial: Responsibility and Small Business. Journal of Business Ethics. 67, 219-226

Morsing, M. \& Perrini, F. (2009). CSR in SMEs: do SMEs matter for the CSR agenda? Business Ethics: A European Review. 18, 1,

Murillo, D. \& Lozano, J. (2006). SMEs and CSR: An Approach to CSR in their Own Words. Journal of Business Ethics. 67, 227-240

Newman, R. (2011). Why U.S. Companies Aren't So American Anymore. US News and World Report. Retrieved from http://money.usnews.com/money/blogs/flowchart/2011/06/30/why-us-companiesarent-so-american-anymore

Noddings, N. (2003). Caring: A Relational Approach to Ethics and Moral Education. Second Edition. University of California Press. Berkeley, CA.

Oakley, J. (2000). Gender-based Barriers to Senior Management Positions: Understanding the Scarcity of Female CEOs. Journal of Business Ethics. 27, 4, $321-334$

Observatory of European SMEs. (2002). European SMEs and Social and Environmental Responsibility. European Commission. Brussels, Belgium. 
Olphert, C. (2015). Creating value by investing in community involvement. Boston College Center for Corporate Citizenship. Retrieved from http://corporatecitizenship.bc.edu/creating-value-by-investing-in-communityinvolvement

Orlitzky, M. (2001). Does Firm Size Confound the Relationship Between Corporate Social Performance and Firm Financial Performance? Journal of Business Ethics. $33,167-180$

Orlitzky, M., Schmidt, F.L., \& Rynes, S.L. (2003). Corporate social and financial performance: a meta-analysis. Organizations Studies, 24, 403-411

Pastrana, N.A. \& Sriramesh, K. (2014). Corporate Social Responsibility: Perceptions and practices among SMEs in Colombia. Public Relations Review. 40, 14-24

Perrini, F. (2006). SMEs and CSR Theory: Evidence and Implications from an Italian Perspective. Journal of Business Ethics. 67, 305-316

Perrini, F., Russo, A., \& Tencati, A. (2007). CSR Strategies of SMEs and Large Firms. Evidence from Italy. Journal of Business Ethics. 74, 3, 285-300

Prieto-Carrón, M., Lund-Thomsen, P., Chan, A., Muro, A., \& Bhushan, C. (2006). Critical perspectives on CSR and development: what we know, what we don't know, and what we need to know. International Affairs, 82(5), 977-987.

Porter, M.E. (2013). Speech at TedEx Global. http://blog.ted.com/2013/06/14/got-socialproblems-business-can-help-michael-porter-at-tedglobal-2013/

Porter, M.E. \& Kramer, M.R. (2006). Strategy and Society. The Link Between Competitive Advantage and Corporate Social Responsibility. Harvard Business Review, 84, 12, 78-92 
Reputation Institute. (2015). The Global CSR RepTrak 100. Retrieved from https://www.reputationinstitute.com/Resources/Registered/PDF-Resources/2015Global-CSR-RepTrak-Download.aspx

Roberts, S., Lawson, R., \& Nicholls, J. (2006). Generating Regional-Scale Improvements in SME Corporate Responsibility Performance: Lessons from Responsibility Northwest. Journal Of Business Ethic. 67, 3, 275-286

Roy, A., Vyas, V., \& Jain, P. (2013). SMEs Motivation: Corporate Social Responsibility. Journal of Indian Management.

Russo, M. \& Fouts, P.A. (1997). A Resource-Based Perspective On Corporate Environmental Performance And Profitability. Academy of Management Journal. $40,3,435-559$

Russo, A. \& Perrini, F. (2010). Investigating Stakeholder Theory and Social Capital: CSR in Large Firms and SMEs. Journal of Business Ethics. 91, 207-221

Sanchez, P.E. \& Benito-Hernandez. (2015). CSR Policies: Effects on Labour Productivity in Spanish Micro and Small Manufacturing Companies. Journal of Business Ethics. 128, 705-724

Schwartz, M. \& Caroll, A. B. (2003). Corporate Social Responsibility: A Three Domain Approach. Business Ethics Quarterly. 13, 4, 503-530

Small Business Administration. (2014). Frequently Asked Questions. Retrieved from http://www.sba.gov/sites/default/files/FAQ_March_2014_0.pdf

Small Business Administration. (2015). Key Provisions Under the Affordable Care Act for Employers with 50 or More Employees. Retrieved from https://www.sba.gov/content/employers-50-or-more-employees 
Smith, K., \& Alexander, J. (2013). Which CSR-Related Headings Do Fortune 500 Companies Use on Their Websites? Business Communications Quarterly. 76, 2, $155-171$

Spence. L. (1999). Does size matter? The state of the art in small business ethics. Business Ethics: A European Review. 8, 3

Spence, L. (2007). CSR and Small Business in a European Policy Context: The Five "C"s of CSR and Small Business Research Agenda 2007. Business and Society Review. $112,4,533-552$

Spence, L.J. \& Rutherfoord, R. (2001). Social Responsibility, Profit Maximisation and the Small Firm Owner-Manager. Small Business and Enterprise Development. 8, 2, 126-139

Surroca, J., Tribo, J., \& Waddock, S. (2009). Corporate Responsibility and Financial Performance. The Role of Intangible Resources. Strategic Management Journal, $31,463-490$

Tencati, A., Perrini, F., \& Pogutz, S. (2004). New Tools to Foster Corporate Socially Responsible Behavior. Journal of Business Ethics. 53, 173-190

Turban, D.B. \& Greening, D.W. (1997). Corporate social performance and organizational attractiveness to prospective employees. Academy of Management Journal. 40, 3, $658-672$

Udayasankar, K. (2007). Corporate Social Responsibility and Firm Size. Journal of Business Ethics. 83, 167-175

United States Department of State. (2014). Retrieved from http://www.state.gov/e/eb/eppd/csr/ 
van Oosterhout, J. \& Hougens, P. (2006). Much Ado About Nothing: A Conceptual Critique of CSR. Research in Management. Erasmus Research Institute in Management. Rotterdam, The Netherlands.

Vazquez-Carrasco, R. \& Lopez-Perez, M. (2013). Small \& Medium Sized Enterprises and Corporate Social Responsibility: A Systematic Review of the Literature. Quality and Quantity. 47, 3205-3218

Vitaliano, D. (2010). Corporate social responsibility and labor turnover. Corporate Governance: The international journal of business in society. 10, 5, 563 - 573

Vives, A. (2006). Social and Environmental Responsibility in Small and Medium Enterprises in Latin America. Inter-American Development Bank.

Vogel, D. J. (2005). Is There a Market for Virtue? The Business Case for Corporate Social Responsibility. California Management Review, 47, 4

Waddock, S. \& Graves, S. (1997). The Corporate Social Performance - Financial Performance Link. Strategic Management Journal. 18, 4, 303-319

Wang, T. \& Bansal, P. (2012). Social Responsibility in New Ventures. Strategic Management Journal, 33, 1135-1153

Web of Knowledge. (2015). Query results found at http://0apps.webofknowledge.com.sally.sandiego.edu

Welford, R., Chan, C., \& Man, M. (2007). Priorities for Corporate Social Responsibility: a Survey of Businesses and their Stakeholders. Corporate Social Responsibility and Environmental Management. 15, 52-62

Welsh, J.A. \& White, J.F. (1981). A small business is not a little big business. Harvard Business Review. 20-32 
World Business Council for Sustainable Development. (2013). Action 2020 retrieved from http://www.wbcsd.org/action2020.aspx

Yosifon, D.G. (2013). The Law of Corporate Purpose. Berkeley Business Law Journal. 181

Zadek, S. (2004). The Path to Corporate Responsibility. Harvard Business Review. 82, 12, p125-132

United States Census Bureau. (2014). Retrieved from http://censtats.census.gov/cgibin/cbpnaic/cbpsect.pl 
APPENDIX: SURVEY INSTRUMENT

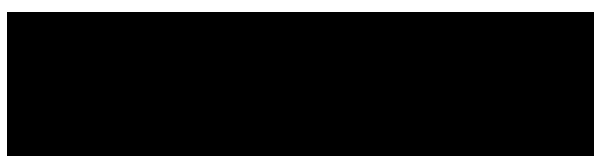

Important instructions for filling out the Employer Questionnaire:

Please fill out the questionnaire as completely as possible. Your answers will be used to rank companies and determine the "Best" list. If your organization makes the list, all or a portion of the information you submit may be shared in the publication and/or website announcing the list, as well as in "spotlighting" each organization should there be an awards event.

1: All questions apply to operations in the state, unless otherwise noted.

2: All questions apply to operations within your organization's most recently completed fiscal year, unless otherwise noted.

3: Please navigate within the questionnaire using the "Back" and "Save and Continue" buttons found at the bottom of each page.

$>$ Please do not use the back and forward arrow buttons on your Internet browser. To page forward in the questionnaire, you must select the "Save and Continue" button. To page backward, please select the "Back" button. Both the "Back" and "Save and Continue" buttons appear at the bottom of each page.

$>$ If you should unintentionally select your browser's back or forward arrow, simply click the Refresh button on your Toolbar which will take you back to the questionnaire.

$>$ The "Save and Continue" button will automatically save your most recent changes to that page in the questionnaire.

4: For questions requiring a NUMERIC RESPONSE:

> Please respond using whole numbers only, rounding to the nearest whole number if necessary.

$>$ If a question relates to a employee benefit and your organization provides different benefits for different classes of employees, please provide the average value across all employees. For example, if the question asks "How many vacation days do you provide for an employee who has been with the company for at least one year?" and you offer 15 vacation days per year to professional staff, 10 to clerical staff and 20 to executives, you would enter 15 , which is the average of $15+10+20$.

> If a question does not apply to you or if the requested information is not available, please leave the question blank.

5: For questions requiring a TEXT RESPONSE: 


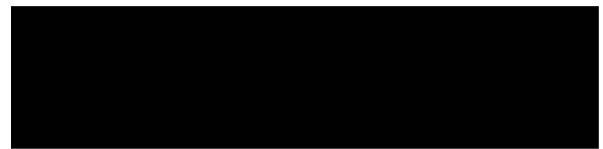

$>$ In some instances, the size of the response box represents the approximate text characters available for that response. For other questions, a character counter has been provided to indicate the available remaining character spaces as you input your response. If you exceed the maximum limit, the character counter will reflect a negative number and any additional text entered beyond the maximum limit will not appear.

$>$ Please be as brief as possible and use language and phrasing that is easy to comprehend. Avoid industry jargon. Do not include employee or client testimonials or quotes within your responses. Do not include any information you cannot support or would not be comfortable having publicized about your company if you make the list.

$>$ If the question does not apply to you, the requested information is not available, or you do not wish to disclose the requested information, please enter "N/A".

6: If you need further clarification of any question, place your cursor over the "?" icon near the individual question and a definition will appear.

7: The Employer Questionnaire is hosted in an online database, so you are able to access the questionnaire as often as necessary prior to the $E Q$ submission deadline. When your questionnaire is complete, select the option that reads "The questionnaire is complete and ready to be submitted" and then click the "Save and Continue" button.

8: "Oh, no! I've submitted our questionnaire, but now I realize I need to revise something!" Not to worry. Should you "Submit" the EQ and need to make changes, you may login to make any necessary updates as often as you like until the questionnaire deadline.

9: Once the submission deadline has passed, only the most recently saved version of your questionnaire will be used during the ranking analysis process. Incomplete questionnaires will not be considered.

10: Only one person can be in the questionnaire at any given time. If more than one person needs to complete this questionnaire, we recommend that you collect the data from the appropriate departments and then have one person input all of the data.

11: At the end of the questionnaire, you will have an option to print out your responses and/or e-mail a copy to yourself for your records. We recommend that you do select one or both of these options, as we will not be able to send you a copy. To print the entire list of questions and responses, do not simply skip to the last page and click "Print". You must "Save and Continue" each page of the questionnaire to the end and then click "Print".

12: If at any time you need to review these instructions regarding the Employer Questionnaire, simply click on the "Click Here for More Information" icon found at the top of each page. 


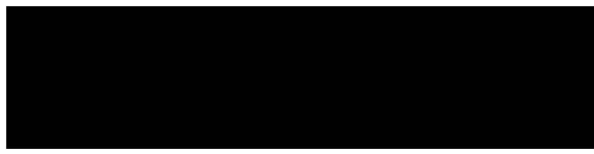

\section{Organization and Contact Information:}

1: Organization Name (As you would like it to appear on reports and in print if you make the list):

Organization Name

Please type the full employer name EXACTLY as you would like it printed on all reports and list-related publications/communications.

2: Survey Administrator Name:

Survey Administrator Name

Name of person who is serving as primary contact for this program. This is the person to whom all program-related correspondence will be directed.

3: Survey Administrator email address:

\section{Email}

Email address of person who is serving as primary contact for this program. This is the person to whom all program-related correspondence will be directed.

3a: Re-enter Survey Administrator email address:

4: Survey Administrator phone number:
Phone Number

$$
\text { Email }
$$

Phone number, including area code, of the person who will be the primary contact for the survey program. Please use dashes to separate the area code, prefix and exchange and add the extension number if applicable (example: 800-555-1212 $\mathrm{x} 100)$. 


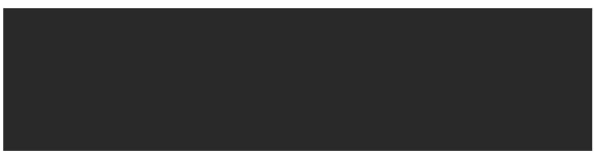

5: Survey Administrator business mailing address: Company Name

Address

City

State

Zip

$\square$ Check this box if the addresses are the same.

We recommend a business mailing address for the person listed as the organization's primary Assessment Coordinator for this program. We caution against providing a home address, as this address may be used for publication purposes.

6: U.S. Employer Headquarters Address, if applicable: Company Name

Address

City

State

Zip

6a: Is the Survey Administrator an employee of the organization?
$\mathrm{O}$ Yes
O No

This question is designed to ensure that the contact information for the organization, rather than a public relations or marketing vendor, appears within the awards publication.

7: Employer Web site address:

(Example www.bestcompaniesgroup.com)

Do not include "http://" but do include "www" if applicable.

7a: Employer Twitter handle:

(Example "Best Companies Group @BestCompaniesGP") 


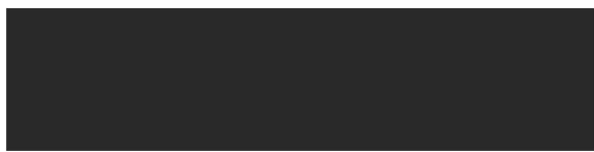

Organization and Contact Information Continued:

8: Industry:

Accounting

Odvertising/Public

Relations/Marketing

O Architecture

O Banking

Construction

Consulting

O Distribution

Education

$O$ Engineering

O Government

Financial Services Other

O Healthcare -

Insurance/Services

O Healthcare - Provider

O Insurance (nonhealthcare)

$O$ Legal

Non-Profit - Health \& Human Services

O Non-Profit - Other
O Manufacturing

Publishing/Printing

O Real Estate

O Restaurant

O Retail

O Services - Other

O Staffing

O Technology

O Telecommunications

O Transportation

O Other - Please list

Please choose the industry that best describes your organization. If none apply, please select 'Other'

8a: Other (Please tell us your industry if not in the list above.) Industry 


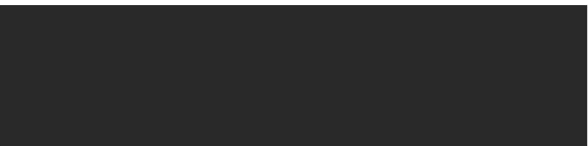

Organization and Contact Information Continued:

9: Optional: Should your organization be named to the list, we would like to notify your top four vendors or suppliers. Please provide the names and contact information of your top four business vendors (Please include contact name, address, email and telephone.)

Should your organization be named to the list, we would like to notify your top four vendors or suppliers (i.e. health insurer, benefits administrator, bank, accounting firm, etc.).

\section{Vendor 1:}

Company Name:

Contact Name:

Address:

City, State, Zip:

Telephone:

E-mail Address:

Vendor 2:

Company Name:

Contact Name:

Address:

City, State, Zip:

Telephone:

E-mail Address:

Vendor 3:

Company Name:

Contact Name:

Address:

City, State, Zip:

Telephone:

E-mail Address:

Vendor 4:

Company Name:

Contact Name:

Address:

City, State, Zip:

Telephone:

E-mail Address: 


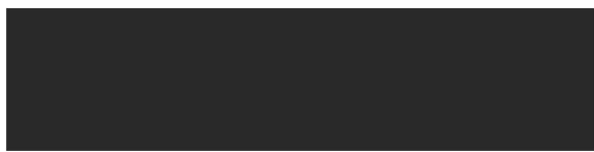

\section{Organization and Contact Information Continued:}

Open-ended responses are limited to a maximum number of characters as indicated by the character counter near each text box. When the maximum limit has been reached, the text box will no longer accept additional text. If you input text by copying/pasting from a Word Document, the text box will indicate if you have exceeded the maximum character limit. If this occurs you will need to condense your response in order to continue with the survey. If there is no character counter, the response box is unlimited.

\section{0: Please provide a brief overview of your organization's products/services.}

\section{Character Counter}

11: If we were to ask your employees, "What three things does your employer do for you that you love?" what would they say? Examples are: chair massages, holiday party, 4-day work week, etc. Be specific; don't just reply, "We are like a family." (Please limit your response to the space provided.)

One

Two

Three

11a: Other than the three items listed in Question 11, are there any other unique or creative employee benefits or programs offered by your organization? Examples are: a "Biggest Loser" weight loss challenge, a ping-pong table, paid time off to provide on-site relief effort to disaster victims, ice cream Fridays, etc. (Please limit your response to the space provided.)

One

Two

Three

Should your organization make the list, responses to this question may be used as a brief employer highlight within the award publication and/or recognition event. 


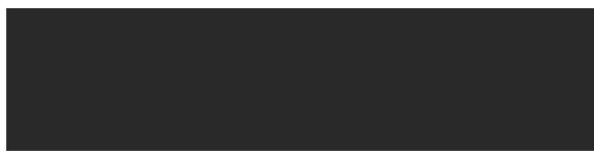

\section{Organization and Contact Information Continued:}

12: What is the name of the highest ranking official/CEO within your entire organization? First Name, Last Name

Please include first name, last name and any suffix if appropriate (examples: Mr. Leslie Smith, Dr. Maria Santiago, Mr. Marcus Williams, Jr.). If your organization does not have a CEO, please provide information for the senior-most position within the organization (e.g., President, Senior Partner, etc.)

12a: Please confirm the title of the highest ranking official/CEO within your entire organization. Title

"President", "CEO", "Grand Poobah."

$12 \mathrm{~b}$ : Please indicate the office location of the highest ranking official/CEO within your entire organization. City, State

For example, "U.S. Corporate Office," "San Diego Office," "London, England," etc.

12c: Please indicate the e-mail address of the highest ranking official/CEO. (This email address will only be used to contact this individual to arrange a possible media interview and will not be shared publicly.)

This email address will only be used to contact this individual to arrange a possible interview for publication purposes and will not be shared publicly.

12d: How many years has your highest ranking official/CEO been in this position within the organization? (Please enter a whole number. If less than one year, please put 1. Do not enter year of start date.) Year(s) 


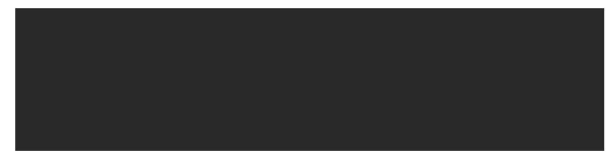

\section{Organization and Contact Information Continued:}

12e: Please provide the name of the highest ranking individual in the program area of the nominated workplace.

First Name, Last Name

12f: Please confirm the title of the highest ranking individual in the program area of the nominated workplace.

Title

12g: Please indicate the office location of the highest ranking individual in the program area of the nominated workplace.

$$
\text { City, State }
$$

12h: Please provide the email address of the highest ranking individual in the program area. (This email address will only be used to contact this individual to arrange a possible media interview should you make the list, and will not be shared publicly.) E-mail 


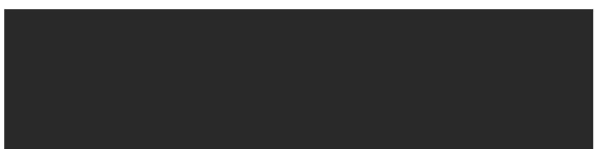

\section{Organization and Contact Information Continued:}

Please answer the following questions using the appropriate employee counts as of [registration deadline]. Please round to the nearest whole number and do not include text, decimal places or commas.

13: Please enter the total number of full-time, permanent staff employed in the United States. (This number should include partners, founders and other salaried executives. Do not include part-time, temporary, seasonal or per diem employees, nor consultants and independent contractors.)

\section{Full-Time U.S. Employees}

This number should include partners, founders and other salaried executives. Do not include part-time, temporary, seasonal or per diem employees, nor consultants and independent contractors.

13a: Please enter the total number of part-time, permanent staff employed in the United States. (This number should include partners, founders and other salaried executives. Do not include full-time, temporary, seasonal or per diem employees, nor consultants and independent contractors.)

Part-Time U.S. Employees

This number should not include full-time, temporary, seasonal or per diem employees, nor consultants and independent contractors.

14: Please enter the total number of full-time, permanent staff employed in the state. (This number should include partners, founders and other salaried executives. Do not include parttime, temporary, seasonal or per diem employees, nor consultants and independent contractors.)

Full-Time Program Employees

This number should include partners, founders and other salaried executives. Do not include part-time, temporary, seasonal or per diem employees, nor consultants and independent contractors. 


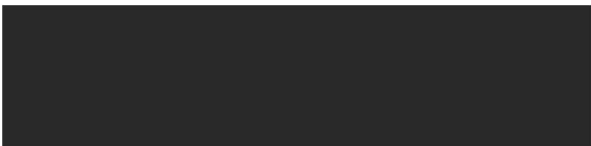

\section{Organization and Contact Information Continued:}

14a: Please enter the total number of part-time, permanent staff employed in the state. (This number should include partners, founders and other salaried executives. Do not include full-time, temporary, seasonal or per diem employees, nor consultants and independent contractors.) Part-Time Program Employees

This number should not include full-time, temporary, seasonal or per diem employees, nor consultants and independent contractors.

14b: Please provide the total current number of full-time permanent staff employed outside of the United States. (This number should include partners, founders and other salaried executives. Do not include part-time, temporary, seasonal or per diem employees, nor consultants and independent contractors.)

Full-Time Employees outside of the U.S.

This number should include partners, founders and other salaried executives. Do not include part-time, temporary, seasonal or per diem employees, nor consultants and independent contractors.

14c: Please provide the total current number of part-time, permanent staff employed outside of the United States. (This number should not include full-time, temporary, seasonal or per diem employees, nor consultants and independent contractors.)

Part-Time Employees outside of the U.S.

This number should include partners, founders and other salaried executives. Do not include full-time, temporary, seasonal or per diem employees, nor consultants and independent contractors.

14d: Our organization only employs individuals within the program area, and not anywhere else inside or outside of the United States.

$\mathrm{O}$ Yes

O No

"Program Area" refers to the city, state or region for this "Best" workplace competition. 


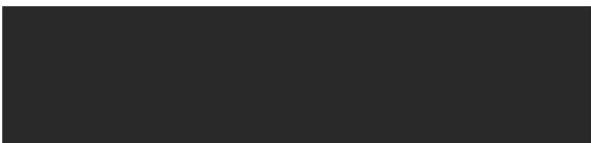

\section{Organization and Contact Information Continued:}

14e: Please provide your organization's total worldwide employee count, both domestic and international. This number should equal the total combined U.S. and non-U.S. employee counts you entered in question 13,13a, 14b, and 14c.

Total Worldwide Employee Count

14f: Within your organization, what is the minimum number of hours per week that an individual must work to be considered a full-time employee?
O 1 - 19 Hours
O 20 Hours
21 - 24 Hours
O 25 Hours
O 26 - 29 Hours
O 30 Hours
O 31 - 34 Hours
O 35 Hours
36 - 39 Hours
O 40 Hours

15: How many full-time Human Resources staff persons do you employ within your organization?

Full-Time HR staff

Please indicate the total number of full-time staff dedicated solely to human resources functions. This number should not include employees of the organization acting in other roles who also perform the HR function, such as a CFO with HR decision-making responsibilities or a staff accountant who performs payroll functions, nor any outsourced or contracted HR personnel. 


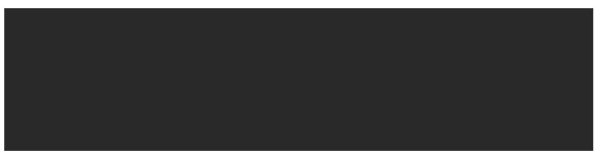

\section{Organization and Contact Information Continued:}

16: What professional Human Resources certifications are currently held by your organization's HR staff (Select all that apply.)

$\square$ Professional in Human Resources (PHR)

Senior Professional in Human Resources (SPHR)

$\square$ Global Professional in Human Resources (GPHR)

$\square$ Certified Compensation Professional (CCP)

$\square$ Certified Benefits Professional (CBP)

$\square$ Global Remuneration Professional (GRP)

$\checkmark$ Work Life Certified Professional (WLCP)

$\square$ Certified Executive Compensation Professional (CECP)

$\square$ Certified Sales Compensation Professional (CSCP)

$\square$ Other

Other: (Please respond with full certification title, not just initials, and the accrediting institution.)

List only professional HR certifications such as those granted by the Human Resources Certification Institute (PHR/SPHR/GPHR), World At Work Society of Certified Professionals (CCP/CBP/GRP/WLCP) or other accredited institutions.

17: What percentage of your employees are male? Percent

To calculate this percentage, divide the number of male employees by the total number of employees and multiply by 100 .

18: What percentage of your employees are female? Percent

To calculate this percentage, divide the number of female employees by the total number of employees and multiply by 100 . 
Organization and Contact Information Continued:

19: What percentage of your executive team is male? Percent

Executive Team refers to Vice President/Partner level and above, but does not include the Board of Directors. To calculate this percentage, divide the number of male executives by the total number on the executive team and multiply by 100 .

20: What percentage of your executive team is female? Percent

Executive Team refers to Vice President/Partner level and above, but does not include the Board of Directors. To calculate this percentage, divide the number of female executives by the total number on the executive team and multiply by 100 .

21: In the most recently completed fiscal year, what was the average annual salary for exempt employees in your organization? (Include partners if salaried.)

Average Salary for Exempt Employees

Exempt employees are those who, because of their duties, responsibilities, and level of decision-making authority are exempt from the overtime provisions of the Fair Labor Standards Act (FLSA). Exempt employees are expected, by most organizations, to work whatever hours are necessary to accomplish the goals and deliverables of their positions and are not compensated for overtime.

22: In the most recently completed fiscal year, what was the average annual salary for nonexempt employees in your organization? Average Salary for Non-Exempt Employees

Non-exempt employees are usually non-professional employees who are paid on an hourly basis and are subject to all Fair Labor Standards Act (FLSA) provisions. Nonexempt employees are normally required to account for hours and fractional hours worked and must be compensated for all hours worked, including overtime hours. To calculate the average annual salary of non-exempt employees, multiply the average hourly rate for all non-exempt staff by 2,080 hours. For example, if the average hourly rate for all non-exempt staff in your organization is $\$ 10$, the average annual rate would be $\$ 10 \times 2,080=\$ 20,800$.

Best Companies Group (C)

Proprietary \& Confidential

Page 14 of 46 
Organization and Contact Information Continued:

23: How many new, full-time hourly or salaried permanent positions were created in the most recently completed fiscal year?

Positions Created

"Newly created positions" are job roles which previously did not exist and were not performed by any individual. Do not include existing positions which were vacated due to voluntary or involuntary turnover, layoffs, discharges or retirement.

24: How many open, full-time hourly or salaried permanent positions were filled in the most recently completed fiscal year?

Positions Filled

Open positions filled" includes new hires, and internal transfers and promotions to fill both vacated and newly-created hourly and salaried positions.

25: Of all open, full-time permanent salaried positions filled in the most recently completed fiscal year, what percentage of those positions were filled by internal staff? Percent

To calculate this percentage, divide the number of transfers and promotions of existing employees within the company by the total number of filled positions and multiply the result by 100 .

26: What was your organization's percentage of voluntary turnover in the most recently completed fiscal year? Percent

Voluntary turnover refers to instances where management agrees that the employee had the option to continue employment with the organization at the time of separation (i.e., the employee chose to leave rather than was asked to leave the organization). Include anyone who was on the payroll, both full- and part-time. Do not include layoffs, discharges and retirees. To calculate this percentage, divide the number of voluntary separations by the total number of employees and multiply this result by 100 . If there was no turnover, please respond 0 


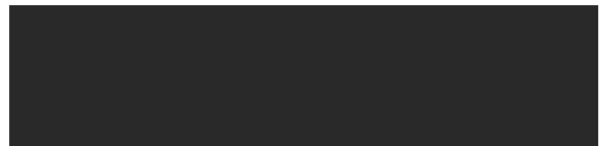

\section{Organization and Contact Information Continued:}

27: What was the 2013 average percentage of voluntary turnover within your organization's industry? If you do not know this figure, please click on the ? icon to the left for more information. (? icon will link to the Department of Labor's rates of annual turnover by industry on the actual EQ) Percent

$\square$ Information Not Available

Click the ? icon to access the Industry Turnover chart. If you are unable to access this document, please temporally allow popups.

28: In the most recently completed fiscal year, what percentage of your full-time permanent, hourly or salaried employee population was involuntarily separated from employment due to a layoff or reduction in force? Percent

A layoff is an involuntary separation initiated by the employer and includes a layoff with no intent to rehire, a formal layoff lasting or expected to last more than 7 days, or a discharge resulting from a merger, downsizing or closing. To calculate this percentage, divide the number of layoffs by the total number of employees and multiply this result by 100 . 


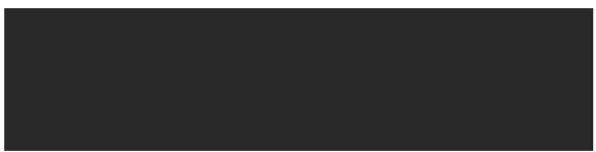

Hiring and Employment Practices:

29: Does your organization employ any programs/practices to actively recruit/retain employees of varying ethnic and cultural backgrounds?

$$
\begin{aligned}
& O \text { Yes } \\
& O \text { No }
\end{aligned}
$$

29a: If yes, beyond simply stating that your organization is an Equal Opportunity Employer please briefly describe any programs/practices you employ to actively recruit/retain employees of varying ethnic and cultural backgrounds.

\section{0}

Examples may include partnering with and recruiting from local ethnic, cultural and religious organizations; recognizing holidays within your multi-cultural workforce; planning multi-cultural awareness activities; providing diversity training; etc.

30: Does your organization employ any programs/practices to actively recruit/retain members of the disabled community?

$$
\begin{aligned}
& O \text { Yes } \\
& O \text { No }
\end{aligned}
$$

30a: If yes, beyond simply stating that your organization is an Equal Opportunity Employer, please briefly describe any programs/practices you employ to actively recruit/retain members of the disabled community.

Examples may include partnering with and recruiting from local vocational rehabilitation organizations; insuring the workplace provides accommodations for disabled individuals; providing diversity training; etc. 


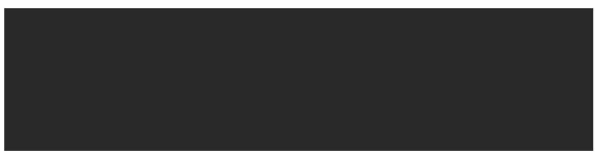

Hiring and Employment Practices Continued:

31: Does your organization employ any programs/practices to actively recruit/retain an aging workforce?

$O$ Yes
No

31a: If yes, beyond simply stating that your organization is an Equal Opportunity Employer, please briefly describe any practices you employ to actively recruit/retain an aging workforce.

\section{0}

Examples may include partnering with and recruiting from local senior's organizations; offering semi-retirement options to tenured employees; providing diversity training; etc.

32: Does your organization provide any formalized resources or support to employees who feel they have been treated unfairly?

$$
\begin{aligned}
& O \text { Yes } \\
& \text { O No }
\end{aligned}
$$

Refers to a formal process, other than approaching an immediate supervisor, for an employee to express fairness concerns. Examples include non-biased third-party conflict resolution or mediation, formal grievance procedures, etc.

33: What pre-employment screening tools does your organization utilize in the hiring process? (Select all that may apply.)

$\square$ Personality or behavioral assessments

$\square$ Criminal background checks

$\square$ Credit checks

$\square$ Professional references

$\square$ Personal references

$\square$ Our organization does not use any pre-employment screening tools

$\square$ Other, please describe

While drug testing is not required under the Drug-Free Workplace Act of 1988, many employers elect to test for a wide variety of substances including amphetamines, cannabinoids, cocaine and opiates. 


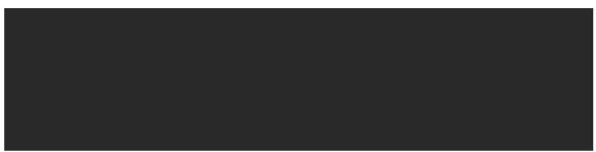

Hiring and Employment Practices Continued:

34: Does your organization have a formal policy regarding employee blogging, online social networking, or use of employer equipment for personal email access, etc.?

$\mathrm{O}$ Yes

O No

An organization may block access to social media sites on employer equipment, or may enforce a policy that use of the employer's electronic resources to access social media sites (such as Twitter, Facebook or MySpace) for non-business purposes is prohibited.

35: Does your organization have a formal policy to protect intellectual property, trade secrets or other proprietary information?

$\mathrm{O}$ Yes

O No

Intellectual property refers to intangible proprietary information such as formulas and ideas, inventions, designs, literary and artistic works and web pages. Examples include specific manufacturing processes, plans for a product launch, or a chemical formula. 


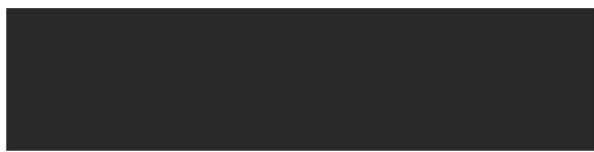

Pay \& Benefits Continued:

36: Does your organization offer any employee bonus or incentive programs?

O Yes

O No

Performance bonus/incentive plans are those which provide a financial or other tangible reward based on an employee's performance during a specified time period. Examples of rewards may include cash bonuses, company stock, gifts, vacations, use of a company vehicle or residence, free parking, etc.

If yes, please briefly describe your top three employee bonus or incentive programs including who is eligible, typical rewards, and any unique aspects.

One of Three: Top employee bonus or incentive programs:

250

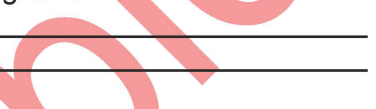

Two of Three: Top employee bonus or incentive programs:

250

Three of Three: Top employee bonus or incentive programs:

250

37: Do you offer bonuses to employees who refer new hires?

Y Yes

Commonly referred to as recruitment bonus or employee-referral bonus. Do not include salary or bonuses that may be provided to recruitment staff. An Employee Referral Bonus provides an incentive award to a current employee who refers a new applicant who is subsequently selected and successfully employed. 


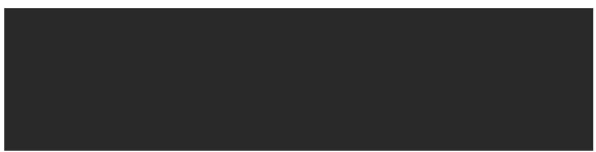

Pay \& Benefits Continued:

38: Do you offer a Profit Sharing Program?

$\mathrm{O}$ Yes

O No

A profit sharing program is a compensation arrangement in which employees receive additional pay or benefits when the employer earns or increases profits. It is separate from employee's regular salaries or bonuses.

39: Do you offer an Employee Stock Option Program (ESOP)?

O Yes

O No

An ESOP (also known as a stock purchase plan) is a trust set up by a corporation to allot some of its stock to be purchased by its employees over time. Used as an employee incentive, an ESOP may be a profit sharing, stock bonus, or money purchase pension plan.

40: Do you offer a retirement savings program such as a $401(k), 403(b)$ or 457 plan?

$O$ Yes
No

A $401(\mathrm{k})$ plan is a retirement plan sponsored by employers. Employees may choose to have a portion of their salary deferred to any of the plan's investment choices selected by the employer. The employer also may contribute to the employee's $401(\mathrm{k})$ by matching a portion of the investment (for example, $\$ .50$ for every $\$ 1.00$ the employee invests). The investments to which money is deferred may include stocks, bonds, money market funds, and employer stocks. A 403(b) plan is a retirement plan for civil governments and for nonprofit and nonpolitical religious, charitable, scientific, educational and other public interest-oriented organizations such as private schools, colleges, universities, research institutions and teaching hospitals. It has most of the same characteristics and benefits of a $401(\mathrm{k})$. A 457 plan is typically offered to government (and some non-government) employees and operates similarly to a $401(\mathrm{k})$ or $403(\mathrm{~b})$ plan. The key difference is that unlike a $401(\mathrm{k})$ plan, there is no $10 \%$ penalty for withdrawal before the age of $591 / 2$. Also, 457 plans can allow independent contractors to participate wherein $401(k)$ and $403(b)$ plans cannot. 


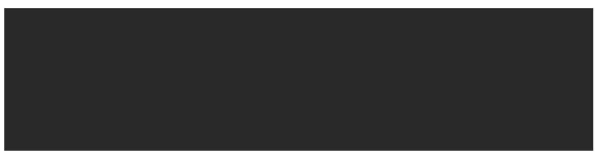

Pay \& Benefits Continued:

40a: If yes, when is an employee eligible to begin contributing to their retirement savings plan account?
O 30 days after hire
90 days after hire
O months after hire
O 1 year after hire
Other, please describe

40b: If yes, do you match employee contributions to an employee's retirement savings plan account?

$$
\begin{aligned}
& O \text { Yes } \\
& \text { O No }
\end{aligned}
$$

A match is when an employer matches all or part of an employee's contribution to their $401 \mathrm{~K}$ or $403 \mathrm{~b}$ plan. Please answer yes only if your organization contributes according to an established policy and independent of employer profits (e.g., not only when profits reach or exceed a certain level).

40c: If yes, do you also offer a discretionary match above and beyond the standard employer match?

$\mathrm{O}$ Yes

O No

A discretionary match is when the company decides from year-to-year how much of the employee's contribution to match. This may occur in the form of an additional profit sharing contribution.

41: Does your organization offer a defined benefit pension plan?

$$
\text { Y Yes }
$$

O No

In a defined benefit pension plan, an employee's post-retirement salary is predetermined based on a percentage of average earnings for a specified number of years during the employee's career. 


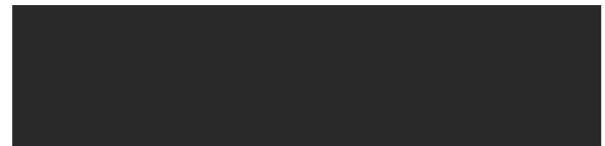

Pay \& Benefits Continued:

42: For each of the following benefits, indicate what percentage of the premium (cost of the benefit) is paid for by the employer. "Employee" refers to full-time employees only. If your organization offers more than one plan for any benefit, please select the response which describes your most basic plan. If your organization does not offer a benefit, please select "This benefit not offered." Mouse over the name of the coverage for more information.

\begin{tabular}{|c|c|c|c|c|c|c|}
\hline & $\begin{array}{l}\text { Employer } \\
\text { pays } \\
100 \% \text { of } \\
\text { premium }\end{array}$ & $\begin{array}{l}\text { Employer } \\
\text { pays } 75 \% \\
-99 \% \text { of } \\
\text { premium }\end{array}$ & $\begin{array}{l}\text { Employer } \\
\text { pays } 50 \% \\
-74 \% \text { of } \\
\text { premium }\end{array}$ & $\begin{array}{l}\text { Employer } \\
\text { pays } 25 \% \\
-49 \% \text { of } \\
\text { premium }\end{array}$ & $\begin{array}{l}\text { Employer } \\
\text { pays less } \\
\text { than } 25 \% \\
\text { of } \\
\text { premium }\end{array}$ & $\begin{array}{l}\text { This } \\
\text { benefit } \\
\text { not } \\
\text { offered }\end{array}$ \\
\hline Medical coverage (employee) & 0 & 0 & O & 0 & 0 & $\mathrm{O}$ \\
\hline $\begin{array}{l}\text { Medical coverage } \\
\text { (dependents) }\end{array}$ & O & 0 & 0 & & 0 & 0 \\
\hline $\begin{array}{l}\text { Prescription coverage } \\
\text { (employee) }\end{array}$ & $\mathrm{O}$ & $\mathrm{O}$ & 0 & & $\mathrm{O}$ & $\mathrm{O}$ \\
\hline $\begin{array}{l}\text { Prescription coverage } \\
\text { (dependents) }\end{array}$ & 0 & 0 & 0 & 0 & 0 & 0 \\
\hline Dental coverage (employee) & 0 & O & 0 & 0 & 0 & $\mathrm{O}$ \\
\hline $\begin{array}{l}\text { Dental coverage } \\
\text { (dependents) }\end{array}$ & $\mathrm{O}$ & 0 & o & 0 & O & $\mathrm{O}$ \\
\hline Vision coverage (employee) & 0 & 0 & 0 & $\mathrm{O}$ & 0 & 0 \\
\hline $\begin{array}{l}\text { Vision coverage } \\
\text { (dependents) }\end{array}$ & $\mathrm{O}$ & $\mathrm{O}$ & $\mathrm{O}$ & $\mathrm{O}$ & $\mathrm{O}$ & $\mathrm{O}$ \\
\hline $\begin{array}{l}\text { Long-term care insurance } \\
\text { (employee) }\end{array}$ & 0 & 0 & O & $\mathrm{O}$ & $\mathrm{O}$ & 0 \\
\hline $\begin{array}{l}\text { Long-term care insurance } \\
\text { (dependents) }\end{array}$ & 0 & O & 0 & 0 & 0 & $\mathrm{O}$ \\
\hline Life insurance (employee) & 0 & 0 & 0 & 0 & 0 & 0 \\
\hline Life insurance (dependents) & $\mathrm{O}$ & $\mathrm{O}$ & $\mathrm{O}$ & $\mathrm{O}$ & $\mathrm{O}$ & $\mathrm{O}$ \\
\hline Short-term disability benefits & 0 & 0 & 0 & 0 & 0 & 0 \\
\hline Long-term disability benefits & $\mathrm{O}$ & $\mathrm{O}$ & $\mathrm{O}$ & $\mathrm{O}$ & 0 & $\mathrm{O}$ \\
\hline
\end{tabular}

42a: Our organization offers the following healthcare plan(s) to its employees (Select all that apply.)

$\square$ Health Maintenance Organization (HMO)

$\square$ Preferred Provider Organization (PPO)

$\square$ Point-Of-Service Plan (POS)

$\square$ High Deductible Healthcare Plan (HDHP)

Consumer Driven Healthcare Plan (CDHP)

$\square$ None of the above 


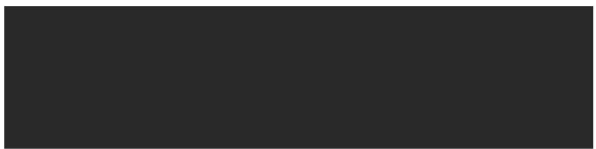

Pay \& Benefits Continued:

42b: Does your organization offer employees a choice of healthcare plans?

$\mathrm{O}$ Yes

O No

42c: If necessary, please use this space to briefly describe any unique aspects of your healthcare benefits (health, dental, vision, long-term care, disability, supplemental health insurance, pet insurance, etc.)

\section{0}

43: When is a new employee eligible to enroll in the organization's healthcare plan?

First day of hire

First day of the next month after hire

O 30 days after hire

O 60 days after hire

90 days after hire

More than 90 days after hire

Other, please describe

44: Our organization offers the option to enroll in health benefits to:

O Full-time employees only

O Full-time and part-time employees

Full-time, part-time and seasonal employees

O Our organization does not offer employee health benefits

Please consider whatever definition of "full-time" and "part-time" employment that your organization recognizes when answering this question.

45: Does your organization make any contribution toward an employee's Health Savings Account (HSA) or Health Reimbursement Account (HRA)?

$\mathrm{O}$ Yes

O No

Our organization does not offer a Health Savings Account or Health Reimbursement Account. 


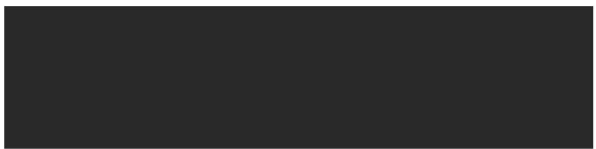

Pay \& Benefits Continued:

45a: If yes. Is this a one-time employer contribution or an annual contribution?

O One-time employer contribution

O Annual Contribution

45b: If yes, is the amount of the employer contribution the same for all employees?

$\bigcirc$ Yes

O No

A health savings account (HSA), is a tax-free medical savings account available to employees who are enrolled in a High Deductible Health Plan (HDHP). Unlike a flexible spending account (FSA), funds roll over and accumulate year to year if not spent.

46: Does your organization offer Flexible Spending Accounts (FSA)?

$\mathrm{O}$ Yes

O No

A Flexible Spending Account (FSA) is a tax-advantaged savings account set up by an employer to allow employees tax-free savings for qualified medical or dependent care expenses.

47: Does your organization offer domestic partner benefits?

$O$ Yes

Yes, this benefit is required by law

O No

A domestic partner is defined as a person of the same or opposite sex with whom the employee lives as a couple, not necessarily joined in any legal partnership, marriage, or civil union.

48: What is the number of paid holidays your organization offers per year? Paid Holidays

If the number varies from year to year, please provide the number offered in the latest fiscal year. If holidays are included in a PTO (paid time off) bank, enter the number the employer allotted in defining the total PTO bank accrual. 


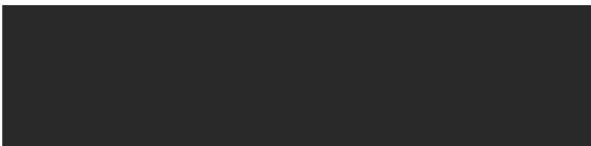

Pay \& Benefits Continued:

49: Does your organization provide time off as PTO (one bank of time) or as vacation/sick/personal days (separate banks)?

O PTO (PTO $\rightarrow$ Enable Q49a)

O Vacation / Sick / Personal (Vacation Sick Personal $\rightarrow$ Enable Q49c - Q49h)

In the traditional model, an employer offers separate banks of time for vacation, sick, and personal days, and employees may accrue hours at a different rate for each bank. A paid time off (PTO) model, on the other hand, combines vacation, sick time and personal time into a single bank of paid time for employee use for any purpose. If an employer with separate banks of time allotted 10 vacation days, 5 sick days, and 3 personal days per year and that organization moved to a PTO model, their PTO plan would either provide 18 days of available time (for any purpose) at the beginning of the year, or would allow employees to accrue the 18 days over the course of the year.

49a:Do you offer an unlimited number of PTO days after one year of employment?

$\mathrm{O}$ Yes

No (If no, enable Q49b)

49b: What is the number of PTO days available after one year of employment? (Do not include company holidays.) Days

49c: Do you offer unlimited number of vacation days after one year of employment?

$\mathrm{O}$ Yes

No (if no, enable Q49d)

49d: What is the number of vacation days available after one year of employment? Days

49e: Do you offer unlimited number of sick days after one year of employment?

$\mathrm{O}$ Yes

No (if no, enable Q49f)

49f: What is the number of sick days available after one year of employment? Sick Days

49g: Can an employee use sick days to care for an ill dependent?

$\mathrm{O}$ Yes

O No 


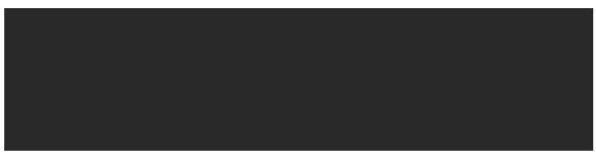

Pay \& Benefits Continued:

49h: What is the number of personal days available after one year of employment? Personal Days

50: Can employees trade accrued days for pay once the maximum accrual has been reached?

$\mathrm{O}$ Yes

O No

Some companies allow employees to "cash-in" all or some of their unused paid time off either at the end of the year or when they are close to or at their maximum accrual. The employee receives a lump-sum payment in exchange for the day/hours cashed in.

51: Can employees "donate" accrued PTO/sick days to any fellow employees in need?

O Yes

O No

Eligible employees may voluntarily donate, and/or receive donations, of accrued paid time off for critical personal situations and family medical emergencies.

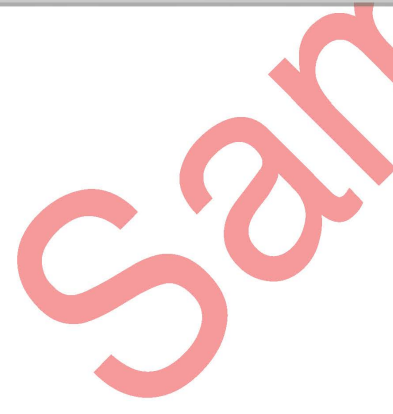




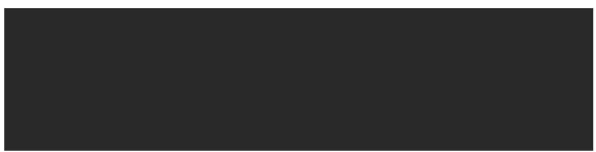

Work/Life Balance and Wellness Initiatives:

52: Does your organization allow employees additional paid time off for community service activities/volunteer work?

$O$ Yes
No

Select 'yes' only if you offer this in addition to employee's regular vacation, personal, or paid time off (PTO) days. Time off may be for an employee's chosen activity, or may be for an employer-sponsored organization or event.

53: Does your organization sponsor or actively support any community service initiatives?

$\mathrm{O}$ Yes

O No

Examples include support of nonprofit organizations such as Boy/Girl Scouts, Big Brothers/Big Sisters, United Way, Habitat for Humanity and local initiatives such as food banks, anti-littering programs, literacy programs, local shelters or kitchens, disaster relief programs, etc.

If yes, please briefly describe the top three community service initiatives your organization sponsors or actively supports through financial means or volunteer time.

One of Three: Top community service initiatives:

250

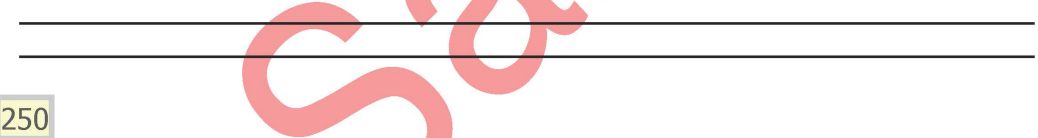

Two of Three: Top community service initiatives:

250

Three of Three: Top community service initiatives:

250 


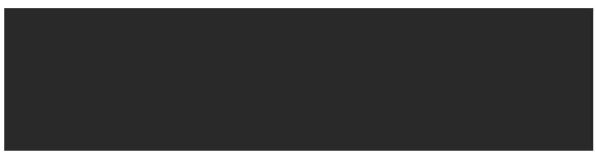

Work/Life Balance and Wellness Initiatives:

Please tell us about any of the following benefits and/or programs you may provide. The phrase "As a standard practice" implies that the program/benefit is widely accepted within your organization and not an exception to the normal routine.

54: As a standard practice, does your organization offer telecommuting options to your employees?

$\mathrm{O}$ Yes

O No

Telecommuting may also be known as telework, work-from-home or e-work. It refers to a work arrangement in which employees are given flexibility to work from a location other than the company's offices - most often from their home. Some employees may be fulltime teleworkers; others may be extended this arrangement on a limited (e.g., 1-3 days per week) or as-needed basis (e.g., when staying home to care for a sick child, etc.). It is understood that telecommuting is not appropriate for all positions (e.g., receptionists, maintenance or manufacturing staff, etc.).

55: As a standard practice, does your organization offer job sharing options?

\section{$\mathrm{O}$ Yes \\ O No}

Job sharing is a work arrangement in which two employees share one position in an organization, each working part of the week. 


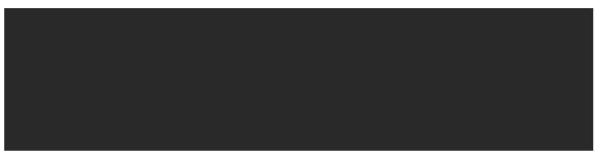

Work/Life Balance and Wellness Initiatives:

56: As a standard year-round practice, does your organization offer employees the option to work flexible hours or a compressed work week?

$\bigcirc$ Yes
No

A compressed work week is one in which an employee has the flexibility to work more hours per day in order to work fewer days per week (e.g., four 10-hour days per week instead of five 8-hour days per week). Please answer "Yes" only if a compressed work week option is available year-round, and not just during off-peak seasons.

57: What dress code applies to the majority of your employees?

O Business

O Business Casual

O Casual

O Uniforms

Business attire generally means suits with a matching jacket and ties for men, and dresses or pant/skirt sets for women. Business Casual refers to more relaxed attire such as trousers and collared shirts without a tie or jacket for men, and slacks/skirts with blouses or sweaters for women. A Casual dress policy may allow blue jeans, sweatpants and/or sweatshirts, shorts, t-shirts and thong-style sandals. Uniforms refer to companyissued or required standardized clothing such as scrubs for healthcare staff, jumpsuits or workpants/shirt sets for mechanics, required colors and/or styles of clothing for restaurant servers, etc.

58: Does your organization provide any workplace facilities to promote exercise and fitness?

$\mathrm{O}$ Yes

No

On-site fitness facilities may include a gym, workout room, exercise equipment, lockers, a shower, walking/jogging trail, bike racks, etc.

If yes, please briefly describe up to three facilities provided at your workplace which promote exercise and fitness.

One of Three: Facilities to promote exercise and fitness: 


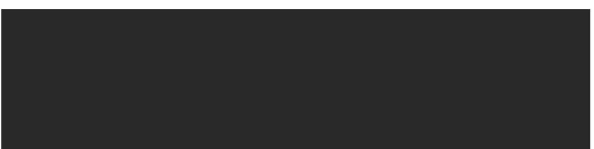

Work/Life Balance and Wellness Initiatives Continued:

Two of Three: Facilities to promote exercise and fitness:

250

Three of Three: Facilities to promote exercise and fitness:

59: Does your organization provide any fitness and/or wellness programs or practices within the workplace?

$\mathrm{O}$ Yes

O No

Examples may include on-site health fairs or fitness challenges, on-site health screenings and/or flu shots, Weight Watchers at Work (or similar) programs, chair massages, etc.

If yes, please briefly describe up to three successful fitness and/or wellness programs available to your employees in your workplace.

One of Three: Fitness and/or Wellness Programs:

250

Two of Three: Fitness and/or Wellness Programs:

250

Three of Three: Fitness and/or Wellness Programs:

250

Best Companies Group @

Proprietary \& Confidential

Page 31 of 46 


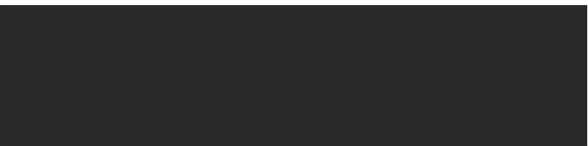

\section{Work/Life Balance and Wellness Initiatives Continued:}

60: Does your organization pay all or part of employees' costs for health club memberships or fitness or wellness programs?

$\mathrm{O}$ Yes

O No

60a: If yes, do you also pay all or a part of the cost for health club memberships or fitness or wellness programs to an employee's partner and/or other family members?

O Yes

O No

Examples of costs that may be fully or partially reimbursed include: health club/fitness club/gym memberships, registration and/or weekly fees for weight loss programs, costs associated with smoking cessation programs, registration fees for stress management seminars, etc.

61: Does your organization provide cafeteria or meal subsidies, free daily snacks or beverages? $\mathrm{O}$ Yes

O No

Examples include free or reduced-cost cafeterias, free meals (regularly or during peak seasons), free beverages (coffee, tea, bottled or filtered water, soft drinks, juices), free snacks (fruit, pretzels, chips, bagels, doughnuts, etc.)

62: Does your organization promote any sustainable or "green" practices?

$$
\text { Yes }
$$

No

Examples include recycling aluminum cans, paper products and ink/toner cartridges; shifting to more paperless work processes; purchasing products made from recycled materials; turning off lights, using renewable energy (e.g., solar or wind power); constructing new facilities using sustainable building practices, etc. 


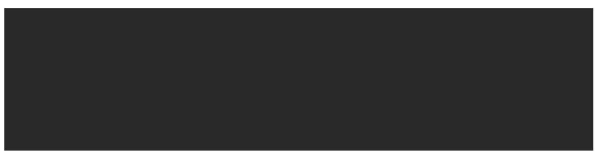

Work/Life Balance and Wellness Initiatives Continued:

If yes, please briefly describe up to three sustainable or "green" practices your organization promotes within your workplace to encourage conservation of the environment and its natural resources.

One of Three: Sustainable or Green Practices:

250

Two of Three: Sustainable or Green Practices:

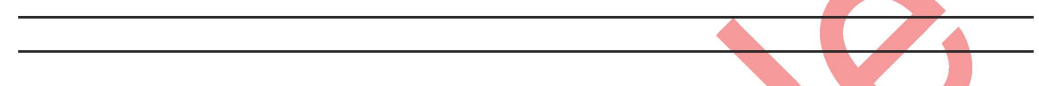

250

Three of Three: Sustainable or Green Practices:

250

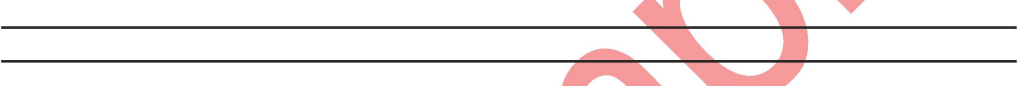




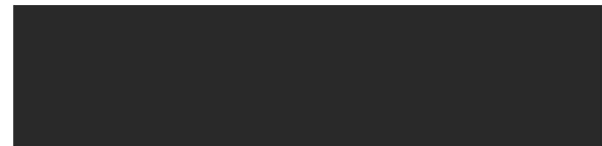

\section{Training \& Career Development:}

63: How often does your organization conduct Employee Performance Reviews for all staff?

O As needed

Once per year

O Twice per year

More than twice a year

O Our organization does not conduct Employee Performance Reviews for all staff.

This question refers to employee performance evaluations. Do not include employee engagement or satisfaction surveys.

64: Does your organization conduct 360-degree Performance Reviews?

O Yes, all staff

Yes, only supervisors and above

O Our organization does not conduct 360-degree Performance Reviews.

360 degree feedback is an evaluation technique that provides each employee the opportunity to receive performance feedback from his or her supervisor and four to eight peers, direct reports, coworkers and customers. Most also include a self-assessment.

65: Is an employee's compensation tied to performance?

$\mathrm{O}$ Yes

O No

Performance-based compensation is a system in which an employee receives an increase to their base pay ("merit pay"), or a bonus, for highly-ranked performance above and beyond the standard job requirement as defined by a performance appraisal.

66: What is the average number of hours a new employee spends in orientation? (Do not include departmental orientation or probation.) Average Whole Number

If orientation differs by type of position (e.g., clinical vs. non-clinical, professional vs. nonprofessional), please provide the AVERAGE number of hours across all positions. 


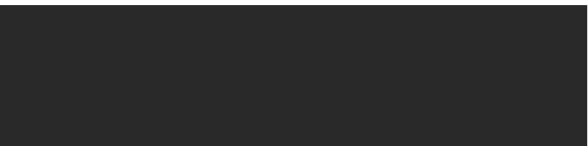

Training \& Career Development Continued:

69: What form(s) of tuition reimbursement/assistance does your organization offer? (Select all that apply.)

$\square$ Advanced or post-graduate degree

$\square$ Certifications

$\square$ Business education workshops and/or conferences

$\square$ Other, please describe

$\square$ Our organization does not offer tuition reimbursement/assistance.

Refers to reimbursement of tuition for college-level or above classes. May be limited to classes taken toward a degree, or may include any job-related class or seminar. The level of reimbursement may depend on the employee's final grade, or may be capped at a certain number of credits, or a certain dollar amount, per year.

70: Does your organization offer formal employee career development/job advancement programs or practices?

$\mathrm{O}$ Yes

O No

Refers to programs or practices designed to help employees to grow within their current positions or to transfer or advance to a different position within the organization.

If yes, please briefly describe any three formal employee career development/job advancement programs/practices.

One of Three: Programs/practices:

\section{0}

Two of Three: Programs/practices:

\section{0}

Three of Three: Programs/practices:

\section{0}




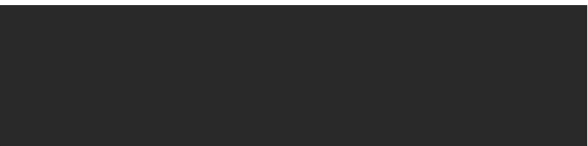

Training \& Career Development Continued:

71: Does your organization have any formalized programs/practices for succession planning? O Yes

O No

Succession planning refers to a deliberate process used to ensure that staff are developed who are able to replace senior management as they retire or leave the organization.

72: Does your organization offer any programs and/or practices focused on employee leadership training/development? Select all that apply.

$\square$ Mentoring

$\square$ Job shadowing/cross training

Attendance at leadership workshops or other formal leadership education

$\square$ Support of leadership roles within volunteer organizations outside of your organization

$\square$ Our organization does not offer any programs or practices focused on employee training and development

$\square$ Other

Refers to programs or practices specifically designed to help employees become leaders or improve their leadership skills within the organization.

Other, please describe:

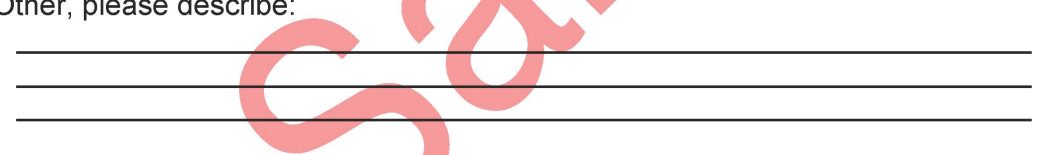




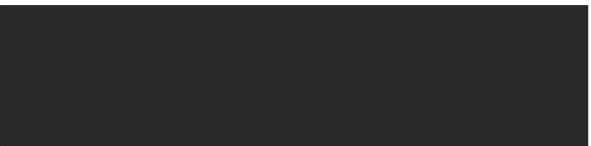

Corporate Culture \& Communications:

73: Does your organization offer any unique internal communications tools and/or practices? $\mathrm{O}$ Yes

O No

Examples include an employer Intranet, quarterly "town hall" meetings with upper management, front-line worker meetings without middle managers present, regular employee satisfaction surveys, etc.

If yes, please briefly describe any three unique tools and/or practices your organization utilizes to communicate with and encourage two-way dialogue between your upper management and employees.

One of Three: Unique communication tools and/or practices:

250

Two of Three: Unique communication tools and/or practices:

250

Three of Three: Unique communication tools and/or practices:

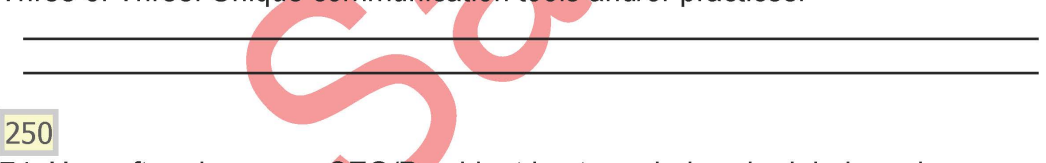

74: How often does your CEO/President host regularly-scheduled employee meetings?

O At least monthly

O Quarterly

O Bi-Annually

O Annually

Less often than once a year

Our CEO/President does not host regularly-scheduled employee meetings. 


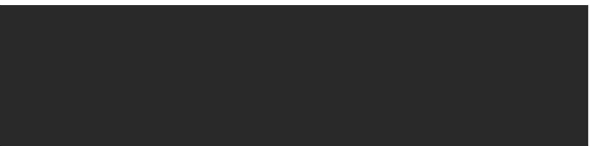

Corporate Culture \& Communications Continued:

75: How often does your organization regularly conduct a formal survey of its employee population? Please consider only workplace satisfaction or employee opinion surveys, either administered internally or as part of a competition.

O More than twice a year

T Twice a year

O Once a year

Every other year

$O$ Less often than every other year

O As needed

Our organization does not regularly conduct a formal employee survey.

76: Does your organization offer formal employee recognition/appreciation programs?

$\mathrm{O}$ Yes

No

Refers to practices or programs designed to recognize extraordinary employee performance, show appreciation for employee service or loyalty, etc. Examples include: Years of Service Awards, Employee of the Month Awards, Employee Appreciation dinners or picnics, etc.

If yes, please briefly describe up to three employee recognition/appreciation programs.

One of Three: Recognition/Appreciation Programs:

250

Two of Three: Recognition/Appreciation Programs:

250

Three of Three: Recognition/Appreciation Programs:

250

Best Companies Group $(\odot$

Proprietary \& Confidential

Page 39 of 46 


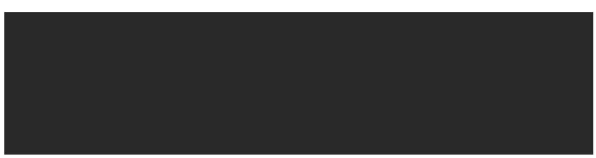

Corporate Culture \& Communications Continued:

77: Please describe any family-friendly benefits or practices your organization provides to its employees. Select all that apply.

Paternity leave (either paid or unpaid) for the birth or adoption of a child

Adoption assistance, such as reimbursement of agency fees, travel fees, legal assistance, paid time off before or after adoption, etc.

$\square$ Lactation facilities for breastfeeding mothers

All or part of an employees' full- or part-time childcare paid, either on a regular basis or only during busy seasons

Flexible hours to accommodate school events, taking a family member to the doctor, etc.

$\square$ Back-up child or elder care if an employee's regular caregiver is suddenly not available

After-school or summer programs for school-aged children of employees

Employer-sponsored Eldercare Assistance for employees with aging family members, such as transportation to medical appointments or meal delivery; securing of proper care and/or assistance facilities; information about financial resources; or counseling support for caregiver stress.

Immediate families invited to corporate events

Free or discounted tickets to local family entertainment or sporting events

$\square$ Our organization does not offer any family-friendly benefits or practices.

$\square$ Other

Other, please describe:

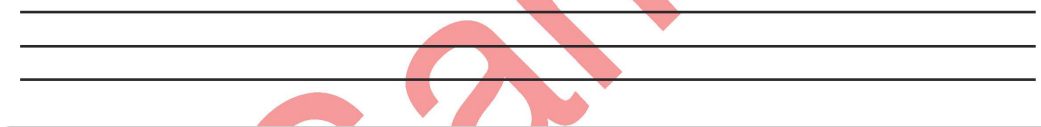

Family-friendly practices or benefits are those which help employees balance work with the demands of caring for family members. 


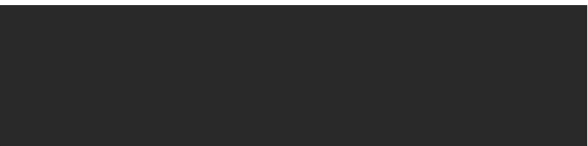

\section{Corporate Culture \& Communications Continued:}

78: Please describe any programs or practices your organization provides to promote a healthy work/life balance. Select all that apply.

$\square$ No overtime, or overtime kept at a minimum

Meetings and staff-only events limited to during work hours only

Monetary incentives or extra paid time off when overnight travel is required

- An employer-sponsored Employee Assistance Program (EAP) which may provide

counseling for marital, parental or financial problems, and/or assistance for specific conditions such as substance abuse, smoking and gambling

Productivity or time management workshops, seminars or classes

$\square$ On-site personal development and/or stress management workshops, seminars, or classes - Paid sabbaticals

Financial Education workshops, seminars or classes

Our organization does not offer any work/life balance programs nor practices.

$\square$ Other

Other, please describe:

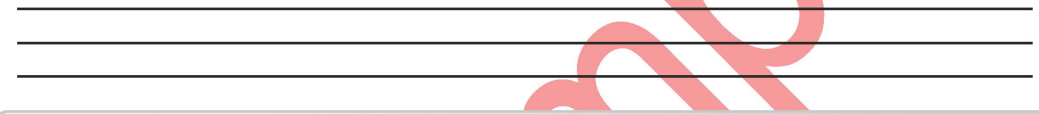

Work/life balance refers to the ability to balance the demands of, and satisfactions of, one's personal and work life.

79: Does your organization initiate any activities to relieve stress and promote fun?

O Yes

No

Examples include office chair races, silly contests, game tables, costumes at Halloween, allowing pets at work, announcing surprise Fridays off, etc. 


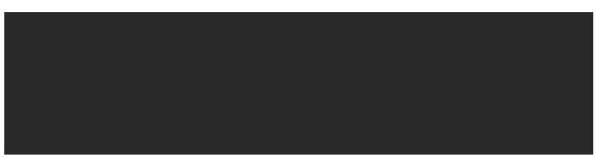

Corporate Culture \& Communications Continued:

If yes, please briefly describe up to three activities your organization initiates to relieve workday stress and promote fun.

One of Three: Activities to relieve stress and promote fun:

\section{0}

Two of Three: Activities to relieve stress and promote fun:

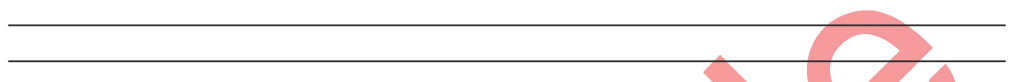

Three of Three: Activities to relieve stress and promote fun:

\section{0}

80: Please list any other awards your organization has been given for best practices in the workplace including the name of the award, by whom it was presented, rank (if applicable) and the year awarded.

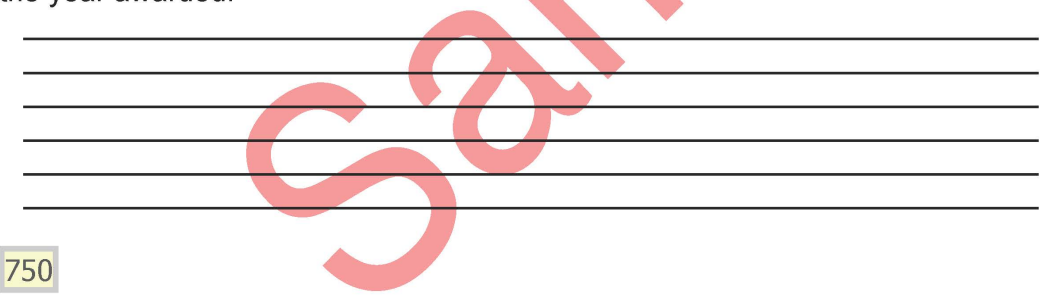

Examples may include \#15 "Working Mother Best 100 Companies in 2008" by Working Mother magazine, \#98 "Top 100 Companies to Work for in 2002" by Fortune magazine, etc. 


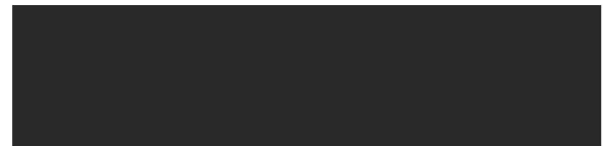

Media Information Request:

Should your company be named to the list, we would like to provide the following information to our publication partners for use in their special publication or awards event. This information will not be distributed or shared if your company does not make the list. Submitting your organization's logo and photos implies that you are granting permission to publish this information. We would like to request 4 images. (1 company logo, 3 company pictures.)

Please note - if you log out and then re-enter the EQ your photos and logos will not be visible as they are stored in a database. If you have uploaded your images, there is no need to re-upload them. Any duplicate photos will be removed.

First, your company logo:

Upload a color logo using the following specifications:

1: The file should be a vector EPS file, a high-resolution JPG, TIFF, AI, or PNG.

2: You will NOT be able to upload images larger than $3 \mathrm{MB}$. If your image is larger than $3 \mathrm{MB}$, please resize it smaller and resubmit.

3: PDF, GIF, or BMP files will not be accepted.

4: Do not use a scan off a piece of letterhead.

5: If you have any questions regarding your image, please email: support@bestcompaniesgroup.com.

Remember: Image must be less than 3MB. Select Browse button first, then select Upload Image Please upload your logo: 


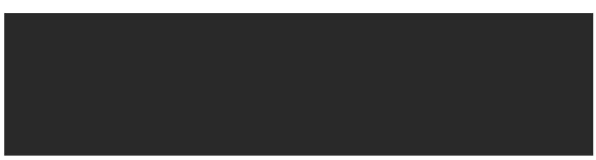

Media Information Request Continued:

We are requesting three photos that demonstrate why your company is a great place to work such as company outings, community service, and employee events.

Please note - if you log out and then re-enter the EQ your photos and logos will not be visible as they are stored in a database. If you have uploaded your images, there is no need to re-upload them. Any duplicate photos will be removed.

Please upload your photos using the following specifications:

1: ALL images should be high-resolution. Usable photos are at least: $300 \mathrm{dpi} ; 800 \times 600$ pixels; $100 \mathrm{~KB}$ in size.

2: You will NOT be able to upload images larger than $3 \mathrm{MB}$. If your image is larger than 3MB, please resize it smaller and resubmit.

3: JPEG or JPG files are preferred. TIFF files are acceptable. BMP files will not be accepted.

4: Cell phone images are typically not of good enough quality to be used.

5: Please do not copy \& paste images from your website - they will be too small and too low-resolution to use on a big screen or in print. If you want a photo from your site, ask your marketing or web department for the original file.

6: Do not paste your photos into a Word document, PowerPoint slide, the body of an email, PDF, etc. These documents will not be accepted in the upload.

7: Please do not send photo collages, slides from a presentation, or scan an image off a piece of letterhead, because they cannot be seen clearly.

8: Must be recent and NEW. (Please do not submit photos from a previous year.)

9: Please provide a short caption (less than 25 words) describing the photo in the space provided.

Remember: Image must be less than 3MB. Select Browse button first, then select Upload Image

\section{Company Photo 1 :}

Please upload the file:

Company Photo 1 Short Caption:

\section{Company Photo 2:}

Best Companies Group (C)

Proprietary \& Confidential

Page 44 of 46 


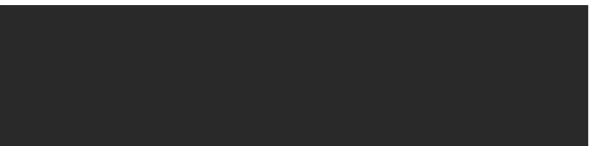

Please upload the file:

Company Photo 2 Short Caption:

\section{Company Photo 3:}

Please upload the file:

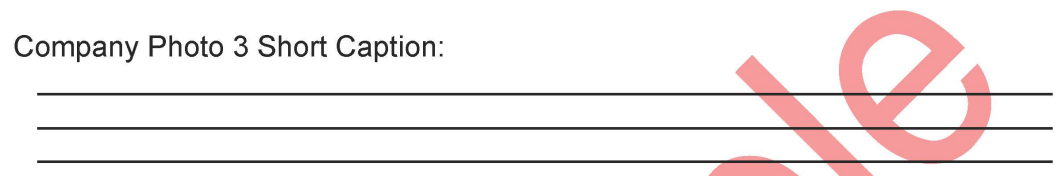

You have reached the end of the questionnaire. Please select the current status of your questionnaire and then select the "Save and Continue" button to save your responses. If you are ready to submit your questionnaire, please select the first option followed by the "Save and Continue" button. Should you choose to re-access the survey and make changes, the most recent version of your saved questionnaire will be used during the analysis process.

Please indicate the current status of your company's Employer Questionnaire:

Best Companies Group $\subset \quad$ Proprietary \& Confidential

Page 45 of 46 


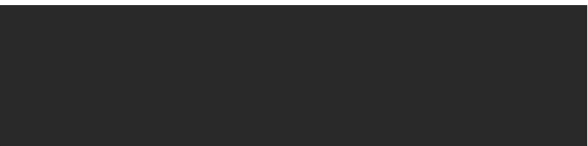

The questionnaire is complete and ready to be submitted.

$O$ The questionnaire needs minor changes or to be reviewed before submitting.

The questionnaire is halfway complete.

The questionnaire still needs a great deal of work.

How long (in hours) did it take to complete this questionnaire? Hours

Thank you for submitting your Employer Benefits \& Policies Questionnaire!

This is formal confirmation that your Employer Questionnaire (EQ) has been successfully uploaded for our review. Please ensure that you select one of the options on the next page to print or email a copy of your questionnaire responses for your records. If you do not select any of these options, you may log back into the questionnaire using your username and password and select an option before submitting

Each time you click "Submit," the previous submission is updated with any new information so Best Companies Group will only be able to view your most recent questionnaire responses. You may make as many changes as desired prior to the submission deadline. 